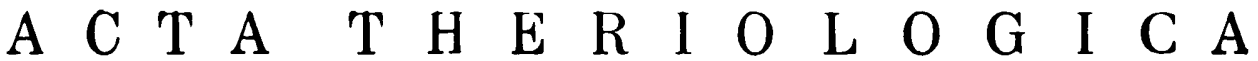 \\ VOL. X, 6: 195-267.

\section{Osteologische Untersuchungen über den Rothirsch in Polen}

\author{
[Mit 4 Tabellen $u$. 33 Abbildungen]
}

Sich auf ein aus 22 kompletten Knochengerüsten und 116 Schädeln von erwachsenen Hirschen $\sigma^{\circ} \sigma^{\circ}$ (Cervus elaphus L.) bestehendes Material stützend, führte man Untersuchungen durch, deren Zweck darin lag, die osteologische Charakteristik wie auch evtl. lokale Unterschiede unter den das Gebiet von Polen bewohnenden Hirschen festzustellen. Die Analyse der morphologischen Einzelheiten und der 235 Knochengerüstmasse (34 Schädel und $201 \mathrm{Knochengerüste} \mathrm{des} \mathrm{Rumpfes} \mathrm{und} \mathrm{der}$ Gliedmassen) erweisen das Fehlen an genügend markanten Merkmalen, um sich auf das Knochenmaterial stützend, die das Gebiet der polni;chen Karpaten bewohnenden Hirsche in eine besondere Unterart absondern zu können. Der tatsächliche Grössenunterschied, der zwischen den Karpaten- und Flachlandhirschen besteht, kann in diesem Falle nicht berücksichtigt werden, denn derartige Unterschiede kommen zwischen den einzelnen lokalen Gruppen aus dem Flachland ebenfalls vor.

I. Einleitung . . . . . . . . . . . . . . . 196

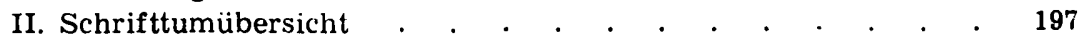

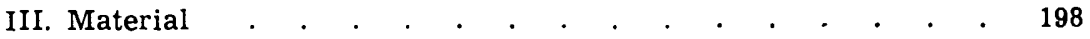

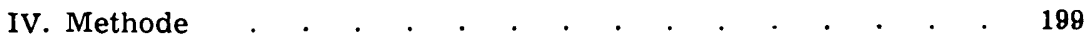

V. Eigene Beobachtungen . . . . . . . . . . 203

1. Schädel (Cranium) . . . . . . . . . . . . 203

2. Wirbelsäule (Columna vertebralis) . . . . . . . . 206

3. Knochenrippe (Costa ossea) . . . . . . . . . . 232

4. Brustbein (Sternum) . . . . . . . . . . . . . 233

5. Vorderes Gliedmass (Extremitas anterior) . . . . . 234

6. Hinteres Gliedmass (Extremitas posterior) . . . . 240

VI. Besprechung der Ergebnisse . . . . . . . . . . 246

1. Schädel . . . . . . . . . . . . . . . 246

2. Skelett des Rumpfes und der Gliedmassen . . . . . 262

Schrifttum . . . . . . . . . . . . . . 265

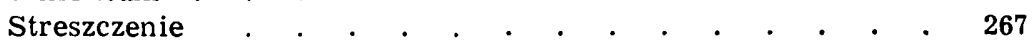




\section{EINLEITUNG}

Das Auftreten von Unterarten des Hirsches auf dem Gebiet von Polen oder seiner rirtlich begrenzten Abarten ist ein offenes Problem.

Das Leitmotiv vorliegender Arbeit bestand eben im Bestreben einer,Aufklärung dieser Angelegenheit von seiten osteologischer Untersuchungsergebnisse.

Bei Weidmännern und Züchtern von Jagdwild erweckt der Hirsch, der die Bieszczaden (Ostbeskiden - weitere Umgegend von Sanok) bewohnt und auch volksmündlich Karpatenhirsch genannt wird, das grösste Interesse. Seine Überlegenheit gegenüber dem Flachlandhirsch in Betreff des Körpergewichtes wie auch „der Geweihgrösse" war die Ursache einer Reihe von Zuchtversuchein, deren Ziel es war, vermittels der Einführung des Karpatenhirsches in Tieflanajagabezirke die bestehende Kopfanzahl an Flachlandhirschen aufzubessern.

Obwohl es heute schwer ist, etwas über den Einfluss dieser Mischungen auf die ortsständige Population auszusagen, so kann man jedoch nicht verschweigen, dass dieser in den ersten Jahren nach der Umsiedlung recht deutlich war (hauptsächlich in Betreff der Geweihgrösse).

Heutzutage interessiert uns der Karpatenhirsch nicht als eventuelles Umsiedlungsmaterial, denn man kann schwerlich positive Resultate erwarten, wenn es sich um sein Hineinlassen in einen von örtlicher Population voll ausgefülten Flachlandjagdbezirk handelt. Als Zweck stellt man sich vor allem die Erhöhung seiner zahlenmässigen Kopfanzahl, was eine richtige Exploatation eines Areales von zirka 100000 ha Waldbestand in den Bieszczaden ermöglichen würde, das in Hinsicht auf Gestaltung und Pflanzendecke ein ausgezeichneter Siedlungsplatz für Hirsche ist.

Die Geschichte des Auftretens des Hirsches in den Bieszczaden deutet wahrscheinlich darauf hin, das seine augenblickliche Zahlenstärke weit von der optimalen entfernt ist.

Mit dem Ansteigen der Auswertung der Karpatenwälder in den letzten Jahrhunderten und mit der Lichtung von grossen Flächen, die danach durch von Hirschen bevorzugte Pflanzen bewachsen wurden, verbesserten sich die Lebensbedingungen für das Rotwild ansehnlich und als noch gegen Ende des 19. Jahrhunderts die Wolfsplage beherrscht wurde, war die Kopfzahl der Hirsche beträchtlich. Leider verursachte der zweite Weltkrieg eine übergrosse Ausrottung dieser Tiere. Die Nachkriegsjahre brachten keine grössere Aufbesserung, denn Wilddiebereien, aber vor allem der Anwuchs der Kopfzahl der Wölfe, liessen keine schnelle Regeneration dieser Art zu. Ein weiterer Anstieg der Wolfsanzahl wurde erst im Jahre 1960 aufgehalten. Erst seit einigen Jahren scheint der Hirschbestand in den Bieszczaden sich $\mathrm{zu}$ erhöhen, obwohl noch die durch Wölfe verursachten Schäden weiterhin beträchtlich sind.

Die genaue Hirschanzahl ist bei den, in den Bieszczaden, waltenden Bedingungen schwer festzustellen. Schätzungsangaben, aus denen es sich ergibt, dass die Besiedlungsdichte in diesen Gebieten in den Grenzen von 1-2 Stk auf 1000 ha Waldbestand schwankt, weisen auf die Notwendigkeit von erhöhten Kraftaufwänden hin, um den aktuellen Stand zweckmässig aufzubessern.

Die Wildhege des Menschen, die den Zweck verfolgt, die Kopfzahl zu erhöhen, jedoch ohne Verminderung der Qualität, müsste auf wissenschaftlich bearbeiteten Grundlagen für jede Art basieren. Währenddessen muss festgestellt werden, dass wenn auch nur geringe wissenschaftliche Arbeiten über unseren Flachlandhirschbestehen, so wurden derartige über den grössere Gebiete unseres Landes bewohnencien Karpatenhirsch bisher überhaupt nicht publiziert. Schwache Auskünfte in Be- 
treff der Körpergewichten und der Geweihqualität wie auch gewisse biologischer Angaben sind nur Beschreibungen von Jagderinnerungen oder weidmännischen Beobachtungen entnommen worden, aber absolut nicht aus methodisch durchgef ührten Untersuchungen.

\section{SCHRIFTTUMÜBERSICHT}

Ly dekker, 1898 (nach Lubicz-Niezabitowski, 1933) zählt in seinem Werk „The deer of all lands" Hirsche, die das Gebiet der Ostkarpaten bewohnen, zu Cervus elaphus maral. B ot e z a t (1903) proponiert dagegen, sich hauptsächlich auf die Geweihgestaltung und Informationen von Weidmännern bei Heranziehung von traditionellen durch die Ortsbewohner geschaffenen Namen stützend, zwei die ungarische Bukowina bewohnenden Unterarten abzusondern und zwar: den grösseren, helleren im Frühling ins Tiefland gehenden und dort seine Brunft verbringenden als - Cervus vulgaris campestris, und den kleineren dunklen mit gedrungenem Bau aber ebenfalls mit starkem Geweih als Cervus vulgaris montanus.

Nach der Revision seiner Ansichten beschreibt Bote z.at (1922) die Unterart Cervus elaphus carpaticus und in ihr die zwei höher erwähnten Formen var. montanus und var. campestris. Es muss daran erinnert werden, dass B ot e $\mathrm{z}$ a $\mathrm{t}$ nach Pöhrig angibt, dass in Ungarn ausser dem heimischen Hirsch noch ein zweiter kleinerer als wandernder oder als polnisch benannter existieren; der letztere besitzt ein verkümmertes Geweih und einen kurzen Kopf.

L u b i c z-Nie zabitow s ki (1963) spricht in seinem Schlïssel zur Bestimmung der Säugetiere Pole.as von zwei Hirscharten im Gebiet von Polen. Zur ersten gehört Cervus elaphus germanicus Desmarest - das Flachland besiedlend, zur zweiten der im Gebiet der Ostkarpaten vorkommende - Karpatenhirsch (Cervus maral Ogilby).

Beninde (1940) von den im Gebiet von Polen hausenden Hirschen sprechend, teilt diese in Flachlandhirsche, die seines Erachtens nach als typisch mitteleuropäische Hirsche eine Gruppe mit den westeuropäischen bilden und in Karpatenhirsche, die den ungarischen Hirschen gleich kommen. Diese Letzteren sondert der Autor von der mittel-europäischen Gruppe ab, denn die Schädellänge der ungarischen Hirsche liegt weit hinter dem Scheidewert dieses Masses für deutsche Hirsche. Heptner \& Calkin (1947) zählen die West- und Zentraleuropa bewohnenden Hirsche zur Unterart C. e. hippelaphus, aber mit Ausnahme der Karpaten, der Slowakei, Rumäniens, Jugoslawiens und Ungarns, da diese Gebiete durch die Unterart C. e. montanus bewohnt werden, die ihren äusserlichen Merkmalen nach an den kaukasischen Hirsch (C. e. maral Og i l by, 1840) angenähert ist.

F l e r ov (1952) zählt den Hirsch aus der Krimhalbinsel und von ganz Westeuropa (mit Ausnahme Nordskandinaviens, Südspaniens und Korsikas und Sardiniens) zu nur einer einzigen Unterart C. elaphus elaphus Linn a u s. Der Autor erwähnt, dass Hirsche aus der oberen (höheren) Krim, den Karpaten und der Balkanhalbinsel sich von den übrigen unterscheiden, aber diese Unterschicde sind nicht genügend gross, um als Grundlage zu einer selbständigen Unterart dienen zu können.

B a li š (1959), gestützt auf kraniometrische Untersuchungen, die auf einem grossen Material ausgeführt worden sind, neigt dazu. Hirsche aus der Ost-Slowakei zu C. e. montanus B o t. anzurechnen, denn er fand Unterschiede im den Schädelmassen in Betreff der Population aus der Hohen Tatra, die von eingefährten deutschen Hirschen abstammen (C. e. hippelaphus). Philipow icz (1961) vom Karpatenhirsch aụs Rumäniẹn berichtend, kehrt zu den zwei von $\mathrm{B}$ ot e $\mathrm{z}$ at beschriebenen Formen 
zurück. Er verneint zwar ihr Vorkommen grundsätzlich nicht, obwohl er gleichzeitig behauptet, dass man sie in Anlehnung an die Schädelmasse nicht teilen kann und er legt dies mit einer weitgehenden Hybridisation aus.

$\mathrm{Szunyoghy}$ (1963) sich mit ziemlich eingehenden kraniometrischen Untersuchungen (32 Masse) befassend, bearbeitete ein Material, das aus zirka 200 Schädeln von ungarischen Hirschen bestand. Sich auf diese Angaben wie auch auf das Körpergewicht und das Geweihgewicht und Gestaltung stützend, vertritt der Autor die Meinung, dass der ungarische Hirsch von C. e. hippelaphus ( $\mathrm{K}$ e $\mathrm{r}, 1792$ ) abgesondert werden müsste. Seine kraniometrischen Angaben mit denjenigen von Heptner \& C a lk in (1947 vergleichend, stellt er fest, dass der ungarische Hirsch mit dem kaukasischen (C. e. maral Ogilby) und dem altaischen (C. e. sibiricus S everzov) gleichkommt, aber den Hirsch aus der Krim (C. e. brauneri Charle$\mathrm{m}$ a g $\mathrm{n}$ e) übertrifft. Der Meinung des Autors nach kann der ungarische Hirsch mit dem asiatischen verglichen werden, wenn es sich um die Körpergrösse handelt, aber der Geweihgestaltung nach ist er vielmehr an die mittel-europäischen Formen angenähert.

In der Arbeit von Sokolov et al. (1963) werden Hirsche aus West-Europa, den Karpaten, der Umgegend von Woronež, dem baltischen Küstenstreifen und der Krim zur Unterart C. 'e. elaphus gezählt, aber unter dem Begriff der Unterart C. e. maral Ogilby werden Hirsche aus den Gebieten des Kaukasus und des süd-westlichen Turkmeniens gemeint. Es ist möglich, dass diese systematische Einteilung etwas anders ausfallen würde, wenn der Autor die Möglichkeit gehabt hätte, sich früher mit den Ergebnissen der Arheit von Szu n y o g h y (1963) bekannt zu machen.

K ow alski (1964) berichtet sich dabei auf Ansichten anderer Autoren berufend, vom Auftreten des mitteleuropäischen Hirsches C. elaphus elaphus $\mathrm{L}$ in n a e $\mathrm{s}$ in den Flachlangebieten Polens und im Karpatengebiet des Gebirgshirsches C. elaphus montanus Botezat, er unterstreicht jedoch, dass diese Frage noch weiterhin ungeklärt bleibt.

Als erste umfangreiche Arbeit über Hirsche, die das Gebiet von Polen bewohnen, gilt die Bearbeitung von M y tk ow k a (1966), die sich auf ein grosses kraniologisches Material stützt. Sie erbringt eine ganze Reihe von wertvollen Mitteilungen, aber diese Arbeit betrifft nur ausschliesslich Hirsche aus dem Flachland.

\section{MATERIAL}

1. Schäde l. Das Material für kraniometrische Messungen bildeten Schädel von erwachsenen Hirschen $\left(\sigma^{x} \sigma^{x}\right)$ die aus den im Bieszczadengebiet gelegenen Oberförstereien wie auch aus denjenigen aus den Woiwodschaften Olsztyn und Poznań stammten.

Die Messungen wurden während der Preiskrönungen der besten ausgestellten Jagdtrophäen durch die Woiwodschaftlichen Räte für das Jagdwesen in Rzeszów, Foznań und Olsztyn durchgeführt. Unabhängig davon wurde das Material aus den eigenen Sammlungen der Anstalt für Jagdwesen des Forstforschungsinstitutes und aus dem Institut für Säugetierforschung der Polnischen Akademie der Wissenschaften ausgenutzt. Einen Teil der Schädel, besonders wenn es sich um den Karpatenhirsch handelt, mass man bei Ausnutzung privater Jagdtrophäen. Im Laufe der Jahre 1960-64 wurden insgesamt 116 Schädel gemassen (Tabelle 1).

Das Einsammeln eines grösseren Materiales war insofern erschwert, dass $80 \%$ der verfügbaren Schädel durch Weidmänner präpariert worden waren, aber auf solch cine Weise, dass die Durchführung von Messungen unmöglich war. Aus den zurück- 
gebliebenen 20\% musste man Schädel von erwachsenen Hirschen auswählen d.i. von 6 Jahren aufwärts. Das Alter wurde hauptsächlich auf Grund der Gebissabreibung geschätzt (R a e s f e l d, 1957).

2. Skele t t des Rumpfes und der Gliedmassen. Zur Erwerbung von zur Durchführung des Messungen und Beschreibung des Knochengerüstes des Rumpfes und der Gliedmassen unbedingt notwendigen Knochenmateriales wurden zu diesem Zwecke 22 erwaschsene Hirsche $\left(\sigma^{x} \sigma^{\prime}\right)$ abgeschossein, wovort; 7 Stück aus den Bieszczaden (Oberförstereien: Baligród, Dwernik, Wetlina); 7 Stück aus der Woiwodschaft Poznań (Oberförstereien: Wronki, Bucharzewo, Goraj, Obrzycko); 8 Stück aus der Woiwodschaft Olsztyn (Oberförstereien: Smolniki, Strzałowo, Spychowo, Krut:ń, Mikołajki).

Die enthäuteten Körper der abgeschossener. Hirsche wurden nach Warschau gesandt, wo sie nach Durchführung des Messungen und dem Wiegen vom Fleisch entblösst wurden und die erhaltenen Knochengerüste zur Mazerierung nach dem Institut für Anatomie der Veterinärmedizinischen Fakultät der Landwirtschaftlichen Hochschule überwiesen wurde. Diese Skelette werden dort in den Sammlungen dieses Institutes aufbewahrt.

\section{METHODE}

\section{Schädel}

Die morphologische Analyse wurde dank der Arbeit von M s tk ow sk a (1966) über den Flachlandhirsch erleichtert. Folglich wurde sie nur auf die Vergleichung der Schädel der Karpatenhirsche mit denjenigen der Flachlandhirsche begrenzt.

Die kraniometrischen Masse wurden mit Hilfe einer Schublehre durchgeführt, wobei die kürzesten Entfernungen zwischen den einzelnen Punkten ohne Anwendung von parallelen Projektionen auf eine bestimmte Fläche gebraucht wurden. Bei Messungen von Entfernungen zwischen den Punkten, die in Folge auf ihre Lage die Anwendung der Schublehre zur Unmöglichkeit machte, wurde der zoometrische Zirkel henutzt. Die Entfernungen zwischen den Enden der Zirkenschenkel wurden auf der Millimeterteilung der Schublehre gemessen.

Messpunkte wurden nach Duerst (1926) angenommen, aber sie wurden jedoch curch zwei weitere ( $N s i$ und $M o-M o$ ) von M y tkowska (1966) angewandte ergänzt.

Es wurden 34 kraniometrische Masse nach M s tkow ska (1966) angenommen. Zur Ermöglichung von Proportionsvergleichungen der einzelnen Schädelmessungen wurden 14 Indexe nach der erwähnten Autorin und zwei andere (Ect-Ect $\times 100 / Z l-P$; $N i-N i \times 100 / N s i-N$ ) berechnet.

\section{Skelett des Rumpfes und der Gliedmassen}

Obwohl sehr spärlich, so sind dennoch Publikationen über den Hirschschädel vorhanden, aber es fehlt gänzlich an Arbeiten über die übrigen Bestandteile des Knochengerüstes des Rumpfes und der Gliedmassen des Hirsches. Es fällt schwer hier die Arbeit von $\mathrm{L} \mathrm{i} \mathrm{c} \mathrm{h} \mathrm{a} \mathrm{č} \mathrm{e} \mathrm{v} \mathrm{(1947)} \mathrm{über} \mathrm{die} \mathrm{prozentsatzmässigen} \mathrm{Verhältnisse} \mathrm{in}$ cien einzelnen Skelettabschnitten zu erwähnen, denn aer Autor gibt keine absoluten Werte und Angaben in Betreff des Materiales und der Methode an.

In der vorliegenden Arbcit wurde daher die Beschreibung der einzelnen Knochen mit spezieller Berücksichtigung der charakteristischen. Merkmale des Hirsches durchgeführt. Bei Vergleichungen der lokalen Gruppen sind die Ergebnisse dẹr osteometrischer. Untersuchungen ausschlaggebendẹr, 
Die osteometrischen Untersuchungen stützen sich hauptsächlich auf die Arbeit "on Duerst (1926), aber mit gewissen bei den Untersuchungen durch Roskos z (1962) angenommenen Modifikationen in Betreff der Masselemente der Wirbelsäule und von Roskos z \& Empe1:(1963) bei Massen des Extremitätenskelettes. In einigen Fällen wurden eigene Modifikationen durchgeführt.

Die Messungen wurden bei Ausnutzung von 2 Schublehrtypen durchgeführt. Bei direkten Messungen wurde die Schublehre mit schmalen Schenkeln angewandt, aber bei Messungen in Projektion besass die angewandte Schublehre Schenkel mit breiten Flächen, die in Richtung des zu messenden Objektes gekehrt waren. Das Längenmass der Rippe längs der Krümmung wurde mit einem Messbard durchgeführt. Fin Teil der Messungen der langen Knochen aber besonders diejenigen in Projektion wurden mit Hilfe eines speziellen Messbrettes ( $\mathrm{m}$ pel \& R os k o s z, 1963) ausgeführt. In einem Falle (Mass auf den Beckenpfannen) wurde der Zirkel vom Typus für Schädelmessungen angewandt.

Die Gesamtanzahl (Tabelle 3) der auf einem. Skelett durchgeführten Messungen betrug 201; hiervon entfielen auf die Wirbelsäule 110, das vordere Gliedmass 30, das hintere Gliedmass 35 und auf die Rippen 26. Zu Messungen wurden Rippen und Gliedmassen nur von der linken Seite angewandt. Im Falle einer Beschädigung oder unnormaler Gestaltung eines gewissen Knochens wurde die Messung auf dem. entsprechenden der rechten Seite durchgeführt.

In dem weiter unten angeführten Messungsverzeichnis wurden Abkürzungen angewandt, die folgendes bedeuten: d. M. direktes Mass, Pr - Mass in der Projektion, Mbr. - Mass bei Anwendung des Messbrettisches. Die Ziffern in Klammern besagen Seite und Position in der Arbeit von Duerst (1926), unter der die Art und Weise der Ausführung einer gewissen Messung beschrieben worden ist.

1. Erster Halswirbel

a) Grösste Länge des Wirbels, $\operatorname{Pr}(369-1-$ Hue)

b) Länge des ventralen Bogens, d. M. (369-2)

c) Grösste Breite des Wirbels, Pr. (371-10)

d) Breite des ventralen Bogens - kleinste Breite auf dem Bogen von der ventralen Seite, d. M.

2. Der zweite Halswirbel

a) Grösste Länge des Körpers, $\operatorname{Pr}(374-1)$ in Projektion auf die Achse des Wirbelkanals

b) Physiologische Körperlänge - von der vorderen Gelenkfläche zum am kaudalsten gelegenen Punkt auf dem Körper, von der ventralen Seite, d. M.

c) Breite der vorderen Gelenkfläche, d. M. (375-8)

d) Grösste Breite des Wirbels an den Proc. transversi, d. M. (376-14)

e) Grösste Wirbelhöhe - Entfernung von der Tischfläche zu dem am höchsten gelegenen Punkt auf dem Wirbel in vertikaler Linie bei Lagerung des Wirbels auf der ventralen Seite, $\mathrm{Pr}$.

3. Halswirbel von III bis VII

a) Grösste Länge des Körpers - zwischen zwei am weitesten entlegenen Punkten in Projektion auf den Wirbelkanal, Pr.

b) Grösste Breite des Wirbels an den Proc. transversi, d. M. (383-16)

c) Wirbelgrösse - analogisch wie beim II. Halswirbel

4. Brustwirbel I-XIII

a) Grösste Länge des Körpers - am weitesten anterior und kaudal gelegene Punkte auf dem Körper in Projektion auf die Achse des Wirbelkanals, Pr.

b) Grösste Breite des Wirbels (zwischen den Proc. transversi), d. M. (387--21)

c) Wirbelhöhe - Entfernung vom am inferiorsten gelegenen Punkt auf dem Kop: des Wirbelkörpers bis zum superiorsten Punkt auf dem Dornfortsatz, d. M.

d) Höhe des Dornfortsatzes - Entfernung vom Rand des Bogens über dem Wirbelkanal von vorn bis zum höchsten Punkt auf dem Dornfortsatz, d. $M$. 
5. Lendenwirbel I-IV

a) Grösste Körperlänge - analog wie bei den Brustwirbeln.

b) Grösste Breite des Wirbels zwischen den Querfortsätzen, d. M. (389-15)

c) Grösste Wirbelhöhe - analog wie bei den Halswirbeln III-VI

d) Höhe des Dornfortsatzes über dem Wirbelkanal - Entfernung von am superiorsten gelegenen Punkt auf dem Dornfortsatz vertikal zur oberen Fläche des Wirbelkanals. (Die Messung wird durch Einführung des einen Schenkels der Schublehre in den Wirbelkanal durchgeführt), Pr.

6. Kreuzbein

a) Grösste Länge des Kreuzbeines - Entfernung von der Gelenkfläche von vorn bis zum am weitesten gelegenen Punkt auf dem Gipfel des Kreuzbeines. (Die Messung wurde von der ventralen Seite durchgeführt.), d. M.

b) Grösste Breite des Kreuzbeines - Entfernung zwischen den am lateralsten gelegenen Punkten auf den Flügeln des Kreuzbeines, d. M.

c) Breite der vorderen Gelenkfläche, d. M. (393-10)

d) Höhe der vorderen Gelenkfläche, d. M. (394-19)

7. Schwanzwirbel

a) Grösste Körperlänge - die entferntesten Punkte auf der Achse des Körpers, d.M.

8. Schulterblatt

a) Aussenlänge des Schulterblattes vom oberen Rand an dem Schnittpunkt mit dem Kamm der Scapula, bis zum Rand der Pfanne an der auf der Verlängerung dieses Kammes liegenden Stelle, d. M.

b) Grösste Schulterblattbreite - Entfernung von der Tischfläche bis zum am höchsten gelegenen Punkt, in vertikaler Linie bei Lagerung des Schulterblattes auf dem Achsenhöhlenrand, Pr., Mbr.

c) Kleinste Breite des Schulterblattes am Halse, d. M. (405-8)

9. Armbein

a) Grösste Länge des Armbeines - die entferntesten Punkte am proximalen und distalen Ende in Projektion auf die Achse des Humerusschaftes, Pr., Mbr.; der Knochen ist auf der vorderen Seite gelegen und liegt mit seinem distalen Ende an die vertikale Wand des Tisches an;

b) Länge des Armbeines vom Caput humeri - von dem höchsten Punkt des Caput auf dem Armbein bis zum entferntesten auf dem distalen Ende, Pr., Mbr.

c) Grösste Breite des proximalen Endes - der im Verhältnis zum Niveau des Tisches am höchsten gelegene Punkt, bei Lage des Knochens auf der lateralen Aussenseite, Pr., Mbr.

d) Kleinste Breite des Humerusschaftes, d. M. (411-9)

e) Grösste Breite des äistalen Endes - Lagerung des Knochens wie bei $9 \mathrm{c}$, Pr., Mbr.

f) Dicke des proximalen Endes - der höchst gelegene Punkt im Verhältnis zum Niveau des Tisches bei Lagerung des Knochens auf der vorderen Seite, Pr., Mbr.

g) Dicke des Humerusschaftes - antero-kaudaler Durchmesser gemessen an derselben Stelle wie die kleinste Breite der Diaphyse. d. M.

h) Dicke des distalen Endes - analog wie Dicke des proximalen Endes, Pr., Mbr.

10. Unterarmknochen (Ulna und Radius wurden bei den Massen zusammen gemessen, denn beide sind durch einen dauernden Knochenverwuchs vereinigt).

a) Länge der Ulna, d. M. (424-1)

b) Mediale Länge (Länge an der Innenfläche) des Radius (419-5)

c) Breite des Tuber olecrani, d. M. (426-6)

(1) Breite des proximalen Endes des Radius d. M. (419-5)

e) Kleinste Körperbreite des Radius, d. M. (419-8)

f) Grösste Breite des distalen Endes des Radius - Entfernung von der Tischplatte bis zum am höchsten gelegenen Punkt bei Lage des Knochens auf der medialen Seite, Pr., Mbr.

g) Dicke des Olecranons (Kleinster Durchmesser des Olecranons), d. M. (427-13) 11. Mittelhandknochen III-IV

a) Grösste Länge der Mittelhandknochen - Entfernung zwischen den am weitesten gelegenen Punkten am proximalen und distalen Ende, bei Lage des Knochens auf der dorsalen Seite, mit dem proximalen Ende in Richung der vertikalen Wand, Pr., Mbr. 
b) Grösste Breite des proximalen Endes - Entfernung zwischen den extremen Punkten in Projection auf die Tischplatte bei dorsaler Lage des Knochens, Pr., Mbr.

c) Kleinste Breite des Körpers, d. M. (485-11)

d) Grösste Breite des distalen Endes, d. M. (486-14)

e) Grösste Dicke des proximalen Endes - Entfernung zwischen der geraden Ta.gente zu zwei am handflächigsten gelegenen Punkten, aber zum am dorsalsten vorgeschobenen Punkt, Pr.

f) Kleinste Körperdicke, d. M. (487-20)

g) Grösste Dicke des distalen Endes (488-23)

12. Fingerglieder I u. II

a) Grösste Länge des Gliedes, Pr. (492-1)

b) Kleinste Breite des Gliedes, d. M. (493-6)

\section{Fingerglied III}

a) Dorsale Länge des Klauenknochens, d. M. (498-2)

14. Becken

d) Symphysenlänge, d. M. (439-4)

b) Grösste Beckenbreite, d. M. (437-1)

c) Beckenbreite auf den Pfannen - Entfernung zwischen den am meisten medal liegenden Punkten auf den Pfannen, d. M. (mit Zirkel)

d) Mittlere Breite der Beckenhöhle, d. M. (438-7)

e) Interischialbreite (kaudale Breite des Beckens), d. M. (438-10)

f) Beckenlänge, d. M. (439-1)

g) Grösste Breite der Darmbeinschaufel, d. M. (441-14- B o ja n u s)

h) Kleinste Breite des Darmbeinkörpers (441-15)

\section{Schenkelknochen}

a) Grösste Länge des Femurs - Entfernung von dem am höchsten gelegenen Purkt auf dem grösseren Trochanter zum am niedrigsten gelegenen Punkt auf d:m distalen Ende. Paralelle Projektion bei Lage des Knochens auf der Innensete, mit seinem distalen Ende auf die vertikale Wand des Tisches gestützt, Pr., Mbr.

b) Physiologische Länge des Femurs - vom am höchsten gelegeren Punkt auf d’m Caput des Femurs bis zum am niedrigsten gelegenen Punkt auf dem distaen Ende. Lage wie in Messung 15 a,

c) Grösste Breite des proximalen Endes - von der Tischebene bis zum am hö:hsten gelegenen Punkt bei Lage des Knochens auf der medialen Seite, Pr., Mor.

d) Geringste Breite des Körpers, d. M. (452-16)

e) Grösste Breite des distalen Endes - Entfernung zwischen der Tischebene, ind dem am höchsten gelegen€n Punkt, bei Lage des Knochens auf der mediaen Seite, Mbr.

f) Vertikaldurchmesser des Caput - antero-kaudale Achse des Caput, d. M. (450-7)

g) Dicke des Trochanter major - Entfernung zwischen dem anterioren und kaulalen Rand des Trochanter major, d. M.

h) Dicke des Körpers des Femurs - Entfernung zwischen der dorsalen Fläche ind der Innenfläche des Körpers an dem Messungspunkt 15d; d. M.

i) Dicke des distalen Endes - Entfernung vom am höchsten gelegenen Punkt iuf der Gelenkwalze zur Tischebene. Der auf die Innenseite gelegte Knochen legt mit beiden Condylen an die Ebene an, Pr., Mbr.

16. Schienbein

a) Grösste Länge des Schienbeines - Entfernung von dem am höchsten gelegèen Punkt auf der Erhöhung zwischen den Condylen bis zum am meisten vorgesciobenen Punkt auf dem distalen Ende. Der Knochen ist auf der Innenseite geląert und stützt sich an die vertikale Wand des proximalen Endes. Pr., Mbr.

b) Grösste Breite des proximalen Endes - Entfernung zwischen den marginden Punkten in Projektion auf die Ebene des Tisches. Lage des Knochens auf ler Innenseite, Pr., Mbr.

c) Kleinste Breite des Körpers, d. M. (463-9)

d) Grösste distale Epiphysenbreite, Pr., Mbr. (463-10) - Knochenlage wie in 16i.

e) Grösste Dicke des proximalen Endes - vom höchsten Punkt auf dem proximaen 
Ende in senkrechter Projektion auf die Ebene des Tisches, bei Knochenlage wie oben, Pr., Mbr.

f) Dicke des Körpers der Tibia - Entfernung zwischen der dorsalen Fläche und der Innenfläche der Diaphyse an dem Messungspunkt der Kleinsten Breite (16c). d. $M$.

g) Grösste Dicke des distalen Endes - auf ähnliche Weise wie 16-e, Pr., Mbr.

17. Sprungbein

a) Äussere Länge des Sprungbeines (Grösste Länge des Sprungbeines), Pr. (470-1)

b) Grösste Breite des Sprungbeines - Breite auf der unteren Gelenkrolle, d. M.

18. Fersenbein

a) Grösste Länge des Calcaneus, (475-1)

b) Dicke des Tuber calcanei - Entfernung zwischen dem anterioren und dem kaudalen Rand des Körpers unter dem Fersenhöcker - vertikal zum anterioren Rand, d. M.

19. Rippen I-X

a) Länge der Sehne der Rippe - von dem am inferiorst gelegenen Punkt auf dem Rippenkopf bis zum am niedrigsten gelegenen Punkt auf dem anterioren Rand, d. M.

b) Länge längs der äusseren Kurvatur vom Tuberculum - (Messband) vom am meisten gekrümmt gelegenen Punkt auf der Gelenkfläche des Tuberculum bis zum am meisten inferior gelegenen Punkt der Rippe, auf der Kurvatur, d. M.

20. Rippen XI-XIII

a) Länge der Sehne der Rippe - (Messband) von dem am meisten in der Kurvatur gekrümmt gelegenen Punkt auf der Fläche des Tuberculum bis zum am meisten inferior gelegenen Punkt der Rippe, auf der Sehne (längs der Sehne), d. M.

b) Länge - längs der Kurvatur - vom Rippenkopf - vom am höchsten gelegenen Punkt auf dem Capitulum bis zum inferiorsten Punkt auf der Kurvatur (längs des Umfanges), d. M.

21. Länge der Abschnitte der Wirbelsäule

Die Länge der einzelnen Abschnitte der Wirbelsäule wird durch die Summe der Wirbelkörperlängen ausgedrückt.

Die Messungen der Mittelfussknochen (III u. IV) wie auch der Zehenglieder der Beckenextremität wurden auf identisch oieselbe Weise durchgeführt wie die Messungen der Mittelhandknochen und der Fingerglieder der Brustextremität.

Sich auf die erhaltenen Grössenwerte stützend, berechnete man für jedes Knochenelement des Skelettes des Rumpfes und der Gliedmassen von 1-6 Massenindizes, was insgesamt 158 Indizes ergab (Tabelle 4).

Für einige Werte wurde eine einschlägige Varianzanalyse (Fischer'scher Test) durchgeführt.

Im Text wurden folgende Abkürzungen angenommen: $\mathrm{K}$ - Karpaten, $\mathrm{O}-$ Woiwodschaft Olsztyn, P - Woiwodschaft Poznañ.

\section{EIGENE BEOBACHTUNGEN}

\section{SCHÄDEL (CRANIUM)}

Die Beschreibung der in den Bestand des Schädels des „Karpatenhirsches" tretenden einzelnen Knochen unterscheidet sich rechit wenig von der dürch M y s tk ow ska (1966) durchgeführten über den ,Flachlandhirsch". Hier werden daher nur diejenigen Beschreibungselemente unterstrichen werden, die für beide Gruppen verschieden zu sein scheinen. 
Tabelle 1.

rariabilität der Schädelmasse bei Hirschen aus den einzelnen lokalen Gruppen (in Millimetern).

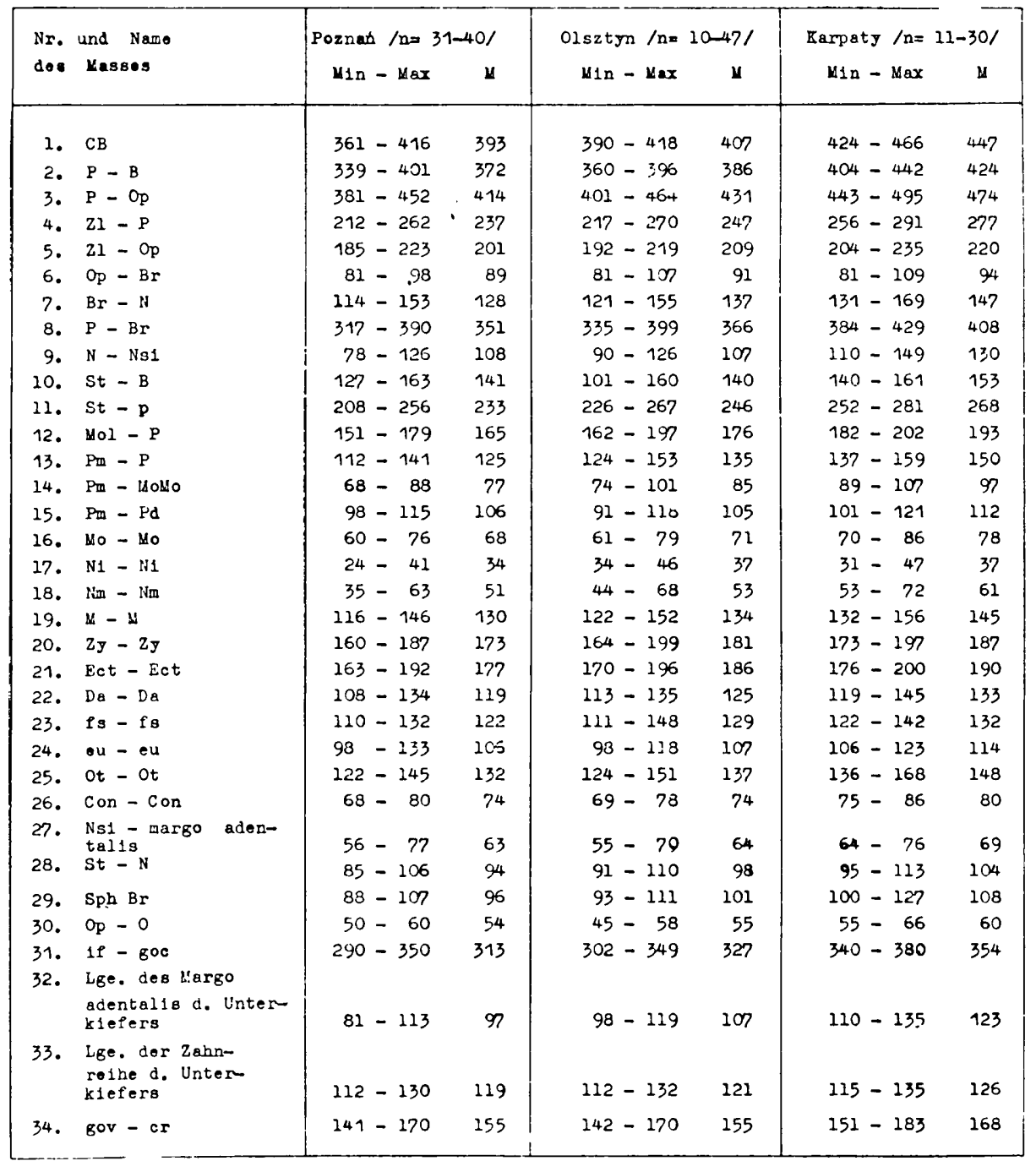

a) Nackenfläche (Planum nuchale)

Der Nackenteil des Hinterhauptbeines besitzt bei dem „Karpatenhirsch" eine ovale Gestalt, ähnlich wie bei dem „Flachlandhirsch”, aber mit dem Vermerk, dass dieses Oval supero-inferior mehr abgeflacht ist. Der Nackenkamm ist stärker ausgestaltet und bildet eine dicke Knochenleiste, die an der Basis breiter ist, aber sich nach oben hin verschmälert. Der 
Tabelle 2.

Variabilität einiger Schädel-Indizes in den einzelnen lokalen Gruppen.

\begin{tabular}{|c|c|c|c|c|c|c|}
\hline \multirow[t]{2}{*}{ Nr. und Name } & \multicolumn{2}{|c|}{ Poznan $/ n=31-40 /$} & \multicolumn{2}{|c|}{ 01sztyn $/ n=10-46 /$} & \multicolumn{2}{|c|}{ Karpaty/n=ll-30/ } \\
\hline & $\operatorname{Min}-\operatorname{Max}$ & $M$ & Min - Mex & $\mathbf{M}$ & $\operatorname{Min}-\operatorname{Max}$ & $\boldsymbol{u}$ \\
\hline 1. $\frac{2 y-2 y \times 100}{P}=\frac{2 p}{O p}$ & $38,5-46,0$ & 41,9 & $39,8-46,6$ & 42,0 & $35,8-49,0$ & 39,8 \\
\hline 2. $\frac{2 y-2 y \times 100}{P-B r}$ & $44,6-54,2$ & 49,3 & $46,2-55,0$ & $.49,3$ & $41,7-49,0$ & 45,8 \\
\hline 3. $\frac{s t-n \times 100}{p-G p}$ & $21,1-24,9$ & 22,8 & $20,9-24,6$ & 22,8 & $20,9-24,4$ & 22,1 \\
\hline 4. $\frac{S t-P}{P} \frac{x 100}{-O p}$ & $54,0-58,7$ & 56,4 & $54,1-59,9$ & 57,3 & $54,9-58,1$ & 56,8 \\
\hline 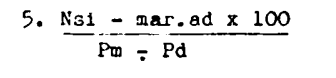 & $51,6-74,8$ & 59,2 & $52,4-70,3$ & 60,7 & $54,7-74,4$ & 61,9 \\
\hline 6. Mo $\frac{\text { Mo } \times 100}{P w-P}$ & $49,3-62,1$ & 54,1 & $47,5-57,0$ & 52,8 & $44,8-59,9$ & 51,9 \\
\hline 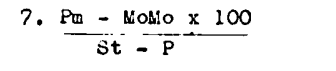 & $29,6-36,2$ & 33,3 & $30,4-40,0$ & 34,6 & $33,6-40,1$ & 36,2 \\
\hline 8. $\frac{N-N 91 \times i \cdot 10}{M-M}$ & $60,5-98,4$ & 82,2 & $64,3-97,6$ & 80,2 & $71,7-105,9$ & 89,3 \\
\hline 9. $\frac{B r-N \times 100}{E c t-E c t}$ & $63,2-90,0$ & 72,5 & $58,5-84,5$ & 73,4 & $68,8-90,0$ & 77,2 \\
\hline 10. $\frac{O p}{C o n-C o n}$ & $51,8-82,2$ & 73,1 & $56,3-84,0$ & 73,0 & $69,1-84,0$ & 76,1 \\
\hline 11. $\frac{M-U \times 100}{S t-P}$ & $52,3-63,5$ & 56,5 & $49,8-58,5$ & 54,8 & $47,0-60,3$ & 54,3 \\
\hline 12. $\frac{e u-u \times 100}{S t-B}$ & $63,2-91,7$ & 75,4 & $65,4-82,2$ & 73,3 & $66,1-81,2$ & 75,2 \\
\hline $\begin{array}{l}\text { 13. Lge d.Margo adent.des } \\
\text { Unterkiefers } \\
1 \bar{f}-\text { goc }\end{array}$ & $27,9-34,2$ & 31,1 & $30,7-34,9$ & 32,9 & $32,3-37,2$ & 34,8 \\
\hline $\begin{array}{l}\text { 14. Lge.d.Zahnre1he d. } \\
\text { Unterikfefers } \\
11-600\end{array}$ & $32,0-38,8$ & 38,2 & $34,3-40,6$ & 37,0 & $32,0-39,4$ & 35,7 \\
\hline 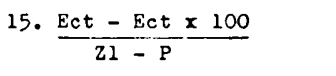 & $68,3-82,5$ & 74,9 & $69,6-89,4$ & 75,0 & $61,7-75,1$ & 68,7 \\
\hline 16. $\frac{N 1-N 1 \times 100}{N s 1-N}$ & $25,9-38,9$ & 31,0 & $26,5-42,7$ & 34,5 & $24,3-39,3$ & 28,6 \\
\hline
\end{tabular}

obere Rand dieser Leiste ist stark kaudal gerichtet und daher macht die iNackenfläche des Karpatenhirsches in den meisten Fällen den Eindruck ciner mehr eingefallenen, aber der sich auf ihr befindende äussere Hinterhauptkanim ist gut sichtbar. 


\section{b) Dachfläche (Fornix)}

Im Scheitelteil des Hinterhauptbeines tritt ähnlich wie beim Flachlandhirsch keine Crista sagittalis ext. auf, aber in ihrenı mittlerem Teil lässt sich eine Knochenverdickung in Form eines gleichseitigen Dreieckes bemerken, dessen Basis der Nackenkamm bildet. Die beim Flachlandhirsch schwach angedeutete Crista parietalis ext. tritt beim Karpatenhirsch nicht auf. Die paarigen Schuppen der Stirnbeine bilden beim Karpatenhirsch eine stärker gefaltene Fläche als beim Flachlandhirsch.

Dies ergibt sich wahrscheinlich aus der stärkeren Entwicklung dieser Partie des Stirnbeines, die die Knochengrundlage für das Geweih, und für Knochenwölbungen auf dem mit den Nasenbeinen grenzenden Teil bildet, was im Ganzen aber den Einaruck des Bestehenes einer starken Einsenkung in der Stirnfläche ausübt. Die Sulci supraorbitales sind umfangreicher, was mitsamt dem sich stark abhebenden Kamm, der auf der Sutura interfrontalis liegt, eine Längsfaltung dieser Umgebung ergibt.

Die paarigen Nasenbeine des „Karpatenhirsches” sind in der Längsrichtung gewölbt, was den Eindruck einer „Buckelnase” ausmacht. Die durch das Nasenbein gebildete Rinne ist ziemlich deutlich in ihrem mittleren Teil lateral abgeflacht, wodurch sie den Eindruck macht, dass sie höher ist als bei Flachlandhirschen.

\section{c) Seitenwand (Paries lateralis)}

Die einzige Besonderheit, die die Schädel beider Gruppen zu differieren scheint, ist die Gestalt des Proc. zygomaticus Os. temporalis. Er hat nämlich bei den Karpatenhirschen auf dem Querschnitt ein dem Rechteck angenähertes Aussehen, aber bei den Flachlandhirschen dagegen ist er von Gestalt eines Dreieckes.

Der Gesichtsteil des Jochbeines bildet in seinem anterioren Teil einen Fortsatz von unregulärer Gestalt, der sich zwischen das Tränenbein und das Os maxillare einkeilt. Dieser Fortsatz scheint beim Karpatenhirsch weiter nach vorn zu reichen als beim Flachländischen.

Die äussere Tränenbeingrube (Fossa lacrimalis ext.) ist bei beiden Gruppen ähnlich ausgebildet, aber beim Karpatenhirsch ist sie jedoch weiter und tiefer. Der die Tränenbeingrube von oben begrenzende Rand ist massiver und zieht sich kaudal hin und reicht bis an den Orbitaring.

\section{WIRBELSAULE (COLUMNA VERTEBRALIS)}

a) Halswirbel (Vertebrae cervicales)

W ir bel I (Atlas). Der ventrale Bogen hat die Gestalt eines ausgedehnten rechteckigen, massiven Balkens. Als seitliche Begrenzung dienen 
weite und tiefe Flügelgrube die eine fast reguläre ovale Gestalt haben: auf der ventralen Seite dieses Bogens ist das Tuberculum ventrale sichtbar. Dieses Tuberculum hat die Gestalt eines infero-kaudal gerichteten massiven Processus. Seine Situationslage ist jedoch nicht bei den einzelnen Individuen gleichartig, denn er ist zuweilen mehr anterior gelegen, aber manchmal ist er sogar bis an den kaudalen Rand verschoben. Der ventrale Bogen des besprochenen Wirbels hat bei dem Karpatenhirsch ein mehr ausgedehntes Aussehen, im Verhältnis zu seiner Breite, als beim Flachländischen.

Die Länge des ventralen Bogens beträgt durchschnittlich $47 \mathrm{~mm}$ für F'lachlandhirsche, beim Karpatenhirsch jedoch $52 \mathrm{~mm}$, aber die Breite im Mittel ist für beide Gruppen gleich und beträgt $42 \mathrm{~mm}$.

Die Fossae art. cran. haben im allgemeinen Umriss die Form einer Ellipse. Die superioren Ränder der linken und rechten Fossae art. cran. bilden in ihrer medialen Verlängerung fast eine gerade Linie, während sie sich bei dem Rind bogenförmig kaudal ausbiegen. Die Gelenkflächen der linken und rechten Fossae art. stülpen sich auf cier ventralen Fläche des inferioren Bogens um, indem sie zwei halbkugelige Felder bilden, die von einander durch eine schwach angedeutete Kerbe abgeteilt werden. Bei den von uns beobachteten Exemplaren machte die Gelenkgrube des Karpatenhirsches den Eindruck, dass sie breiter ist im Verhältnis zu ihrer Höhe.

Der dorsale Bogen ist lang, und das auf ihm auftretende Tuberculum ciorsale in Gestalt eines schwach angedeuteten Kammes ist bei den einzelnen Individuen im verschiedenen Grade ausgebildet.

Die Alae atlantes nehmen die Gestalt von schlanken, schmalen Lamellen an, deren kaudaler Rand stark kaudal verlängert ist, was zur Folge hat, dass der allgemeine Umriss des Atlas an ein Quadrat angenahert ist. Im antero-medialen Teil des Flügels befindet sich eine Öffnung, die bei der Mehrzahl der Individuen durch Knochenlamellen auf eine Reihe von kleinen sekundären ÖIffnungen abgeteilt ist. Diese Offnung bildet den Eingang zu einem kurzen Kanal, der sich vertikal-kaudal verzweigt, sich im der Flügelgrube als For. alare öffnet, aber sich horizontal-medial im Wirbelkanal als For. vert. lat. ausbildet. Von oben schauend hat man den Eindruck, dass die Flügel und der dorsale Bogen zu gunsten des Karpatenhirsches mehr verlängert sind (im Verhältnis zur Breite), aber dies wird durch den Index grösste Länge d. Wirbels $\times 100$

grösste Breite d. Wirbels sehr angenähert ist $(\mathrm{O}=85,1 ; \mathrm{P}=84,9 ; \mathrm{K}=86,0)$.

Der Grössenunterschied des Atlas in den einzelnen Gruppen ist ziemlich deutlich und stellt sich folgendermassen dar: Gröste Länge des 
Wirbels (im Mittel) $\mathrm{P}=99, \mathrm{O}=109, \mathrm{~K}-120 \mathrm{~mm}$, aber die grösste Breite auf den Flügeln beträgt dementsprechend: 123, 128 und $140 \mathrm{~mm}$. Die kaudalen Gelenkflächen in Gestalt von abgeflachten Ovalen umfassen ebenfalls die medialen Ränder der Flügel, was für den Hirsch ziemlich charakteristisch zu sein scheint.

$\mathrm{H}$ a lsw i r bel II (Epistropheus). Der Körper des Épistropheus besitzt eine stark ausgedehnte Gestalt eines Knochenbalkens. Seine grösste Länge, fast identisch für die beiden Flachlandgruppen $(107,5 \mathrm{~mm}$ und $108,5 \mathrm{~mm}$ ) beträgt bei dem Karpatenhirsch durchschnittlich $117 \mathrm{~mm}$. Die physiologische Länge behält ungefähr dasselbe Verhältnis bei. Die Facies articulares craniales haben die Gestalt von halbkugeligen flachen Feldern, die sich bei der Mehrzahl der Individuen unterhalb des Zahnes des Drehwirbels in ein Ganzes vereinigen. Die Breite der kranialen Gelenkfläche weist eine grössere individuelle Variabilität auf und schwankt in den Grenzen von $66-83 \mathrm{~mm}$. Unterschiede im Mittel für die einzelnen Grup.pen überschreiten $6 \mathrm{~mm}$ nicht.

Der Zahn des Epistropheus ist ein Walzenausschnitt, der ventral etwas abgeflacht ist.

Auf der ventralen Seite des Körpers ist eine gut ausgeprägte flache Crista corporis sichtbar, der sich im anterioren Teil etwas senkt und einen charakteristischen Knochenvorsprung bildet.

Auf der lateralen Seite des Wirbels liegt der dorso-ventral abgeflachte Proc. costotransversarius mit einem lateralen inferior umgestülpten Rand. Dieser Processus ist stark kaudal gerichtet und daher reicht sein Höhepunkt hinter den kaudalen Rand des Körpers.

Die auf diesen Processus gemessen Breite beträgt entsprechend für die einzelnen Gruppen 77,91, $104 \mathrm{~mm}$, folglich ist sie gleich oder sogar etwas grösser zwischen dem $\mathrm{P}$ - und O-Hirsche, als zwischen dem Ound K-Hirsche. Die Höhe gibt während dessen eine ardere Anordnung und zwar $\mathrm{P}=96,0 \mathrm{O}=101$, und $\mathrm{K}=110 \mathrm{~mm}$. Im anterioren Teil befindet sich eine ziemlich grosse $Z$ wischenwirbelöffnung. Kaudal und inferior von ihr liegt For. transversum, das zum Kanal führt, der die Basis des Proc. costotransversarius durchbricht.

Der Processus spinalis hat die Gestalt einer ausgedehnten, rechteckigen Lamelle mit scharfem superiorem Rand. Dieser Rand ist durch einen etwas kaudal vorspringenden Höcker beendet. Unter den Proc. art. post. tritt eine deutlich sichtbare Incisura vertebralis post. auf.

Die Wirbelproportionen in Anlehnung an die errechneten Indizes untersuchend, kann man den grössten Unterschied im Index: $\frac{\text { grösste Breite d. Wirbels } \times 100}{\text { grösste Länge d. Körpers }}$ feststellen, der für $\mathrm{P}=71,5 ; \mathrm{O}=83,7$; $\mathrm{K}=89,7$ beträgt. Der Unterschied zwischen dem Karpatenhirsch und 
dom aus Olsztyn ist um die Hälfte kleiner als zwischen dem aus Poznań lind Olsztyn.

$\mathrm{H}$ a ls wirbel (Vertebrae cervicales) III-VI. Im Gegensatz zu den domestizierten Wiederkäuern beobachten wir hier eine Verlängerung der Körper. Dies verleiht den Halswirbeln ein stark ausgedennte Gestalt, die es ermöglicht diese vielmehr mit denjenigen des Pferdes in Einklang z.u stellen.

Tabelle 3.

Shelettmassenwerte von Hirschen aus den verschiedenen lokalen Gruppen, in Millimetern erfasst.

\begin{tabular}{|c|c|c|c|c|c|c|}
\hline \multirow{2}{*}{ Nummecound Kase des Yasses } & \multicolumn{2}{|c|}{ Poznat $/ n=6-7 /$} & \multicolumn{2}{|c|}{$018 z$ tgn $/ n=6-8 /$} & \multicolumn{2}{|c|}{ Karpaty $/ n=5-7 /$} \\
\hline & $M \leq n-M a x$ & $\mathbf{k}$ & $M 1 n-M a x$ & u & M1n - Max & и \\
\hline 1 & ? & & 3 & & 4 & \\
\hline \multicolumn{7}{|l|}{ Halawirbel } \\
\hline 1. Gr. Lge.d. 1 1rbels & $91-109$ & 99 & $101-116$ & 109 & $118-124$ & 120 \\
\hline$C_{1}$ 2. Lge.d.ventralen Bogens & $41-49$ & 45 & $43-53$ & 49 & $51-54$ & 52 \\
\hline 3. Gr.Br. d. 1rbels & $107-129$ & 117 & $117-140$ & 128 & $137-142$ & 140 \\
\hline 4. Br. d. ventralen Bogens & $38-44$ & 41 & $38-49$ & 44 & $38-48$ & 42 \\
\hline 5. Gr.Lge.d.Zurpers & $102-114$ & 107 & $100-121$ & 108 & $113-124$ & 117 \\
\hline 6. Physiologische Lge. des Korpers & $87-100$ & 94 & $88-104$ & 94 & $97-109$ & 103 \\
\hline $\mathrm{C}_{2}$ 7. Br.der ant.Gelenkelachen & $66-78$ & 71 & $69-80$ & 74 & $72-83$ & 77 \\
\hline 8. Gr.Br. d. irbels & $71-82$ & 77 & $83-101$ & 91 & $95-118$ & 104 \\
\hline 9. Gr. Hobe d. Wirbela & $80-101$ & 90 & $95-108$ & 101 & $106-114$ & 111 \\
\hline 10. Gr. Lce.d. KBrpers & $81-93$ & 88 & $85-103$ & 92 & $88-91$ & 95 \\
\hline 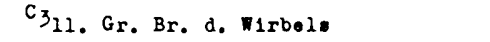 & $80-101$ & 92 & $97-116$ & 106 & $103-123$ & 115 \\
\hline 12. Hobe d.W1rbel. & $68-84$ & 75 & $72-90$ & 78 & $77-91$ & 84 \\
\hline 13. Gr.Lge.d.Korpers & $82-93$ & 89 & $90-103$ & 92 & $90-102$ & 96 \\
\hline $\mathrm{C}_{4} 14, \mathrm{Gr}, \mathrm{Br}$. d. Wirbels & $83-105$ & 96 & $46-115$ & 108 & $107-126$ & 115 \\
\hline 15. Hohe d. Wirbels & $76-90$ & 84 & $87-99$ & 92 & $94-111$ & 102 \\
\hline 16. Gr.Lge.d.Korper & $81-94$ & 88 & $88-90$ & 92 & $91-102$ & 96 \\
\hline$c_{5}$ 17. Gr.br.d.Tirbels & $82-104$ & 94 & $97-116$ & 108 & $106-126$ & 115 \\
\hline 18. Hohe d. Wirbels & $82-105$ & 96 & $99-115$ & 104 & $106-132$ & 120 \\
\hline 19. Gr.Lge.d.KOrpers & $70-83$ & 77 & $80-89$ & 84 & $79-93$ & 86 \\
\hline $\mathrm{C}_{6}$ 20. Gr. Br.d. W1rbels & $80-105$ & 93 & $99-110$ & 104 & $105-122$ & 115 \\
\hline 21. Hoho d. Wirbels & $119-150$ & 136 & $132-160$ & 144 & $139-177$ & 164 \\
\hline 22. Gr.Lge.d.KErpers & $53-63$ & 58 & $60-71$ & 64 & $61-71$ & 66 \\
\hline $\mathrm{C}_{7}$ 23. Gr.Br. d. Hirbels & $83-100$ & 93 & $9 b-109$ & 104 & $108-120$ & 115 \\
\hline 24. Hohe d. Wirbels & $92-119$ & 107 & $107-130$ & 118 & $106-157$ & 137 \\
\hline Brustwirbel / Th/ & & & & & & \\
\hline 25. Gr. Lge.d. ïbrpers & $43-51$ & 47 & $47-54$ & 51 & $50-57$ & 55 \\
\hline 26. Gr. Br.d. Wirbels & $80-95$ & 88 & $88-97$ & 92 & $94-105$ & 98 \\
\hline 27. Hone a. Wirbels & $142-168$ & 157 & $156-190^{-}$ & 170 & $269-241$ & 211 \\
\hline 29. Hothe d. Vorniortsatzes & $96-124$ & 112 & $108-141$ & 123 & $218-192$ & 160 \\
\hline
\end{tabular}




\begin{tabular}{|c|c|c|c|c|c|c|c|c|}
\hline \multirow{2}{*}{\multicolumn{2}{|c|}{ 29. Gr.Ige.d.RBrpers }} & \multicolumn{2}{|l|}{2} & \multicolumn{2}{|l|}{3} & \multicolumn{3}{|c|}{4} \\
\hline & & $39-48$ & 44 & $45-51$ & 49 & 50 & -55 & 53 \\
\hline & 30. Gr.Br.d. W1rbels & $72-83$ & 78 & $79-89$ & 84 & 85 & -98 & 90 \\
\hline & 31. Hohe d. Wirbel: & $160-192$ & 179 & $181-218$ & 202 & 200 & -268 & 241 \\
\hline & 32. Bthe d. Dornfortsatses & $128-159$ & 146 & $150-180$ & 168 & 158 & -228 & 201 \\
\hline & 33. Gr.Lge.d.KBrpers & $40-45$ & 43 & $45-51$ & 48 & 48 & -54 & 52 \\
\hline & 34. Gr.Br. d. Wirbels & $67-77$ & 72 & $73-80$ & 77 & 79 & -85 & 82 \\
\hline 3 & 35. Hobe d.W1rbels & $166-200$ & 186 & $194-226$ & 212 & 214 & -271 & 247 \\
\hline & 36. Hohe d. Dornfortsatzes & $138-167$ & 154 & $161-189$ & 178 & 175 & -234 & 210 \\
\hline & 37. Gr.Lge.d.KUrpers & $39-44$ & 42 & $44-50$ & 47 & 49 & -57 & 52 \\
\hline & 38. Gr.Br.d.nirbels & $61-71$ & 68 & $67-75$ & 71 & 73 & -80 & 77 \\
\hline & 39. Hohe d. Wirbels & $168-197$ & 182 & $192-222$ & $207^{\circ}$ & 215 & -247 & 238 \\
\hline & 40. Hohe d. Dornfortsatzes & $138-163$ & 152 & $162-185$ & 175 & 175 & -209 & 202 \\
\hline & 41. Gr. Lge.d. KUrpeB & $37-44$ & 41 & $43-49$ & 47 & 47 . & -51 & 49 \\
\hline & 42. Gr.Br. d. Wirbels & $61-70$ & 66 & $64-75$ & 69 & 72 & -78 & 75 \\
\hline 5 & 43. Hohe d. Wirbels & $161-188$ & 176 & $186-213$ & 201 & 206 & -233 & 229 \\
\hline & 44. Hohe d. Dornfortsatzes & $133-156$ & 146 & $154-180$ & 167 & 168 & -214 & 195 \\
\hline & 45. Gr.Lge.d. KUrpera & $36-42$ & 39 & $42-48$ & 45 & 44 & -48 & 46 \\
\hline & 46. Gr. Br.d.T1rbels & $61-69$ & 65 & $64-74$ & 68 & 71 & -77 & 73 \\
\hline 6 & 47. Hohe d. Wirbels & $152-176$ & 167 & $177-205$ & 189 & 193 & -228 & 213 \\
\hline & 48. Hohe d. Dornfortsatzes & $127-146$ & 139 & $146-172$ & 158 & 177 & -196 & 179 \\
\hline & 49. Gr. Lge.d. KUrpers & $35-40$ & 38 & $40-45$ & 42 & 43 & -46 & 44 \\
\hline 7 & 50. Gr. Br. d. Wirbels & $62-71$ & 65 & $65-73$ & 69 & 72 & -78 & 75 \\
\hline 7 & 51. Hohe d. Hirbels & $143-166$ & 156 & $161-189$ & 175 & 180 & -207 & 197 \\
\hline & 52. "Uhe d. Dornfortsatzes & $119-137$ & 128 & $132-158$ & 245 & 149 & -175 & 165 \\
\hline & 53. Gr.Lge.d.KBrpers & $35-38$ & 37 & $39-43$ & 41 & 41. & -46 & 43 \\
\hline 8 & 54. Gr.Br. d. W1rbels & $61-72$ & 64 & $67-73$ & 70 & 72 & -80 & 75 \\
\hline 8 & 55. Hohe d."1rbels & $132-154$ & 144 & $150-172$ & 161 & 169 & -192 & 181 \\
\hline & 56. HUhe d. Dornfortsatzes & $107-127$ & 116 & $121-141$ & 131 & 137 & -161 & $2+7$ \\
\hline & 57. Gr. Lge.d.KUrpers & $34-39$ & 37 & $39-43$ & 41 & 41. & -45 & 43 \\
\hline & 58. Gr. Br. d. Wirbels & $57-69$ & 63 & $66-74$ & 70 & 71 & -82 & 75 \\
\hline 9 & 59. Hohe d. Wirbels & $121-143$ & 129 & $137-158$ & 147 & 156 & -171 & 162 \\
\hline & 60. Hbhe d. Dornfortsatzes & $92-107$ & 101 & $106-127$ & 116 & 125 & -143 & 131 \\
\hline & 61. Gr.Lge.d.KUrpers & $36-39$ & 38 & $39-43$ & 41 & 42 & -45 & 44 \\
\hline & 62. Gr.Br.d.Wirbels & $59-70$ & 64 & $65-74$ & 70 & 70 & -81 & 75 \\
\hline 10 & 63. Hohe d. Wirbels & $110-135$ & 120 & $122-141$ & 132 & 141 & -151 & 145 \\
\hline & 64. Hohe d. Dornfortsatzes & $79-107$ & 91 & $91-111$ & 99 & 107 & -121 & 111 \\
\hline & 65. Gr.Lge.d.KUrpers & $37-$ & 39 & $40-44$ & 42 & 40 & -46 & 44 \\
\hline 11 & 66. Gr.Br.d. 1rbels & $56-66$ & 61 & $54-72$ & 66 & 54 & -74 & 70 \\
\hline & 67. Hohe d. Wirbels & $97-113$ & 104 & $103-125$ & 115 & 125 & -134 & 130 \\
\hline & 68. Hohe d. Dornfortsatzes & $63-82$ & 69 & $64-91$ & 78 & 80 & -98 & 91 \\
\hline & 69. Gr.Lge.d. Kסrpers & $38-43$ & 41 & $42-46$ & 44 & 45 & -48 & 47 \\
\hline 12 & 70. Gr. Br. d. Nirbels & $39-62$ & 50 & $50-74$ & 58 & 50 & -64 & 59 \\
\hline & 71. Hohe d. Wirbels & $87-103$ & 96 & $98-215$ & 108 & 114 & -123 & 118 \\
\hline & 72. Hube d. Dornfortsatzes & $51-64$ & 59 & $60-75$ & 67 & 70 & -80 & 76 \\
\hline & 73. Gr. Lge.d. KUrpera & $41-45$ & 43 & $42-48$ & 45 & 47 & -50 & 49 \\
\hline & 74. Gr. Br. d. Mirbels & $55-86$ & 67 & $65-80$ & 72 & 73 & -88 & 80 \\
\hline & 75. Hohe d. Wirbols & $84-98$ & 92 & $95-126$ & 104 & 110 & -117 & 113 \\
\hline & 76. Hyhe d. Dornfottsatzes & $49-59$ & 55 & $55-68$ & 61 & 66 & -75 & 71 \\
\hline
\end{tabular}




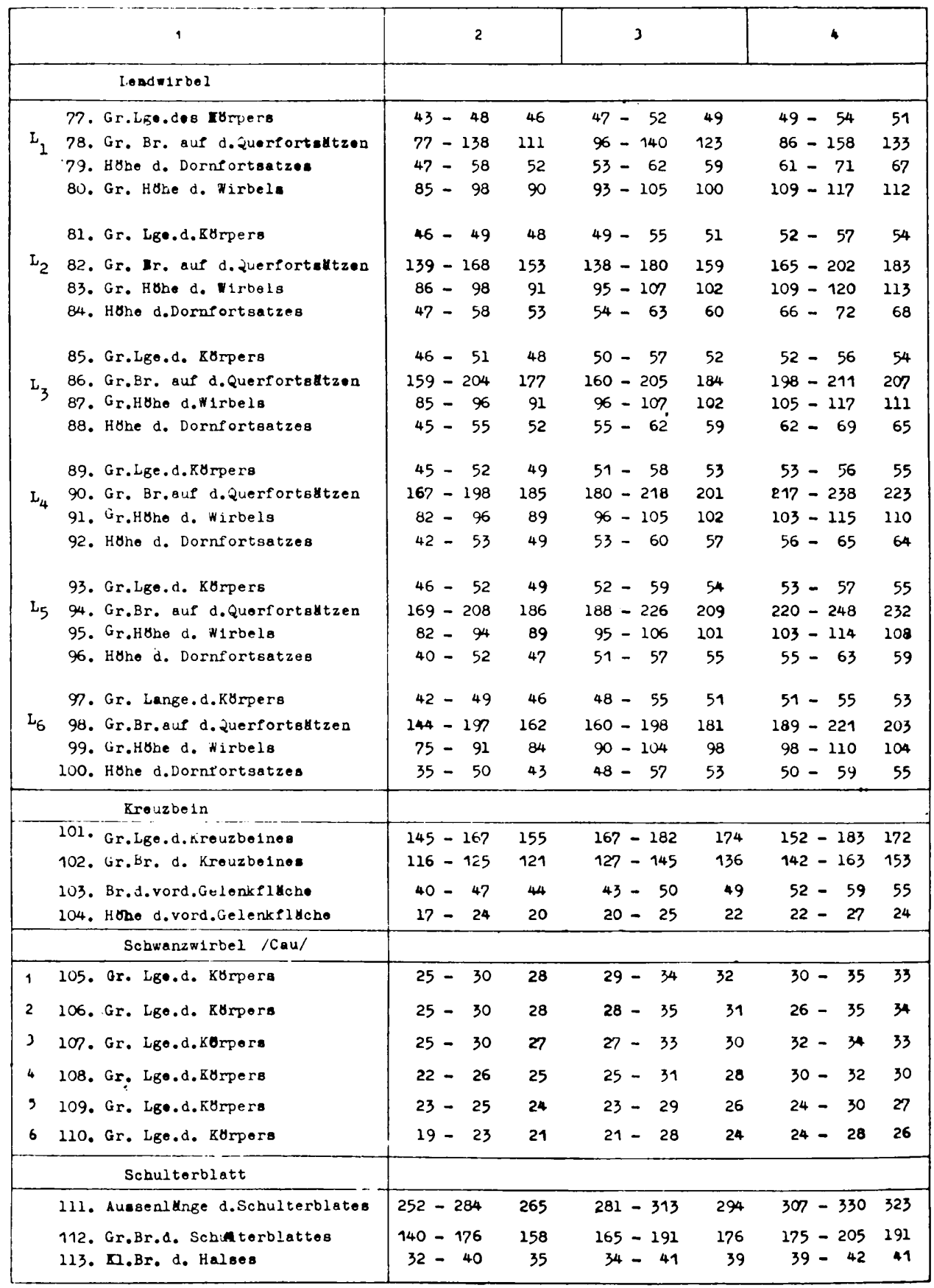




\begin{tabular}{|c|c|c|c|c|c|c|}
\hline 1 & \multicolumn{2}{|l|}{2} & \multicolumn{2}{|l|}{3} & \multicolumn{2}{|l|}{4} \\
\hline 114. Gr. Lge.d.Arrknochens & $240-278$ & 262 & $265-299$ & 282 & $300-312$ & 305 \\
\hline 115. Lge.d.Anmknoch.vom Kopfe aus & $214-250$ & 235 & $239-265$ & 251 & $271 \cdot 280$ & 274 \\
\hline 116. Gr.Br. d.proxim.Endes & $63-73$ & 68 & $69-78$ & 75 & $77-86$ & 82 \\
\hline 117. Kl.Br. d. Humeruschaftes & $23-27$ & 25 & $26-29$ & 27 & $29-33$ & 31 \\
\hline 118. Gr.Br. d.distal.Endes & $52-60$ & 55 & $56-64$ & 59 & $61-67$ & 64 \\
\hline 119. Dicke d.proxim.Endes & $71-86$ & 77 & $71-88$ & 83 & $87-94$ & 91 \\
\hline 120. Dicke d. Ilumer'ısschaftes & $31-36$ & 33 & $36-41$ & 38 & $39-43$ & 41 \\
\hline 121. Dicke d. distalen Indes & $51-58$ & 54 & $54-64$ & 59 & $59-65$ & 62 \\
\hline \multicolumn{7}{|l|}{ Untererraknochen } \\
\hline 122. Lge.d. Ulne & $327-346$ & 331 & $332-397$ & 356 & $362-392$ & 381 \\
\hline 123. Ige.d. Fadius & $228-275$ & 262 & $262-305$ & 278 & $290-304$ & 298 \\
\hline 124. Br. d. Tuber olecran11 & $16-20$ & 18 & $19-23$ & 21 & $20-26$ & 23 \\
\hline 125. Br. d.proxim, Indes d.Radius & $51-58$ & 54 & $57-62$ & 59 & $60-67$ & 63 \\
\hline 126. KI.KBrperbre1to d.Radius & $28-32$ & 29 & $31-35$ & 33 & $35-39$ & 37 \\
\hline 127. Gr.Br.d.d1stel. Endes d.Radius & $47-54$ & 48 & $51-58$ & 54 & $57-61$ & 59 \\
\hline 128. Dicke d. Tuber olecranil & $41-51$ & 44 & $46-51$ & 49 & $48-54$ & 52 \\
\hline \multicolumn{7}{|l|}{ M1ttelhandknochen /III u.IV/ } \\
\hline 129. Gr. Lge.d.Mittel handknochen & $226-2 \cdot 5$ & 251 & $252-284$ & 264 & $269-282$ & 275 \\
\hline 130. Gr.Br. d. proxim. Endes & $38-42$ & 39 & $41-47$ & 43 & $44-50$ & 47 \\
\hline 131. Kl.Br. d. K8rpers , & $20-23$ & 22 & $24-25$ & 24 & $25-29$ & 27 \\
\hline 132. Gr. Br. d.distal. Endes & $39-45$ & 41 & $41-\quad 45$ & 43 & $46-50$ & 47 \\
\hline 133. Gr. D1cke d.proxid. Endes & $27-31$ & 29 & $29-32$ & 31 & $32-35$ & 33 \\
\hline 134. Ba. Edrperdicke & $18-21$ & 20 & $18-22$ & 20 & $20-23$ & 21 \\
\hline 135. Gr. Dicke d.d1stal.Endes & $26-30$ & 28 & $27-31$ & 29 & $30-33$ & 31 \\
\hline \multicolumn{7}{|l|}{ Becken } \\
\hline 136. Lge.d.Symphjse d. Beckens & $102-122$ & 112 & $114-122$ & 121 & $127-140$ & 131 \\
\hline 137. Gr.Br. des Beckens & $240-269$ & 249 & $256-28 y$ & 273 & $235-3.05$ & 235 \\
\hline 138. Br.d..Beckens auf d.PFannen & $86-100$ & 94 & $91-110$ & 102 & $103-116$ & 111 \\
\hline 139. Mittelbreite d.Beckenhyble & $82-87$ & 85 & $82-98$ & 90 & $100-111$ & 105 \\
\hline 140. Kaudale Br.d.Beckens & $149-171$ & 158 & $155-209$ & 175 & $137-203$ & 197 \\
\hline 141. Gr.Bre.d.Fuftbeines & $303-375$ & 335 & $347-387$ & 374 & $365-415$ & 402 \\
\hline 142. Flugelbreite d. Dambeines & $128-148$ & 139 & $137-165$ & 149 & $147-185$ & 166 \\
\hline 143. Kl.Br.d.KUrp.d.Darmbeines & $29-36$ & 32 & $33-38$ & 35 & $34-40$ & 38 \\
\hline \multicolumn{7}{|l|}{ Schenk $\bullet$ lbein } \\
\hline 144. Gr. Lge.d.Schenkelbeines & $304-319$ & $\overline{305}$ & $316-353$ & 331 & $346-358$ & 353 \\
\hline 145 Physiolog.Lgo.Schenkebeines & $270-311$ & 295 & $301-341$ & 316 & $332-343$ & 338 \\
\hline 146. Gr.Br. d. proxim. Endes & $78-87$ & 83 & $82-98$ & 90 & $91-104$ & 96 \\
\hline 147. KI.Br.d.KUrpers & $26-30$ & 28 & $27-32$ & 29 & $32-35$ & 33 \\
\hline 148. Gr.Br.d.distal. Endes & $64-75$ & 68 & $69-78$ & 73 & $72-83$ & 78 \\
\hline $\begin{array}{l}\text { 149. D1cke d.Kopfes d.Schenkelbe- } \\
\text { Ines }\end{array}$ & $32-37$ & 34 & $35-40$ & 37 & $37-40$ & 38 \\
\hline 150. Dicke d.Trochanter ma1or & $36-40$ & 38 & $39-47$ & 41 & $43-48$ & 45 \\
\hline $\begin{array}{l}\text { 151. Dicke d.KUrpers d.Schenkelbe- } \\
\text { Ines }\end{array}$ & $29-33$ & 30 & $31-37$ & 34 & $34-39$ & 37 \\
\hline 152. Dicke d.distalen Findes & $81-97$ & 88 & $92-96$ & 94 & $92-106$ & 100 \\
\hline
\end{tabular}




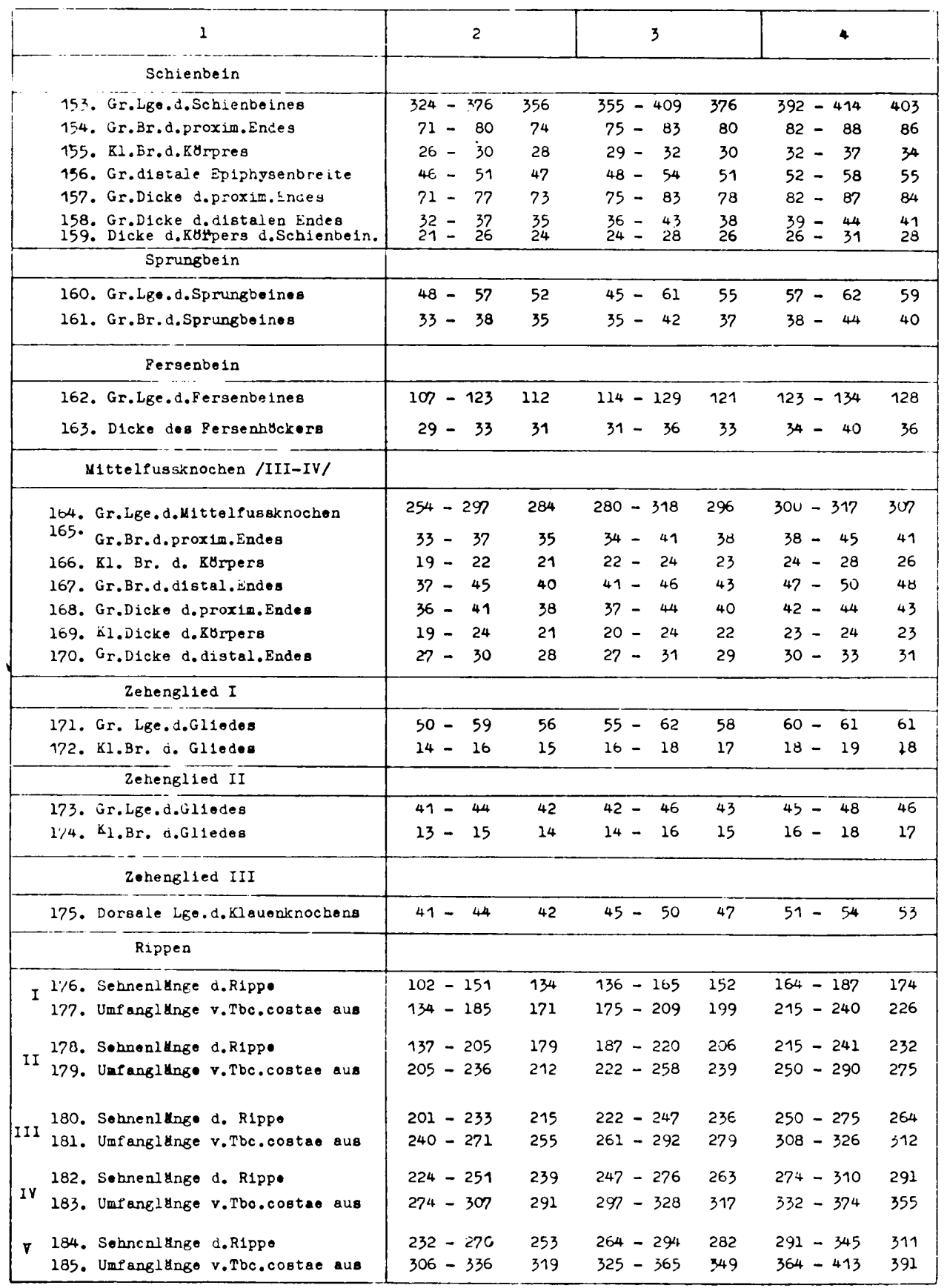




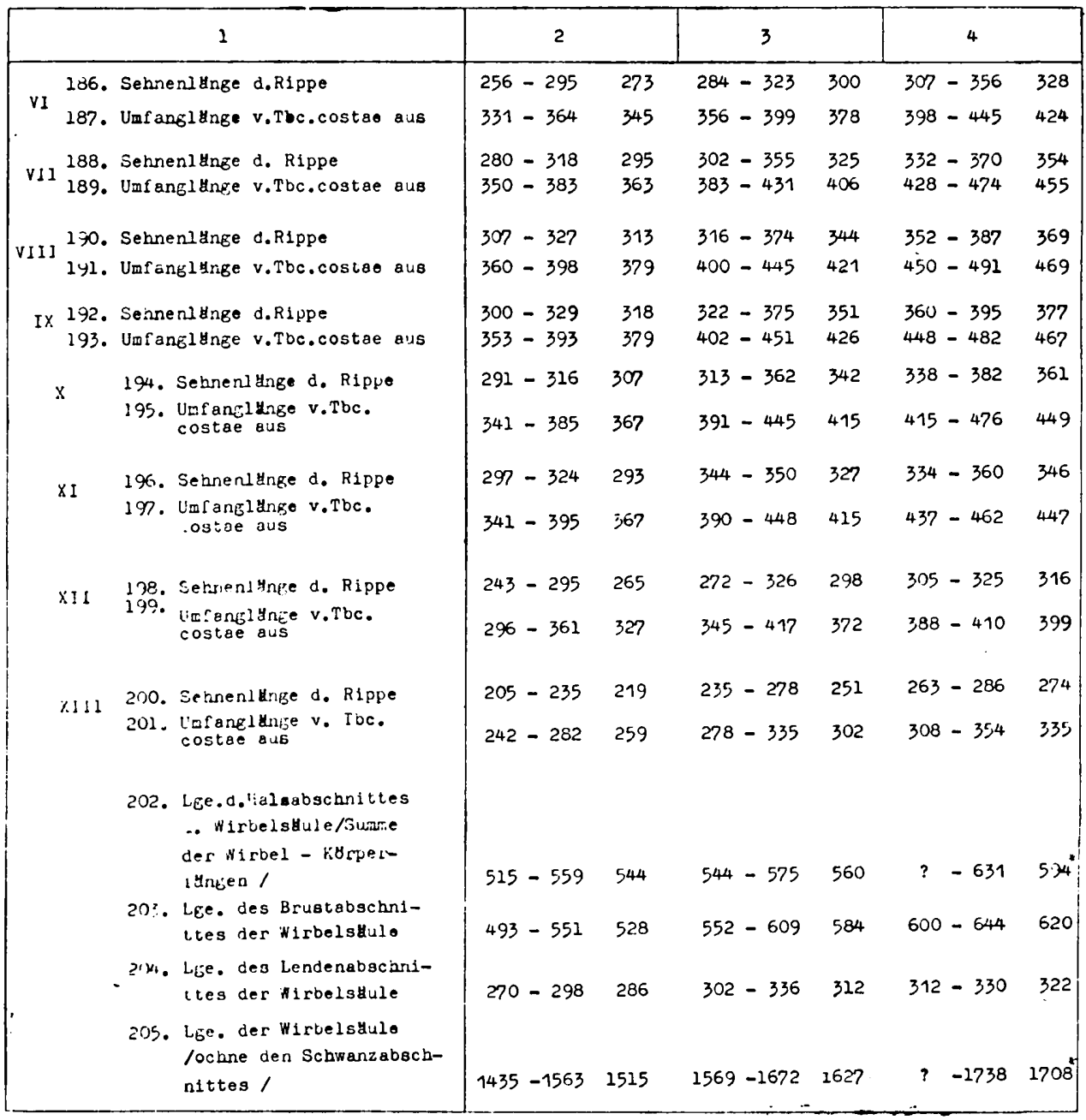

Die Körper der besprochenen Wirbel stellen in ihrem medialen Teil stark verschmälerte Knochenbalken dar.

Die Körperlänge der Wirbel von III bis V erhält sich in denselben Grenzen (Tab. 3). Der Körper des VI. Wirbels unterliegt einer Verkürzung und seine Länge beträgt durchschnittlich $81 \mathrm{~mm}(\mathrm{O}-$ und P-Hirsch) und $86 \mathrm{~mm}$ (K-Hirsch).

Auf der inferioren Fläche des Körpers ist ein Körperkamm sichtbar, der in den Wirbeln III bis V eine Form einer scharfen stark inferior vorgeschobenen Lamelle annimmt, aber besonders in der Umgebung der kaudalen Gelenkfläche, wo sie sich stark verbreitend das Tuberculum cristae bildet. Im VI. Wirbel aber ist die Crista corporis nur in dem vorderen Abschnitt sichtbar und danach unterliegt sie dem Schwund, indem 
sie in eine kaum sichtbare Verdickung übergeht. Der Caput vertebrae verändert sich von der herzförmigen Gestalt im III. Wirbel stufenweise und nimmt eine eiförmige Form im VI. Wirbel an. Seine Wölbung vergrössert sich in derselben Richtung. Die sehr weite Fossa vertebrae be-

Tabelle 4.

Mittel- und Extremwerte der für einige Knochenmasse des Rumpf- und des Gliedmassenskelettes berechneten Indizes.

\begin{tabular}{|c|c|c|c|c|c|c|}
\hline $\begin{array}{c}\text { Nr. u. Neme d. Indexes } \\
1\end{array}$ & $\begin{array}{c}\text { Poznad } / n=5 \\
\operatorname{Min}-\operatorname{Max} \\
2\end{array}$ & 4 & $\begin{array}{c}0182 \operatorname{tyn} / \mathrm{n}= \\
\operatorname{Min}-\operatorname{Max} \\
3\end{array}$ & $\begin{array}{r}-8 / \\
x\end{array}$ & $\begin{array}{c}\text { Karpsty } / n=6 \\
M 1 n-M a x \\
4\end{array}$ & $\begin{array}{r}-7 / \\
M\end{array}$ \\
\hline 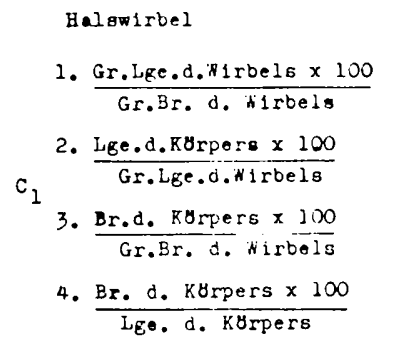 & $\begin{array}{l}83,6-86,4 \\
42,3-49,0 \\
32,8-37,4 \\
83,7-35,2\end{array}$ & $\begin{array}{l}84,9 \\
45,7 \\
34,8 \\
89,9\end{array}$ & $\begin{array}{l}75,4-95,1 \\
39,7-52,5 \\
31,1-37,4 \\
82,6-93,7\end{array}$ & $\begin{array}{l}85,1 \\
44,9 \\
34,2 \\
87,0\end{array}$ & $\begin{array}{l}83,7-90,6 \\
41,9-45,8 \\
26,9-35,0 \\
70,4-92,3\end{array}$ & $\begin{array}{l}86,0 \\
43,6 \\
29,8 \\
79,7\end{array}$ \\
\hline 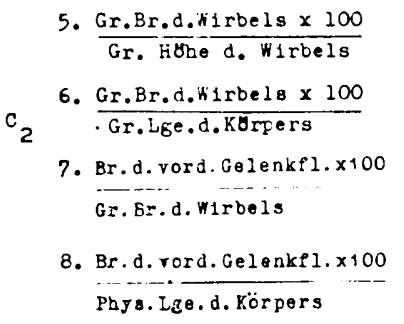 & $\begin{array}{l}81,2-88,7 \\
66,4-77,4 \\
87,3-95,8 \\
72,5-79,3\end{array}$ & $\begin{array}{l}85,0 \\
71,5 \\
90,4 \\
75,8\end{array}$ & $\begin{array}{l}82,7-99,0 \\
78,4-92,7 \\
72,3-88,4 \\
75,0-81,7\end{array}$ & $\begin{array}{l}90,3 \\
83,7\end{array}$ & $\begin{array}{l}89,6-97,2 \\
80,6-95,6 \\
73,5-78,9 \\
69,7-85,6\end{array}$ & $\begin{array}{l}92,9 \\
89,7 \\
75,9 \\
76,0\end{array}$ \\
\hline 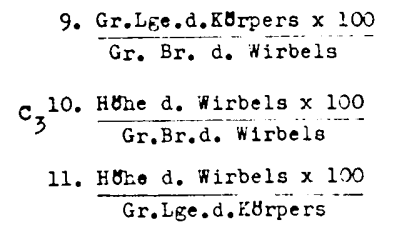 & $\begin{array}{l}86,2-102,3 \\
72,3-89,4 \\
78,5-97,5\end{array}$ & $\begin{array}{l}95,9 \\
83,5 \\
86,6\end{array}$ & $\begin{array}{l}81,7-95,9 \\
64,6-81,8 \\
73,8-97,8\end{array}$ & $\begin{array}{l}87,6 \\
73,9 \\
84,6\end{array}$ & $\begin{array}{l}74,0-87,4 \\
65,2-79,3 \\
81,0-97,8\end{array}$ & $\begin{array}{l}82,9 \\
73,5 \\
88,7\end{array}$ \\
\hline 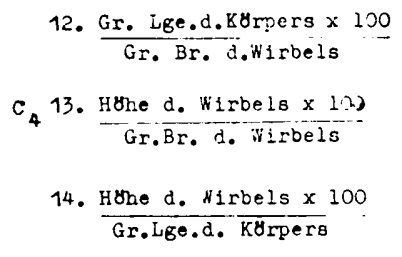 & $\begin{array}{l}37,6-102,4 \\
83,0-101,1 \\
88,8-107,3\end{array}$ & $\begin{array}{l}92,6 \\
87,7\end{array}$ & $\begin{array}{l}79,8-93,7 \\
79,5-93,7 \\
93,2-106,4\end{array}$ & $\begin{array}{l}86,1 \\
86,1\end{array}$ & $\begin{array}{l}75,4-91,0 \\
86,0-96,5 \\
93,1-115,8\end{array}$ & $\begin{array}{l}83,3 \\
88,7\end{array}$ \\
\hline
\end{tabular}




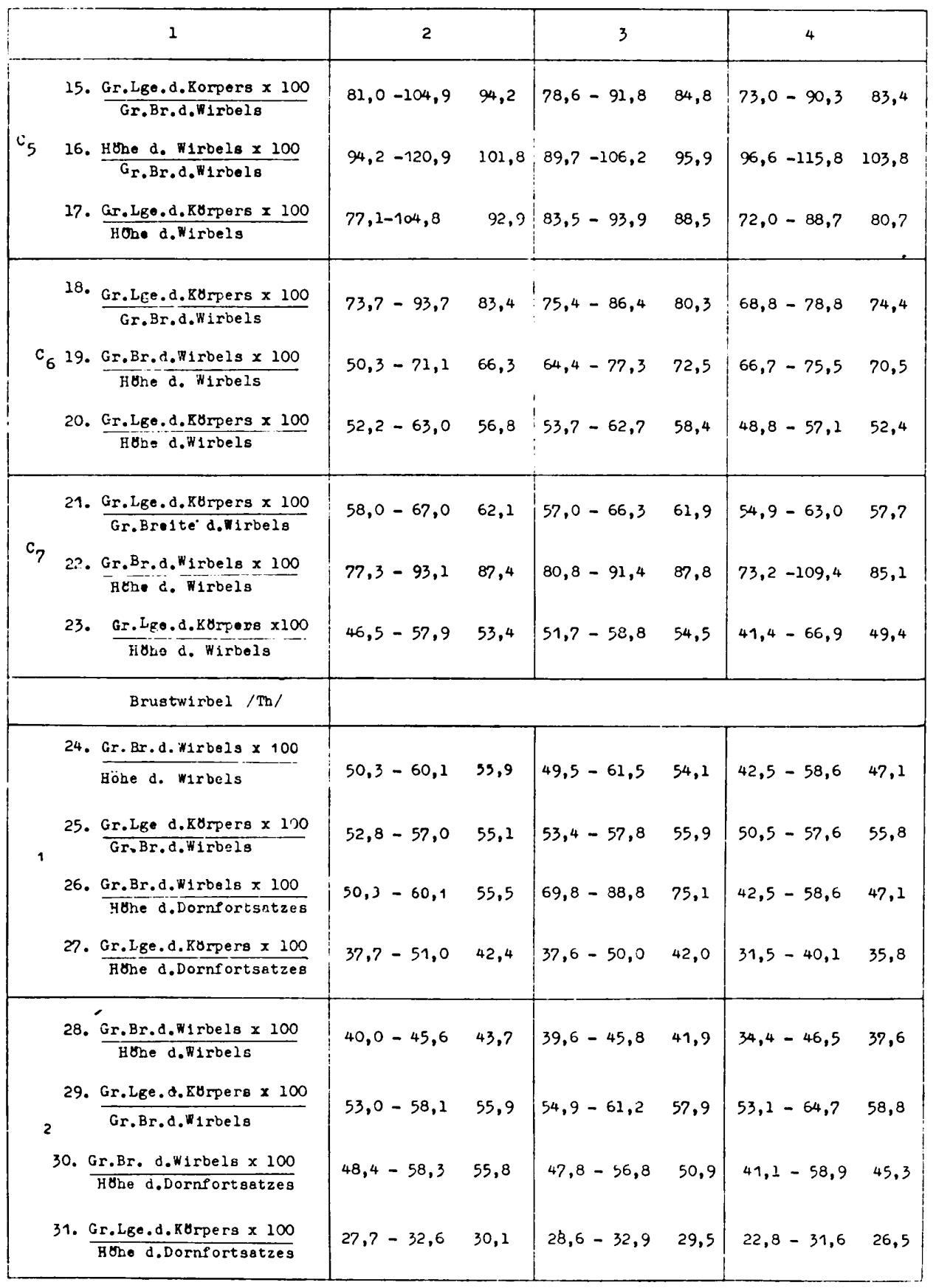




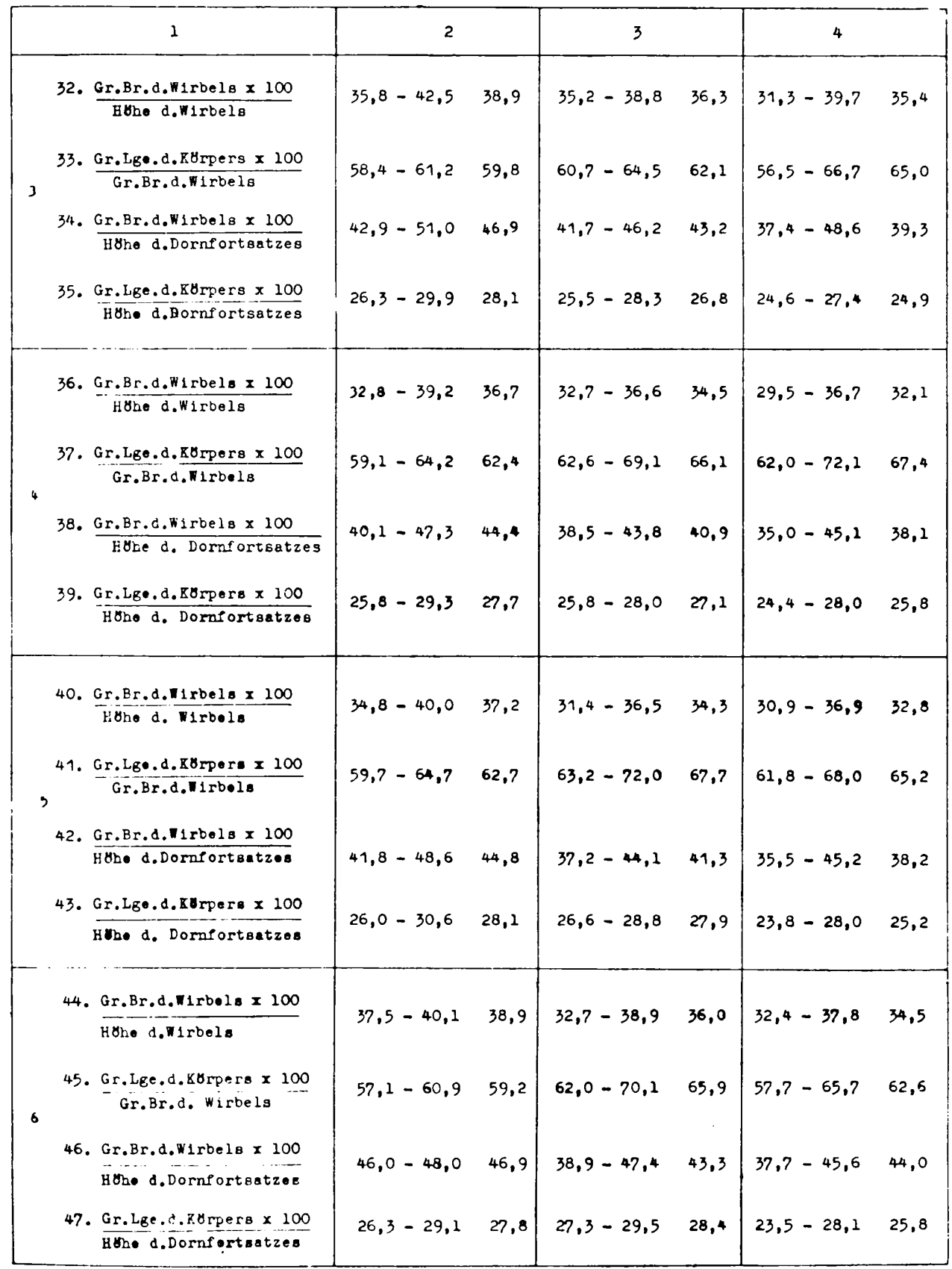




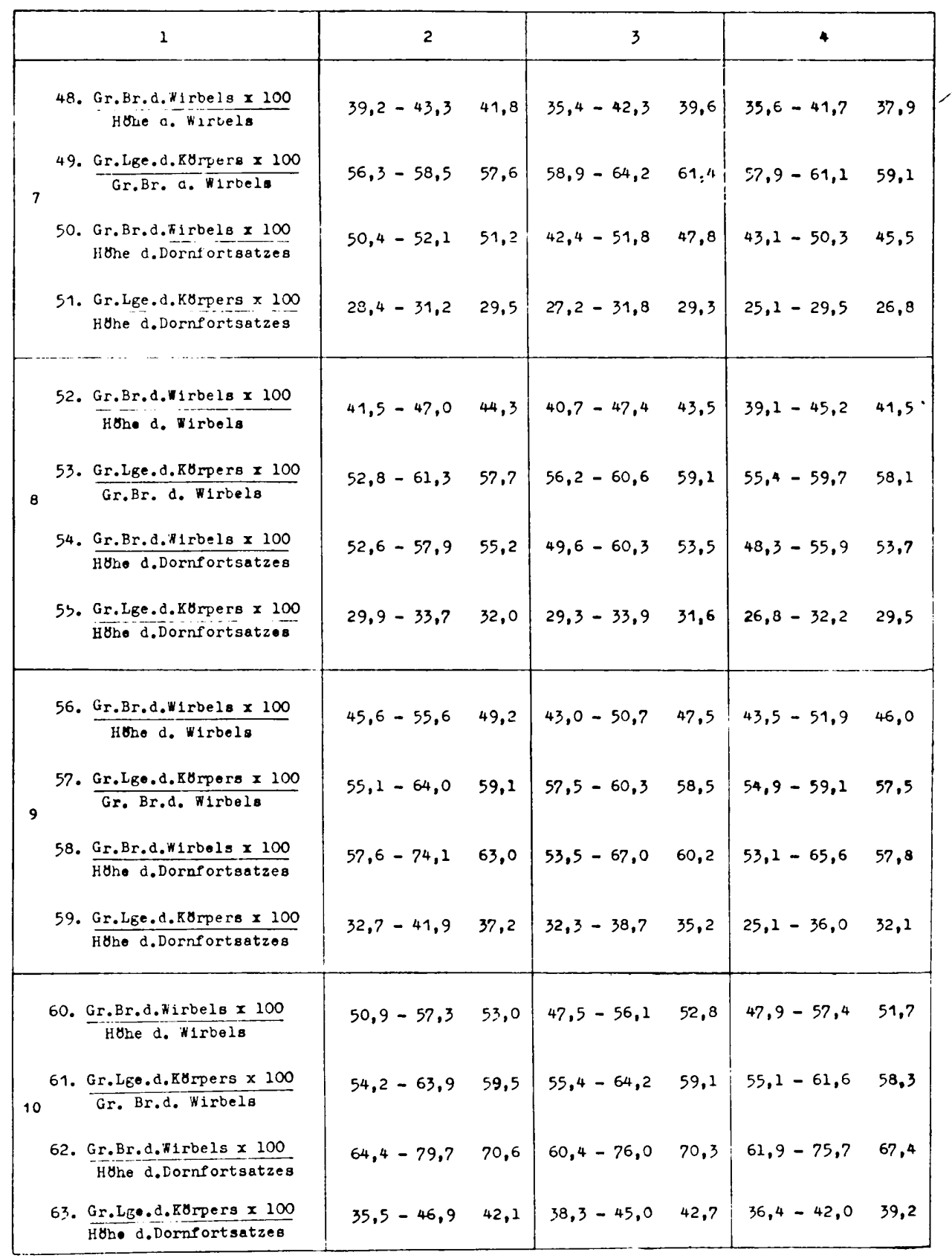




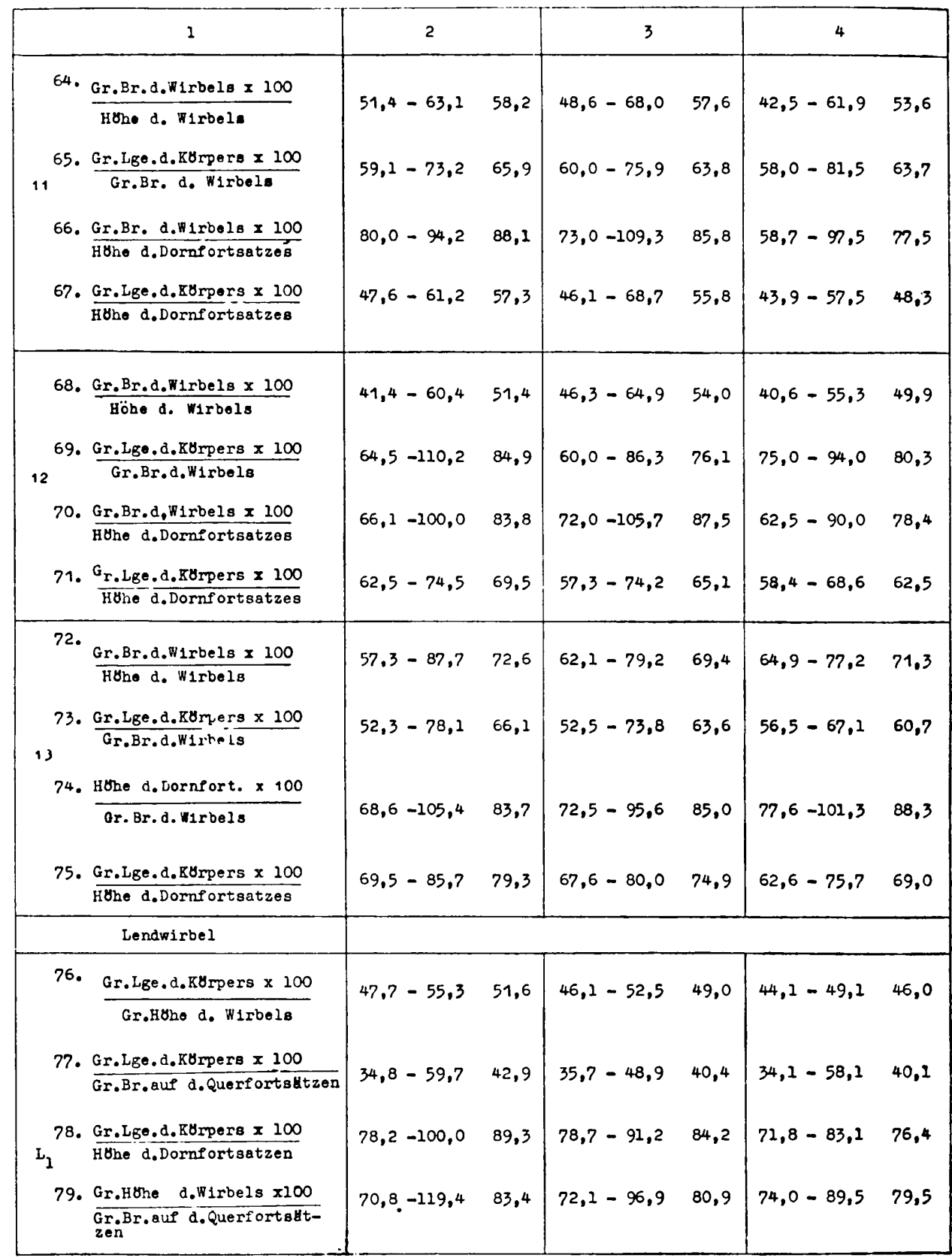




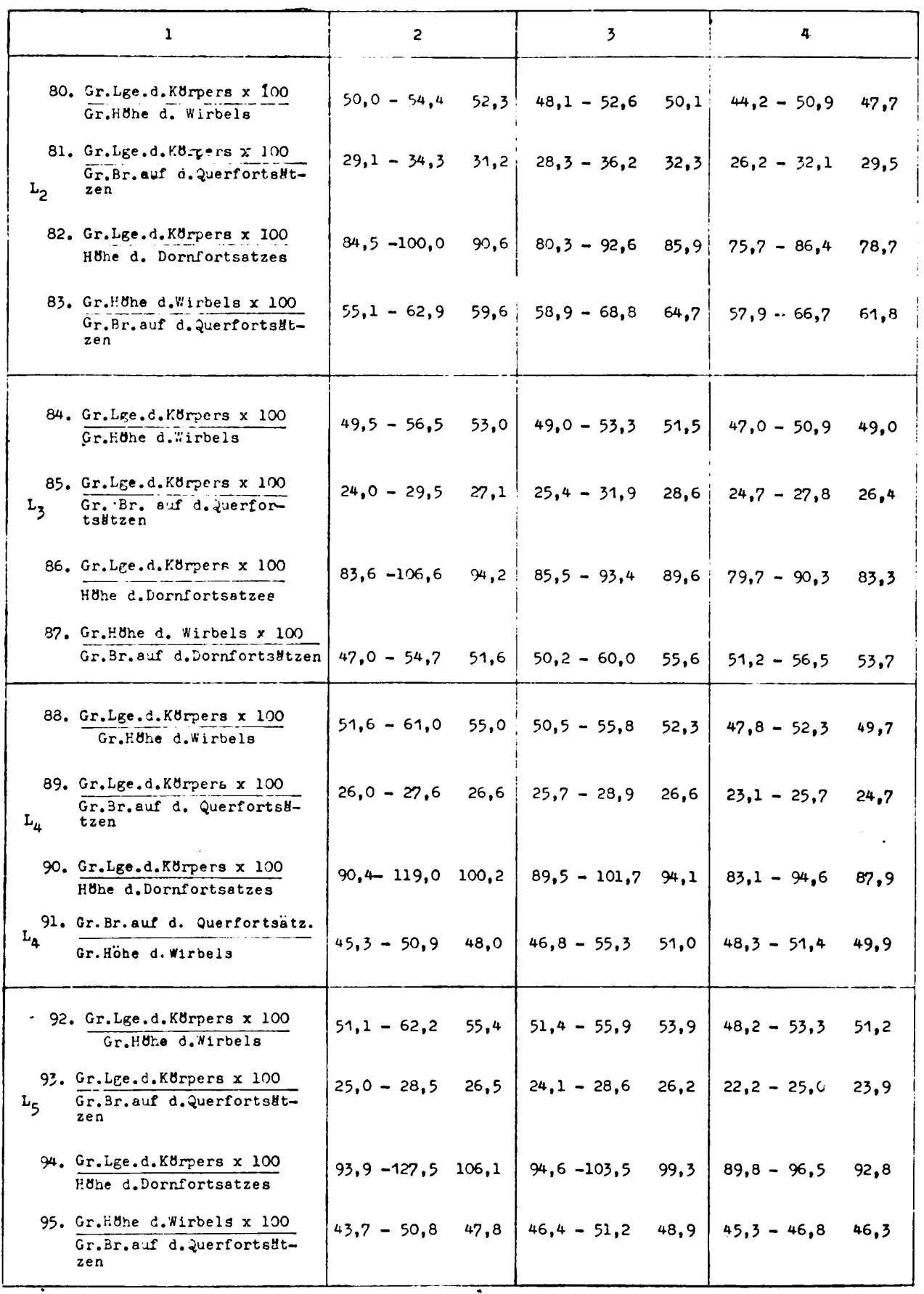




\begin{tabular}{|c|c|c|c|c|c|c|c|}
\hline & 1 & \multicolumn{2}{|l|}{2} & \multicolumn{2}{|l|}{3} & \multicolumn{2}{|l|}{4} \\
\hline 96. & $\frac{\text { Gr.Lge.d.KUrpers } \times 100}{\text { Gr.HOhe d.W1rbels }}$ & $48,3-62,7$ & 54,4 & $49,0-55,5$ & 51,9 & $47,3-53,4$ & 50,8 \\
\hline 97 & $\frac{\text { Gr.Lgo.d.KBrpers } \times 100}{\substack{\text { Gr.Br.auf d.Querferts } \\
\text { zent- }}}$ & $24,9-30,9$ & 28,4 & $26,2-30,0$ & 27,9 & $24,9-27,5$ & 25,8 \\
\hline 98. & $\frac{\text { Gr.Lge.d.K8rpers } \times 100}{\text { H\&ho d.Dornfortsatzes }}$ & $88,0-134,2$ & 106,9 & $87,3-104,1$ & 95,7 & $88,1-104,0$ & 96,5 \\
\hline 99. & $\frac{\text { Gr.Hohe d. W1rbels } \times 100}{\text { Gr.B }_{\text {Br.auf d. Querfortsllt- }}}$ & $46,2-63,2$ & 52,5 & $48,6-61,2$ & 53,9 & $45,6-54,5$ & 51,1 \\
\hline & Erouzbein & & & & & & \\
\hline 100 & $\frac{\text { Gr.Br. d.Kreuzbelnes } \times 100}{\text { Gr.Lge.d.Kreuzbein }}$ & $74,8-83,3$ & 78,3 & $73,6-82,3$ & 79,1 & $82,5-98,0$ & 89,1 \\
\hline & Abschnitte d. Nirbelstule & & & & & & \\
\hline 101. & Lge.d.Halsabschn. $\times 100$ & & & & & & \\
\hline 102. & $\begin{array}{l}\text { Lge.d. Brustabscbnittes } \\
\text { Lge.d. Lendenabsohn. } \times 100\end{array}$ & $99,2-104,4$ & 101,5 & $93,4-99,0$ & 96,7 & $198,4 /$ & \\
\hline & Lge.d. Brustabschn. & $53,1-55,6$ & 54,1 & $52,1-55,3$ & 53.3 & $50,2-52,9$ & 51,8 \\
\hline 103. & $\begin{array}{l}\text { Gr.Lge.d.Kreuzbeines } \times 100 \\
\text { Lge d.Brustabschnittes }\end{array}$ & $28,2-31,0$ & 29,7 & $27,9-30,9$ & 29,6 & $23,6-29,4$ & 27,8 \\
\hline & Schulterblatt & & & & & & \\
\hline $\begin{array}{l}104 . \\
105 .\end{array}$ & $\begin{array}{l}\text { Gr.Br.d.Schulterblattes } \\
\text { Innen-Lge.d.Schulterbla- } \\
\text { ttes } \\
\frac{\text { Kl.Br.d.Halses } \times 100}{\text { Innen-Lge.d.Schulterbla- }} \\
\text { ttes }\end{array}$ & $\begin{array}{l}55,5-67,2 \\
12,3-14,8\end{array}$ & 13,4 & $12,1-14,2$ & 13,4 & $\begin{array}{l}54,0-63,5 \\
12,0-13,7\end{array}$ & 12,7 \\
\hline & Armbein & & & & & & \\
\hline 106. & - Ka. Br, d. Humerusschaf, $\times 100$ & & & & & & \\
\hline & $\begin{array}{c}\text { Lge. d. Armbe1nes rom Kopf } \\
\text { aus }\end{array}$ & $9,7-11,7$ & 10,5 & $10,1-11,5$ & 10,9 & $10,3-12,2$ & 11,2 \\
\hline 107. & 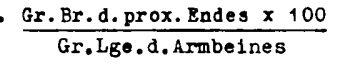 & $25,1-26,8$ & 26,1 & $25,4-28,1$ & 26,5 & $25,4-28,2$ & 27,0 \\
\hline 108. & - Gr.Br.d.dist.Endes $\times 100$ & $19,8-23,3$ & 20,9 & $19.4-21.9$ & 21,0 & $20,1-22,0$ & 20,9 \\
\hline 109. & $\frac{\text { Gr.Br.d.d1st. Endes } \times 100}{\text { Gr.Br.d.proxim.Endes }}$ & $76,0-88,9$ & 80,5 & $74,3-84,2$ & 79,1 & $74,1-79,2$ & 77,3 \\
\hline 110. & - D1oke d.dist. Bndes $\times 100$ & & & & & & \\
\hline & D1cke d.proxim. Bndes & $66,2-73,2$ & 70,0 & $65,8-77,4$ & 70,4 & $65,5-70,3$ & 67,8 \\
\hline 111. & $\frac{\text { Dicke d.Humerusschaftes }}{\text { Dicke d.proxim.Endes }}$ & $40,2-45,1$ & 43,0 & $41,4-52,1$ & 45,4 & $43,3-47,2$ & 45,3 \\
\hline
\end{tabular}




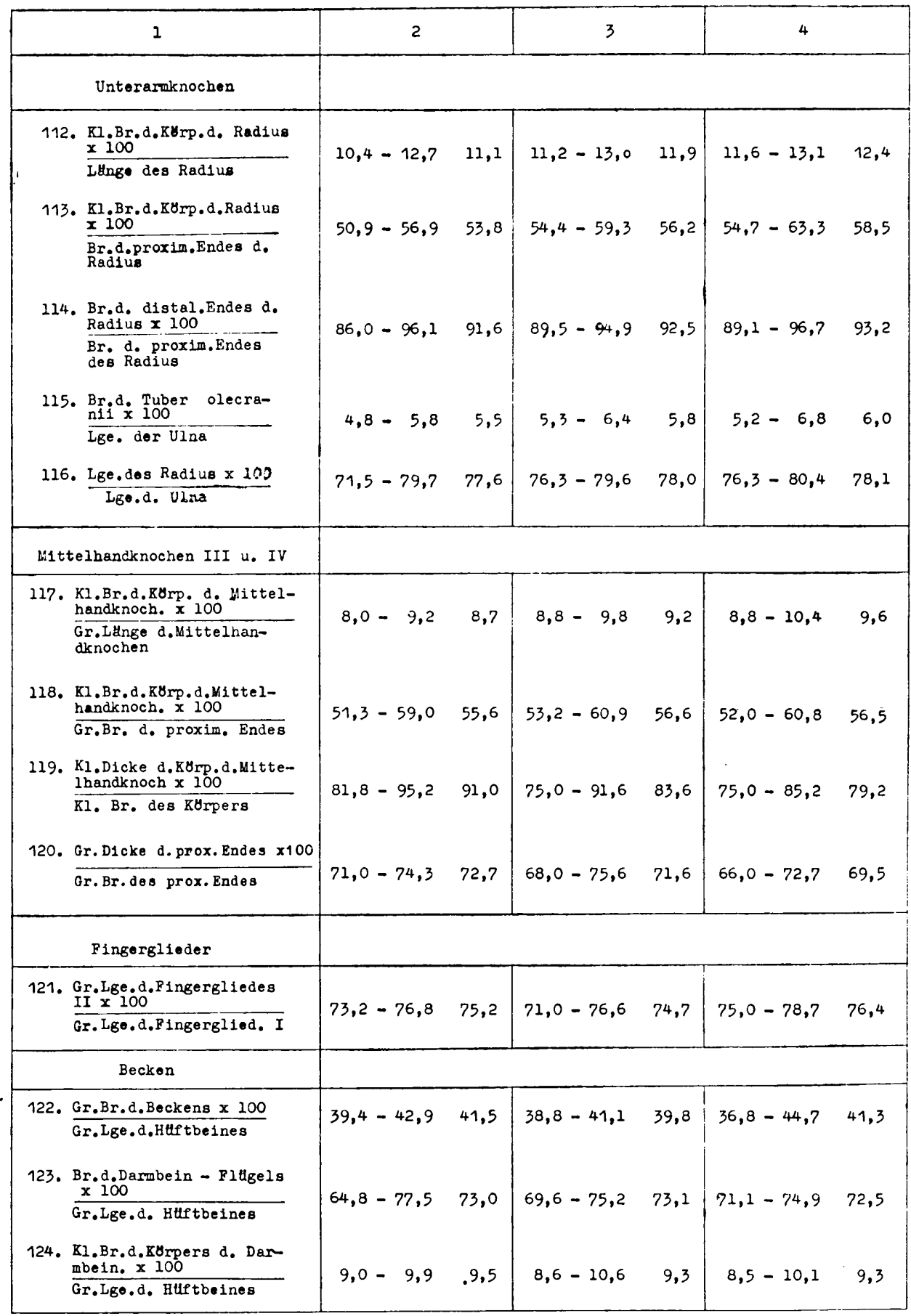




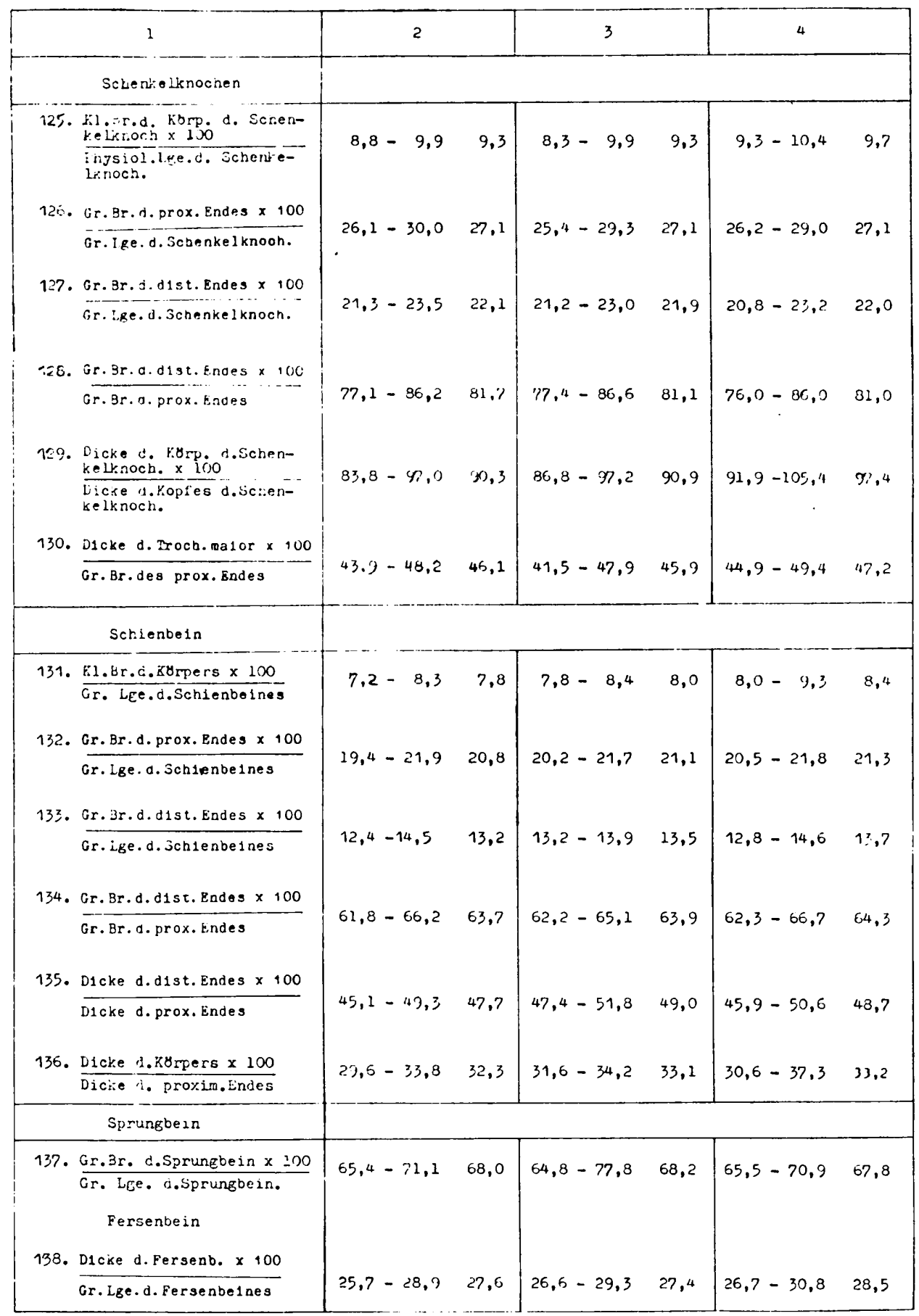




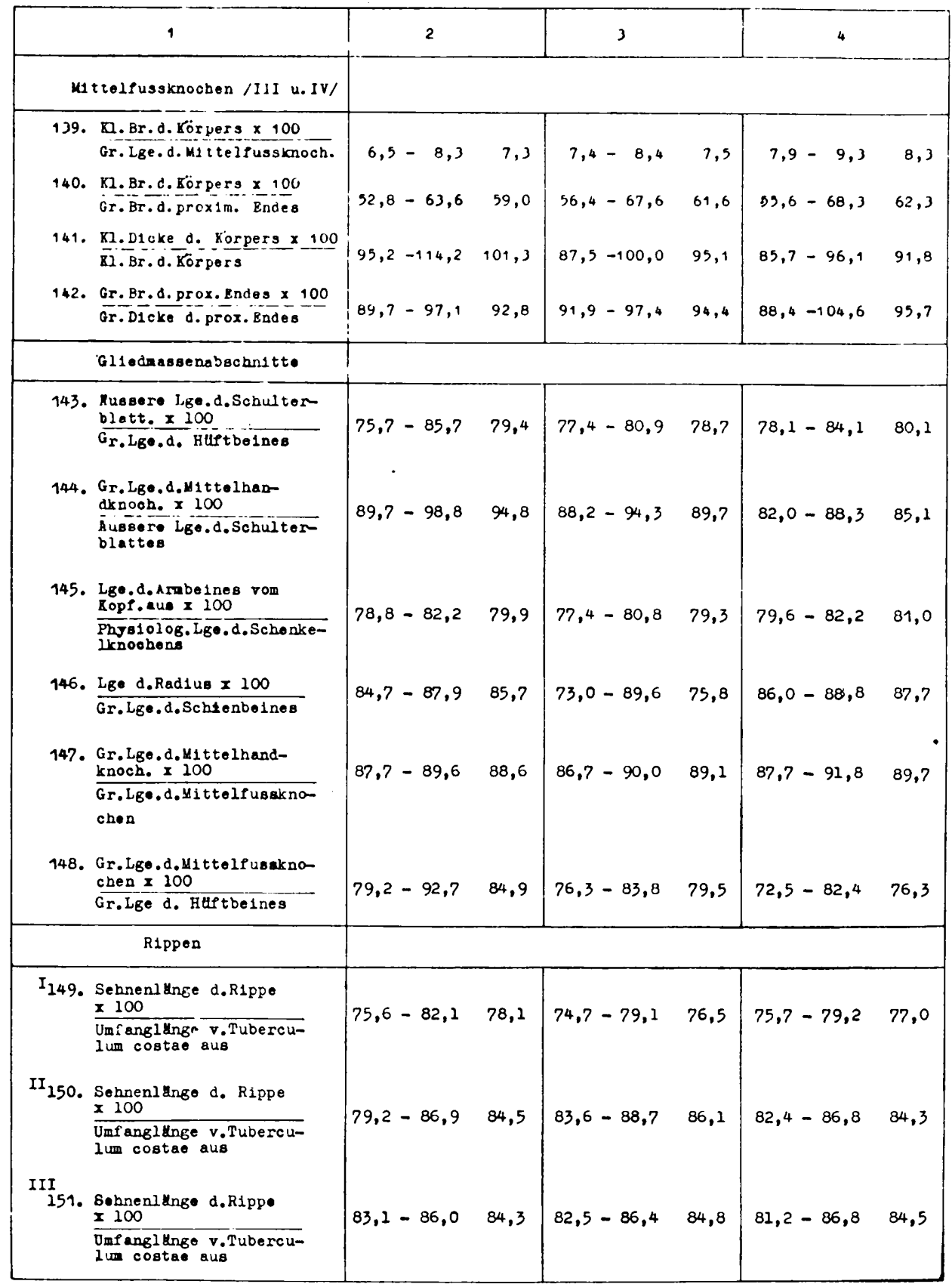

sitzt im III. Wirbel eine runde Form die danach einer leichten lateralen Abflachung unterliegt, um im VI. Wirbel die Form eine sanften Ellipse anzunehmen. Seine Tiefe vergrössert sich entsprechend mit der Wölbungszunahme des Kopfes des Nachbarwirbels. 


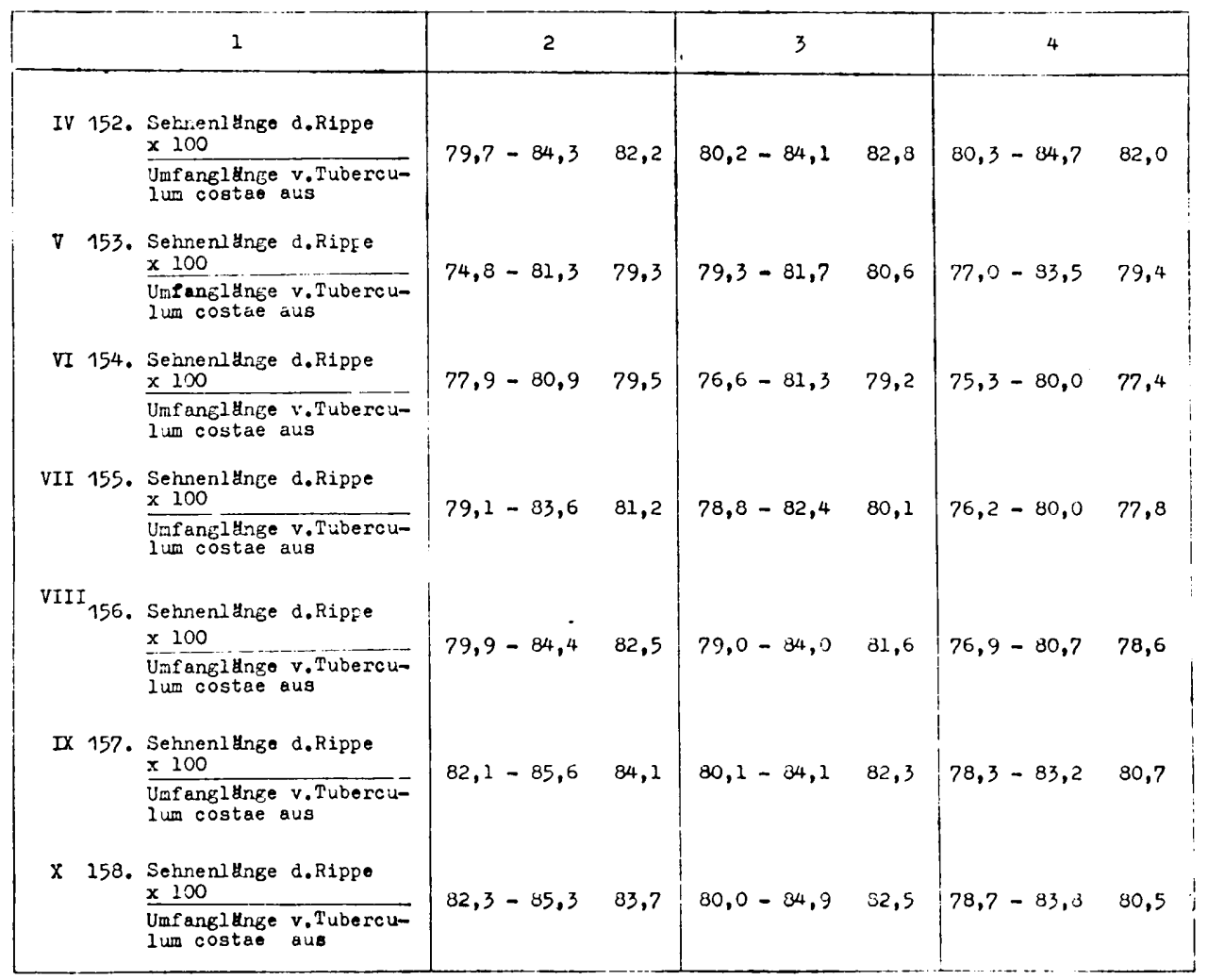

Auf der Grenze des Körpers und des Bogens unter den Proc. art. ant. und post. treten deutlich die Incisurae vert. cran. et caud. auf, von denen die vorderen bei allen besprochenen Wirbeln deutlich tiefer sind. Der Proc. costotransversarius nimmt in Abhängigkeit vom Wirbel eine verschiedene Gestalt an.

Im III. Wirbel stellt er eine schmale, flache inferior und lateral gerichtete Lamelle dar. Der vordere Teil dieser Lamelle oder Proc. costarius schiebt sich anterior, bedeutend hinter den Bereich des Wirbelkopfes vor und zwar in Gestalt eines dünnen zur Mitte hin ungestülpten Processus. Der kaudaje Teil der erwähnten Lamelle, die den eigentlichen Proc. transversus bildet, läuft stark auf die Seiten hinaus und nimmt die Gestalt eines scharfen Dreiecks an. Im IV. Wirbel bricht die Lamelle des Proc. costotransversarius zusammen, und der Proc. cost. wird massiver, indem er sich inferior richtet, aber der Proc. transversarius nähert sich der horizontalen Fläche, indem er gleichzeitig den dreieckigen Umriss verliert. Der Proc. cost. isoliert sich schon im V. Wirbel gänzlich ab, indem er die Form einer schmalen schräg inferior gerichteten Lamelle annimmt, die in ihrem anterioren Teil stark ausgebaut ist, aber nicht aus- 
serhalb des Bereiches des Wirbelkopfes heraustritt. Die erwähnte Lamelle vergrössert sich im VI. Wirbel bedeutend indem sie sich hauptsächlich inferior und kaudal ausbaut. Ihr kaudalo-inferiorer Rand nimmt die Gestalt eines Höckers an. Die Querfortsätze des V. und VI. Wirbels sind fast gleichartig in Gestalt von horizontal gestellten rechteckigen Lamellen ausgebaut.

Die Basis des Proc. costotransversarius ist durch den sagittal verlauSenden Meatus transversarius durchstochen, dessen Länge sich deutlich vom III. bis zum VI. Wirbel verringert. Die grösste Breite des Wirbels, gemessen auf dem Proc. costotransversarius unterliegt zwischen dem ilI., IV., V. und VI. Wirbel keinen Veränderungen.

Die Unterschiede im Mittel, im Rahmen derselben Gruppe übersteigen vier Millimeter nicht. Die Unterschiede zwischen den Gruppen sind wesentlicher und betragen z.B. für den dritten Wirbel: $96(P), 108(O)$ und $115(\mathrm{~K})$. Dies sind ziemlich grosse Unterschiede auf ein so kleines Mass. aber sie haben eine geringe Bedeutung bei Vergleichungen, denn sie sind individuell sehr veränderlich.

Ein Beispiel hierfür ist die Gruppe der O-Hirsche, wo die grösste Breite des VI. Wirbels von 96-115 mm schwankt. Die auf den Arcus vertebrae auftretenden weiten Proc. art. cran. et caud. sind auf den lateralen Seiten der Bögen, mit stark ausgebauten flachen Rändern ohne deutlichen Verdickungen vereinigt.

Die auf den Processus liegenden kranialen Gelenkflächen scheinen bei den Flachlandhirschen mehr horizontal gestellt zu sein und sind proportional zur Grösse des ganzen Wirbel kleiner als bei den $\mathrm{K}$-Hirschen.

Der Dornfortsatz (Proc. spinalis) weist in Abhängigkeit vom Wirbel eine sehr starke Differenzierung auf. Im dritten Wirbel sieht er wie eine ungrosse dreieckige Lamelle oder ein unregulärer Kamm aus. Im vierten Wirbel nimmt er bei einigen Individuen eine rechteckige Gestalt einer niedrigen Lamelle an und bei den übrigen die Form eines unregulären Sockels. Eine deutliche Sockelgestalt nimimt der Dornfortsatz auf dem V. und VI. Wirbel an, aber mit dem Vermerk, dass dieser letztere viel höher und stärker anterior ausgebogen ist, wodurch sein Gipfelpunkt sich vor den superioren Rand des Wirbelkanals vorschiebt.

Diese Differenzierung des Dornfortsatzes im Laufe der Verschiebung vom III. bis zum VI. Wirbel zieht einen grossen Unterschied in der Höhe dieser Wirbel nach sich (Tabelle 3). Das Merkmal dieser Messung bewirkt leider eine grosse individuelle Veränderlichkeit im Rahmen sogar einer Gruppe, was natürlich seinen Vergleichswert bedeutend vermindert, nichtsdestoweniger prägt sich die Massivität und die Höhe des Dornfortsatzes bei den K-Hirschen während ihrer Beobachtung klar aus. Die in drei Kombinationen berechneten Indizes: Länge : Breite; Höne : 
: Breite; und Höhe zur Länge ergaben eine zu grosse Streuung des Wertes, als dass sie eine Hilfe bei der Unterscheidung der einzelnen lokalen Gruppen bieten könnten.

$\mathrm{H}$ a l s w ir bel VII. Diesen Wirbel kennzeichnet eine deutliche Verkürzung des Körpers im Verhältnis zu den übrigen Halswirbeln, eine stärkere laterale Abflachung des Kopfes des Körpers, eine dorso-ventrale Abflachung des unteren Teiles des Körpers, eine deutliche Überlegenheit in der Grösse der anterioren Gelenkfortsätze im Verhältnis zu den kaudalen und das Auftreten von Foveae costales caud. Der Dornfortsatz des besprochenen Wirbels unterliegt einer lateralen Abflachung. Die Körperlänge dieses Wirbels beträgt $\mathrm{P}=61, \mathrm{O}=64, \mathrm{~K}=66 \mathrm{~mm}$, die grösste Breite dementsprechend 93, 104 und $115 \mathrm{~mm}$.

Die Halswirbelmasse kennzeichnet überhaupt eine bedeutende Unbeständigkeit, aber besonders markant tritt dies auf der Höhe des siebenten Wirbels auf, die bei den P-Hirschen von 92 bis $119 \mathrm{~mm}$, bei den O-Hirschen von 107 bis $130 \mathrm{~mm}$ und bei den K-Hirschen von 106 bis $157 \mathrm{~mm}$ schwankt.

\section{b. Brustwirbel (Vertebrae thoracales)}

Der Brustabschnitt (Pars thoracalis) setzt sich aus 13 Wirbeln zusammen. Der Körper des Brustwirbels besteht aus einem verhältnismässig langen Balken, der in den anterioren Wirbeln $\left(T h_{1}-T h_{4}\right)$ dorso-ventral abgeflacht ist und im Laufe des kaudalen Längsschreitens stufenweise einer lateralen Abflachung unterliegt.

Gemäss dem Querschnitt des Körpers nach verändert sich die Gestalt des Facies articularis cranialis, die vom Umriss einer abgeflachten dorso-ventralen Ellipse, durch eine dem Kreis angenäherte Figur in die Form eines senkrecht verlängerten Dreieckes übergeh't, das mit seiner Basis nach oben gerichtet ist. Die Länge der Wirbelkörper des Brustabschnittes stellt sich auf dem Beispiel eines gemeinsamen Durchschnittes für alle Flachlandexemplare wie folgt vor: $T h_{1}-50 \mathrm{~mm} ; T h_{2}-47 ; T h_{3}-$ 46; $T h_{4}-45 ; T h_{5}-44 ; T h_{6}-42 ; T h_{7}-40 ; T h_{8}-39 ; T h_{9}-39 ; T h_{10}$ - 40; $T h_{11}-41 ; T h_{12}-42 ; T h_{13}-45$. Die Ziffern für den K-Hirsch sind etwas grösser, aber sie behalten dieselbe Tendenz bei d. h. sie unterliegen einer stufenweisen Verkürzung bis Wirbel VIII, dann erfolgt ein Ausgleich auf Wirbeln VIII-IX und nachdem tritt ein abermaliger Anwuchs bis zu Wirbel XIII einschliesslich ein.

Die Unterschiede zwischen den Gruppen sind deutlich. Bei jedem der dreizehn Wirbel fallen sie zu gunsten des K-Hirsches aus, aber mit dem Vermerk, dass beim O-Hirsch diese sich dauernd in der Mitte anordnen. Individuelle Unterschiede sind weniger markant als bei den Halswirbeln, 
folglich überdecken sich die Grenzwerte für die einzelnen Gruppen in einem weit geringeren Grade aufeinander.

Auf allen Körpern des Brustabschnittes sind die Foveae costales cran. et caud. deutlich sichtbar mit Ausnahme des Wirbels XIII, der keine Foveae costales cand. besitzt.

Auf der ventralen Seite des Körpers tritt ein auf den ersten zwei Wirbeln deutlich sichtbarer Körperkamm auf. Dieser Kamm deutet sich kaudal immer stärker an.

Die Proc. articulares crain. ausser dem I. und XIII. Wirbel beschränken sich auf flache Gelenkflächen.

Die Proc. articulares caud. bilden flache kaudal und inferior gerichtete Flächen, die eine typische Gestalt eines Fortsatzes erst vom 12. Wrrbel ab annehmen. Der Proc. transversus ist in Gestalt einer kurzen, massiven Wölbung von unregulärer Form ausgebildet, die schräg zum Körper gerichtet ist und die sich im Verlaufe mit der kaudalen Verschiebung stark verringert und eine horizontale Lage annimmt.

Die auf den Querfortsätzen gemessene grösste Breite verhält sich anders, als die Länge des Körpers. Im Verlauf von Wirbel I kaudalwärts beobachten wir anfänglich ein ziemlich gewaltiges Absinken von $90 \mathrm{~mm}$ auf Wirbel I bis 67 auf dem V (für den K-Hirsch betragen die entsprechenden Ziffern 98 und 75), und danach sehen wir keine Veränderungen mehr bis Wirbel X. Auf den Wirbeln XI und XII vermindert sich cie Breite wieder, indem sie $54 \mathrm{~mm}$ erreicht, um sich wieder auf dem Wirbel XIII gewaltsam bis $59 \mathrm{~mm} \mathrm{zu}$ erhöhen. Auf dem Querfortsatz ist eine weite Gelenkfläche - Fovea transversaria sichtbar, die sich kaudal schnell verringert, um in der Umgebung von Wirbel XI, XII gänzlich zu verschwinden. Im vorden Teil dieser Fortsätze treten, ab Wirbel II ab, die stark entwickelten Proc. mamillares auf, die auf dem Wirbel XII und XIII mit dem vorderen Gelenkfortsatz zusammenschmelzen.

Die Incisura vertebralis post. ist sehr tief, aber sie unterliegt keinem Verschluss.

Im untersuchten Material fanden wir einen Fall des Auftretens einer dünnen Knochenleiste auf Wirbel XIII vor, die das For. intervertebrale verschloss.

Der Proc. spinosus nimmt die Gestalt einer ausgedehnten flachen Lamelle an, die sich superior leicht verschmälert. Sein vorderer Rand ist auf der ganzen Höhe ziemlich scharf, der kaudale Rand dagegen ist im unteren Drittel stumpf. Die kaudale Ausbiegung des Dornfortsatzes wächst bis Wirbel VIII an, um sich in den weiteren Wirbeln wieder bis zur Vertikalen anzunähern, die durch den Wirbelfortsatz des Wirbels XIII erreicht wird. Im Zusammenhang damit, kann man den Wirbel XIII uls Vertebra diaphragmatica betrachten. 
Die Höhe der Dornfortsätze wächst von Wirbel I bis Wirbel IV plötzlich an, und auf dem letzten erreicht sie ihre grösste Höhe $(\mathrm{P}=154$; $O=178 ; \mathrm{K}=210 \mathrm{~mm}$ ), aber von diesem Moment ab beginnt sie sich langsam und auf eine gleichmässige Weise bis zu Wirbel XIII zu verkürzen, auf dem sie folgende Höhen der Mittelwerte für die erwähnten Gruppen annimmt: 55, 61 und $71 \mathrm{~mm}$. Die Dornfortsätze der Brustwirbe! sind dasjenige Element, auf dem man auf eine deutliche Weise bei der Pesichtigung Unterschiede $\mathrm{zu}$ gunsten des Karpatenhirsches beobachten kann, bei dem sie massiver und höher sind. Dies ist auf Wirbel I an markantesten sichtbar, wo die Höhe dieses Fortsatzes bei Flachlandhirschen durchschnittlich 118 erreicht $(\mathrm{P}=112$; $\mathrm{O}=123)$, aber bei Karpatenhirschen $160 \mathrm{~mm}$. Solch ein deutlicher Unterschied erhält sich ungefähr bis Wirbel VII, aber von diesem Momente ab beginnen die Grenzwerte sich immer mehr zu überdecken und die Differenzierung wird immer weniger sichtbar.

Aus den für jeden von den Brustwirbeln berechneten vier Indizes scheint sich am meisten hervorzuheben $\frac{\text { Grösste Höhe d. Körpers } \times 100}{\text { Höhe des Dornfortsatzes }}$. Sein Wert fast identisch für beide Flachlandgruppen ist bei dem K-Hirsch deutlich niedriger, was wohl die durch das Auge erhaltenen E.indrücke bestätigen würde, dass der Dornfortsatz im Verhältnis zum Wirbelkörper bei den Flachlandhirschen schwächer entwickelt ist.

Dieser Unterschied erhält sich bis Wirbel VIII und auf Wirbel X verwischt er sich gänzlich.

\section{c. Lendenwirbels (Vertebrae lumbales)}

Der Lendenabschnitt der Wirbelsäule besteht aus sechs Wirbeln. Die Wirbelkörper bilden einen leicht in sagittaler Richtung ausgebogenen Knochenbalken. Auf der ventralen Seite des Körpers ist ein klar angedeuteter Körperkamm sichtbar. Die kraniale Gelenkfläche ist leicht gewölbt, von herzförmiger Gestalt und sie breitet sich im Laufe der Längsverschiebung in Richtung der mehr kaudal gelegenen Wirbel aus. Die Unterschiede in den Körperlängen zwischen den einzelnen Wirbeln sind sehr gering. Etwas kürzer sind Wirbel I und VI, ihre Länge beträgt für Flachlandhirsche $48 \mathrm{~mm}$, aber Wirbel II-V sind fast gleich und ihre durchschnittlichen Längen halten sich in den Grenzen $51-53 \mathrm{~mm}$. Die Unterschiede in den lokalen Gruppen sind nicht gross, und der O-Hirsch gleicht in diesem Falle dem Karpatischen.

Die Proc. transversi bestehen aus verhältnismässig schmalen Knochenleisten, die leicht bogenförmig anterior und inferior gebogen sind. Die 
Länge des Fortsatzes wächst vom ersten bis zum vierten oder fünften Wirbel an. Die Endungen der Fortsätze weisen eine grosse individuelle Variabilität auf. Unterschiede treten sowohl zwischen den einzelnen Wirbeln wie auch zwischen den einzelnen Individuen auf. Die Fortsätze können mit einem rechteckigen, abgerundeten scharfen Rand beendet sein, aber manchmal sind sie auch gespalten.

Die gröste Wirbelbreite gemessen auf dem Querfortsätzen wächst bis zum Wirbel V an (bei Annahme folgender Werte im Mittel für Flachlandhirsche: 117, 157, 181, 194, 197), um dann auf dem Wirbel VI ziemlich beträchtlich abzusinken $(172 \mathrm{~mm})$. Diese Breite ist bei Karpatenhirschen um zirka $15 \%$ für jeden der Wirbel grösser, wenn man diese mit der durchschnnittlichen für beide Flachlandgruppen zusammen vergleicht. Dieser Unterschied ist in Bezug auf den O-Hirsch sehr gering. Die individuelle Variabilität ist gross. Als Beispiel kann hier der Lendenwirbel III aus der Olsztyn'schen Gruppe dienen, wo die Extremalwerte $160 \mathrm{~mm}$ und $205 \mathrm{~mm}$ betragen. Im untersuchten Material traf man auf einen Fall, in dem der erste Lendenwirbel statt eines Rippenquerfortsatzes einen kurzen Querfortsatz und eine mit ihm gelenkig verbundene zusätzliche Rippe besass (Skelett Nr. 27). Die Procc. mammilloarticulares sind gross und haben weite, walzenförmige Gelenkflächen. Die kaudalen Proc. articulares machen massive Zapfen aus, die mit einer gefaltenen Gelenkfläche umschlossen sind.

Der Dornfortsatz tritt hier in Gestalt einer rechteckigen Lamelle auf, deren Höhe bedeutend grösser ist als die Breite. Der vordere Rand des Jornfortsatzes biegt sich in seinem oberen Teil anterior aus, indem er mit dem oberen Rand einen leichten anterior gerichteten Vorsprung bildet.

Die Höhe der Dornfortsätze der Lendenwirbel ist bedeutend und in der Regel übertrifft sie die grösste Wirbelkörperlänge. Der Fortsatz von Wirbel I erreicht $56 \mathrm{~mm}$ (Mittel für Flachlandhirsche), aber in Wirbel II steigt seine Höhe noch ein klein wenig und danach sinkt sie allmählig bis $48 \mathrm{~mm}$ auf Wirbel VI ab.

Der Höhenunterschied des Fortsatzen ist in allen Wirbeln ziemlich jeutlich zu gunsten des K-Hirsches (16-17\%). Die Höhe des Dornfortsatzes von Wirbel III verdient einer Erwähnung, denn die Grössengrenzen dieses Masses überdecken sich in den erwähnten Gruppen nur mit ihren Extremalwerten und dieses stellt sich folgendermassen vor: $\mathrm{P}=$ $45-55 \mathrm{~mm} ; \mathrm{O}=55-62 \mathrm{~mm}$ und $\mathrm{K}=62-69 \mathrm{~mm}$.

Bei der Proportionsanalyse des Wirbels bemerkt man die grösste Differenzierung zwische den Gruppen bei Index $\frac{\text { Grösste Länge d.Körpers } \times 100}{\text { Höhe des Dornfortsatzes }}$. Sie schwankt jedoch in zu grossen Grenzen. 


\section{d. Kreuzbein (Os sacrale)}

In den Bestand des Kreuzbeines treten beim Hirsch gewöhnlich fünf Wirbel, die durch einen Knochenverwuchs vereinigt sind.

In dem untersuchten Material wurde ein Fall einer beweglichen Gelenkverbindung zwischen Wirbel I und II des Kreuzbeines angetroffen.

Die Facies pelvina des Kreuzbeines ist sehr stark eingefallen, wodurch sie die Gestalt eines stark gewölbten Bogens erhält. Medial längs der Facies pelvina verläuft ein schwach angedeuteter Sulcus arteriosus.

Die Forr. sacralia ventralis sind räumig und im Zusammenhang damit scheinen die Wirbelkörper ziemlich schmal zu sein. Diese Öffnungen reichen fast an den lateralen linken und rechten Rand. Der Margo lateralis ciext. et sinistr. sind fast parallel aneinander gelegen. Die auf der Facies dorsalis gelegene Crista sacralis media bildet eine im vorderen Teil superior stark ausgebaute Knochenlamelle, die dann gewaltsam inferior absinkt, was eine zum Dreieck angenäherte Gestalt ausmacht. Die Basis dieses Dreieckes (die kürzeste Seite) bildet der vordere Rand des Dornfortsatzes des Kreuzwirbels I. Der superiore Rand der Crista sacralis bildet im Verhältnis zur Lamellenhöhe eine ungrosse Verdickung.

In einer Reihe von Fällen sondert sich der Dornforsatz des Kreuzwirbels in einem kleineren oder grösseren Grade ab und bildet manchmal das Spatium interspinale. Lateral vom Kreuzkamm verlaufen stark ausgebaute laterale Kreuzkämme, Crista sacralis lateralis sin. et dext. Die Flügel des Kreuzbeines wie auch die vorderen Gelenkfortsätze sind anterior stark vorgeschoben, wodurch sie beträchtlich ausserhalb der vorderen Gelenkfläche hervorragen. Auf der äusseren Seite des Flügels ist die flache sich deutlich abgrenzende Facies auricularis sichtbar, die eine unreguläre Form hat.

Die grösste Länge des Kreuzbeines ist das einzige Mass, wo die Reihenfolge Poznań, Olsztyn, Karpaten nicht eingehalten wurde, denn der Olsztyn'sche gleicht dem Karpatenhirsch. Das Ergebnis im Mittel ist sogar für den Olsztyn'schen um $2 \mathrm{~mm}$ grösser, aber dieser Unterschied erwies sich als statistisch unwesentlich, folglich muss man sie als gleich halten $(\mathrm{O}=172 \mathrm{~mm}$ und $\mathrm{K}=174 \mathrm{~mm})$. Diese Länge ist beim P-Hirsch deutlich niedriger, denn sie beträgt im Mittel $154 \mathrm{~mm}$.

Das die Breite des Kreuzbeines illustrierende Mass entspricht nicht der grössten Länge und ordnet sich wie die Mehrzahl der Masse an d.i für den O-Hirsch in der Mitte (121, 136 und $153 \mathrm{~mm}$ ).

Ganz abgesehen davon, dass die Länge des Kreuzbeines der O-Hirsche den Karpatischen gleich ist, sind jedoch die Proportionen in ihrer Bauart an den Poznań'schen angenähert, denn der Index Grösste Breite d. Kreuzbeines $\times 100$

Grösste Länge d. Kreuzbeines 
landgruppen $(\mathrm{P}=78,3 \mathrm{O}=79,1)$, aber er unterscheidet sich wesentlich vom K-Hirsch $(89,1)$. Trotz wesentlicher, individueller Unterschiede überdecken sich die Grenzwerte dieses Indexes im geringen Grade bei beiden diesen Gruppen (Flachlandhirsch, Karpatenhirsch) aufeinander.

\section{e. Schwanzwirbel (Vertebrae coccygeae)}

Die veränderliche Anzahl der Schwanzwirbel ist in Stützung auf das besassene Material schwer zu bestimmen, denn in der Mehrzahl der Fälle unterliegen die Endabschnitte der Schwänze dem Verlust und zwar höchst wahrscheinlich während der Abhäutung.

Ein kompletter Schwanzabschnitt gehört zum Skelett Nr. 30 und besteht aus neun Wirbeln. Ob dies die kleinste mögliche Anzahl ist, lässt sich schwer aussagen, aber gewiss ist sie die grösste nicht, denn zwei von den kollektierten Skeletten besitzen 11 Wirbelkörper trotz des Mangels der zwei letzten oder des letzten einen. Man kann wohl ohne Risiko einen grösseren Fehler zu begehen annehmen, dass der Schwanzabschnitt des Hirsches bei der Mehrzahl der Individuen aus 9-12 Wirbeln besteht natürlich mit einer Schwankungsmöglichkeit von ein oder zwei Wirbelr. in beiden Richtungen.

Der Rückbildungsprozess der Schwanzwirbel verläuft beim Hirsch auf einem verhältnismässig kurzen Abschnitt, denn er brgrenzt sich auf den Wirbel V. Bis Wirbel IV einschliesslich besteht natürlich eine sich immer schwächer mit dem kaudalen Verlauf andeutende Verschiebung der einzelnen Bestandelemente also: der Proc. articulares craniales, des Proc. spinalis und der Procc. transversi.

Wirbel $\mathrm{V}$ und die weiteren bilden ein schlankes in ihrem Mittelteil verschmälertes Bälkchen, das ein reduzierter Körper des Wirbels ist. Vorn auf der dorsalen Seite der erwähnten Körper sind zwei kleine Höckerchen sichtbar, die ein Überbleibsel der anterioren Gelenkfortsätze sind. Diese Höckerchen erhalten sich fast bis zu den letzten Wirbeln des Schwanzabschnittes. Auf der ventralen Seite der Schwanzwirbel treten keine Gefässfortsätze auf. Die durchschnittliche Länge des Schwanzwirbels I beträgt zirka $32 \mathrm{~mm}$, die nachfolgenden Wirbel unterliegen einer stufenweisen Verkürzung und erniedrigen sich im Endabschnitt bis zu $12-17 \mathrm{~mm}$.

\section{KNOCHENRIPPE (COSTA OSSEA)}

Die Umfangslänge der Rippe wächst bei Flachlandhirschen bis zur neunten an und bei denen aus den Karpaten bis zur achten. Dieser Anwuchs ist wesentlich und beträgt für die einzelnen lokalen Gruppen: $\mathrm{P}=171-379 \mathrm{~mm} ; \mathrm{O}=199-426 \mathrm{~mm} ; \mathrm{K}=226-467 \mathrm{~mm}$. Auf den weiteren Rippen (IX-XIII) beobachten wir eine stufenweise Verkürzung der Umfangslänge. 
Bei der Vergleichung der Rippen zwischen den verschiedenen Gruppen hat man den Eindruck, dass die Rippen des K-Hirsches im Vergleich mit dem Flachländischen nicht viel massiver, aber etwas anders gestaltet sind, wenn es sich um ihre Wölbung handelt.

Auf den Rippen I-III und X-XIII tritt dieser Unterschied nicht auf, aber die Rippen III-IX unterscheiden sich, trotz einer - scheinbar geringen Differenz in der Sehnenlänge. Aus diesem Grunde wurden Messungen der Sehnenlängen an den einzelnen Rippen durchgeführt, die das Berechnen des nachfolgenden Indexes: $\frac{\text { Sehnenlänge } \times 100}{\text { Umfangslänge }}$ ermöglichten. Dieser Anzeiger bestätigt, trotz des für das Auge so sichtbaren Unterschiedes, dieses absolut nicht und hält sich in den für die einzelnen Gruppen sehr angenährten Grenzen.

Jedes der 13 Rippenpaare ist auf der Extremitas vertebralis mit einem Capitulum costae versehen. Die anteriore und kaudale Gelenkfläche des Köpfchens des I. Wirbels verschmelzen auf der vertikalen Crista capituli in einander und bilden einen auf zwei Seiten abfallenden Kegel. Auf den Rippenköpfen aller übrigen Rippen kontaktieren die oben erwähnten Flächen nicht miteinander, denn es trennt sie eine senkrecht verlaufende Rinne.

Die unter dem Köpfchen auftretende Verengung, Collum costae genannt, ist bis Rippen VII-VIII stark ausgeprägt, aber in den nachfolgenden wird sie immer undeutlicher. Den grössten Umgestaltungen unterliegt im antero-kaudalen Verlauf der Rippenhöcker. Aus einem sehr massiven Knochengebilde, aus dem er auf den anfänglichen Rippen besteht, reduziert er sich stufenweise bis zu einem sehr kleinen Fortsatz auf Rippe XIII. Seine Gelenkfläche geht aus einer sehr grossen schnekkenförmigen durch eine gewölbte und danach eingesunkene in eine ganz kleine flache Fläche auf Rippe XI-XII über, um auf der XIII. gänzlich $z u$ verschwinden. Der Rippenkörper bildet in seinem oberen Abschnitt einen Balken von rechteckigem Durchschnitt, aber ausser den ersten vier Rippen, wo er einen ovalen Umriss hat. Den übrigen Teil des Körpers bildet eine Knochenleiste, die einer immer grösseren Abflachung und Ausbreitung bis Rippe VI-VII unterliegt, aber von dieser Stelle ab beginnt sie sich sprunghaft zu verengen.

Das Brustbeinende (Extremitas sternalis) unterliegt ganz unten einer sichtbaren Ausbreitung.

\section{BRUSTBEIN (STERNUM)}

Das Manubrium sterni bildet eine ausgedehnte Knochenwalze, die anterior mit einem kugeligen Knochengebilde beendet ist und die in zwei weite Gelenkflächen versehen ist. Kaudal weitet sich diese Walze 
trichterförmig aus, indem sie eine weite, runde, rauhe Fläche bildet, die mit dem zweiten Brustbeinabschnitt kontaktiert. Auf den lateralen Rändern dieser Fläche sind Incisurae costales sichtbar. Der Brustbeinkörper (Corpus sterni) besteht aus sechs Abschnitten des Brustbeines, von denen der erste mit dem Manubrium kontaktiert und eine Prismengestalt annimmt, aber die übrigen nehmen die Form von flachen dem Quadrat angenäherten Lamellen an. Die Knorpelverwüchse der erwähnten Lamellen sind auf den Seiten mit Kerben versehen, die die Stellen der Zusammensetzung der Brustbeinwirbel mit dem Knorpelteil bilden.

Auf den Seiten der mit dem schwertartigen Fortsatz kontaktierenden Lamelle ist diese Kerbe viel weiter, denn sie kontaktiert mit zwei Rippenbögen, folglich beträgt die Gesamtzahl der Kerben je 8 von jeder Seite.

Der Proc. xiphoideus bildet eine sehr flache stark ausgedehnte rechtekkige Lamelle mit eingesunkenen längeren Seiten.

5. VORDERES GLIEDMASS (EXTREMITAS ANTERIOR)

\section{a. Schulterblatt (Scapula)}

Das Schulterblatt hat die Gestalt einer dreieckigen Platte, die sich superior stark ausbreitet. Dies illustriert das Verhältnis der Grössenmasse: Kleinste Breite des Hälschens und grösste Breite des Schulterblattes, das für Flachlandhirsche 38 bis $168 \mathrm{~mm}$, aber für Karpatische 41 bis $191 \mathrm{~mm}$ beträgt. Beim Vergleichen hat man den Eindruck, dass das Schulterblatt bei den Karpatenhirschen bei einer viel grösseren Länge weniger superior ausgebreitet ist. Die in Millimetern ausgedrückten Masse scheinen diesen Eindruck zu bestätigen, denn der Unterschied der äusseren Längen ist viel deutlicher $(\mathrm{P}=281 ; \mathrm{K}=323)$ als der grössten Ereite (168-191). Der zu diesem Zweck berechnete Index verneint bestimmt diese augenscheinliche Annahme der tatsächlichen Merkmale, denn er beträgt für die Gruppen: $\mathrm{P}=59,6 ; \mathrm{O}=59,9 ; \mathrm{K}=59,1$; folglich ist er gut ausgeglichen.

Die Spina scapulae verläuft schräg, indem sie sich in dem mittleren Teil bogenförmig kaudal ausbiegt. Dieser Kamm reicht bis an den Margo vertebralis. Auf dem Kamm befindet sich in seinem medialen Abschnitt eine rauhe leichte Ausbreitung, die die Tuberositas spinae bildet. In der Ffannenrichtung endet der Kamm als scharfes kaudal vorgeschobenes Acromion. Der besprochene Kamm bildet eine Lamelle, die in ihrem m:dialen und inferioren Teil sehr hoch ist. Diese Lamelle ist in ihrem Mittelteil kaudal herausgelehnt, im inferioren Teil liegt sie vertikal zur Fläche des Schulterblattes und teilt ihre Oberfläche auf Gruben von ungleicher Grösse: Die sehr schmale sich über dem Kamm befindende Grube (Fossa supraspinum) und die sehr breite unter dem Kamm liegen- 
de Grube (Fossa infraspinum). Margo cervicalis ist scharf und in oberem Teil anterior gewölbt. Margo vertebralis bildet eine gerade Linie, die inferior im Schnittpunkt mit dem Schulterblattkamm zusammenbricht. Auf seiner superioren Fläche ist eine schmale rauhe Fläche sichtbar, die die Basis für den Schulterblattknorpel (Cartilago scapulare) bildet. Margo axillaris ist auf seiner ganzen Länge stark ausgebreitet und auf ihm sind die Linien der Muskelansätze deutlich sichtbar. Bei der Mehrzahl der Individuen bildet er eine fast gerade Linie dar. Bei einigen wölbt er sich im Mittelteil etwas kaudal.

Auf der Facies costalia ist eine verhältnismässig leicht eingesunkene Fossa subscapularis ersichtlich und die Facies serrata ist sogar bei alten Individuen durch die zwei senkrecht verlaufenden Holprigkeiten nur schwach angedeutet. Collum scapulae ist schlank und ziemlich lang. Inferior breitet es sich aus und umfasst die fast runde Cavitas glenoidea. Vorn ist auf dem Rand der Pfanne eine deutliche, dreieckige Incisura glenoidea sichtbar. Über ihr und leicht nach der äusseren Seite prägt sich, mit dem Rabenschnabelfortsatz eine einheitliches Ganzes bildend, die Tuberositas supraglenoidea aus und zwar im Umriss eines Dreieckes. dessen Gipfelpunkt sich medial ausbiegt.

Der Index $\frac{\text { Kleinste Breite d. Halses } \times 100}{\text { Aussere Schulterblattlänge }}$ beträgt für beide Flachlandgruppen dasselbe je 13,4 und für die Karpatischen 12,7. Diese Unterschiede halten sich also in den Grenzen der individuellen Variabilität.

\section{b. Armbein (Humerus)}

Das proximale Ende des Armbeines ist im Verhältnis zu seiner Länge nicht zu stark ausgebaut. Seine Dicke beträgt $77-90 \mathrm{~mm}$ und seine Breite 68-82 $\mathrm{mm}$ (die Ziffern berücksichtigen alle drei lokalen Gruppen), während die grösste Länge des Armbeines von der Reihe 262-306 mm ist. Der auf dem proximalen Ende liegende Humeruskopf ist etwas schräg von der antero-lateralen zur kaudalo-medialen Seite aufgestellt. Die Gelenkfläche auf dem Kopf nimmt eine ovale Gestalt an.

Der Hals ist schwach angedeutet. Der grössere Höcker nimmt die Gestalt eines sehr massiven und hohen Kammes an, der das Niveau des Halses beträchtlich überragt und sein oberer Rand verläuft schräg superior und medial. Er ist (nicht so deutlich wie beim Rind) auf den Proc. medialis und Proc. lateralis abgeteilt.

Der mediale Processus mit einem abgerundeten Ende, das sich medial ausbiegt, ist sehr massiv. Sein medialer Rand ist abgerundet und stumpf.

Der Proc. lateralis ist verhältnismässig klein, lateral abgeflacht und von einer eiförmigen Gestalt. Unmittelbar unter diesem Fortsatz auf der lateralen Seite ist eine gut ausgeprägte ovalförmige Impressio infraspi- 
nata sichtbar. Der kleinere Höcker ist von dem grösseren durch den gut angedeuteten Sulcus intertubercularis s. bicipitalis abgeteilt, der jedoch nicht so tief ist wie beim Rind. Dieser Höcker hat eine rundliche Gestalt und ist lateral abgeflacht.

Der Corpus humeri ist ausgedehnt und von schlanker Gestalt. Dies wird am besten durch den Index illustriert $\frac{\text { Kleinste Breite d. Körpers } \times 100}{\text { Länge des Armbeines vom Kopf aus }}$, der 10,7 für die Flachland- und 11,2 für die Karpatenhirsche beträgt. Auf der lateralen Seite des Körpers, anfänglich vom Hals aus, verläuft schräg inferior und anterior die gut sichtbare Crista anconea. Die auf ihr liegende Facies teres hat eine sehr unreguläre Gestalt.

Die Crista anconea ist auf ihrer ganzen Länge deutlich ausgestaltet und bildet einen kaudal umgebogenen Knochenrand. In seinem unteren Teil krümmt und wölbt sich dieser Rand, indem er die Tuberositas deltoidea bildet. Auf der medialen Seite des Körpers ist die gut ausgeprägte Tubercsitas teres sichtbar.

Das distale Ende ist in Gestalt eines massiven Blöckchens des Armbeines ausgebildet und macht den Eindruck eines schwach auf die Breite, aber eines verhältnismässig hoch ausgebauten. Die Massergebnisse bestätigen diesen Eindruck, denn die grösste Breite des distalen Endes beträgt im Mittel $57 \mathrm{~mm}$ für Flachland- und $64 \mathrm{~mm}$ für Karpatenhirsche und die Dicke überschreitet in der Mehrzahl der Fälle 70\% der Dicke des proximalen Endes nicht. Die Achse der Trochlea humeri liegt schräg superior und medial zur Achse des Körpers. Der Condylus medialis ist von dem lateralen beträchtlich grösser. Die Gelenkfläche der Trochlea humeri biegt sich mit ihrem medialen Teil bogenförmig kaudal aus, und unterwegs die zwei Epicondyli abteilend, gelangt sie zur Fossa olecrani, indem sie ihre untere Begrenzung bildet. Diese Grube hat den Umriss eines Dreieckes und ist verhältnismässig tief, aber von der Seite ist sie durch den Epicondylus lateralis et medialis begrenzt, von denen der mediale massiver ist und mehr inferior vorgeschoben.

Der Condylus lateralis bildet eine mehr abgeflachte und kürzere Lamelle, aber mit seiner Crista epicondyli lateralis überragt er die Crista des Epicondylus medialis.

Bei der Vergleichung der Armknochen der Hirsche aus allen drei lokalen Gruppen lassen sich ausser den allgemeinen Ausmassen keine Unterschiede im Bau oder im den Proportionen feststellen, was schliesslich die Tabelle der Indizes bestätigt.

In den absoluten Grössen aller auf dem Armbein durchgeführten Masse ordnen sich die Werte für den O-Hirsch in der Mitte zwischen den Pund dem K-Hirschen an. 


\section{c. Unterarmknochen (Ossa antebrachii)}

Die Unterarmknochen sind dauernd miteinander verwachsen, wobei der stark ausgewachsene Radius über der schwachen Ulna herrscht.

Der Radius ist proportionell zu seiner Länge sehr schmal, oder anders gesagt, zu seinem schlanken Aussehen trägt die Gestaltung des Körpers bei, der lang ist und fast ein und denselben Umfang auf seiner ganzen Länge hat. Dies charakterisiert am besten der Index Kleinste $\frac{\text { Breite d. Körpers } \times 100}{\text { Länge d. Radius }}$, der im Mittel 11,6 beträgt und nur das proximale und distale Ende sind sehr unwesentlich ausgebreitet. Auf das obere Ende von vorn schauend, hatten wir den Eindruck, dass es stark auf die Aussenseite hinausgebeugt ist. Diesen Eindruck ruft die augenscheinlich sehr starke Entwicklung des äusseren Tuber ligamento. sum herbei, bei einem fast kaum angedeuteten Tuber medialis. Solch eine Gestaltung des oberen Endes verursacht, dass die Facies trochlearis auf die Aussenseite der Vertikalen verschoben ist und ihr medialer Rand überhaupt nicht oder nur in einem minimalen Grade über den medialen Rand des Körpers hervorragt. Der schwache Ausbau auf den Enden und die sanft bogenförmige Ausbiegung nach vorn verursacht, dass der auf die $F$. dorsalis gelegte Radius mit seinem Mittelteil des Körpers mit der 'Tischebene kontaktiert und sich nicht auf den Ansätzen stützt, wie dies z. B. beim Rind der Fall ist.

Die Tuberositas radii bildet in der Mehrzahl der Fälle nur eine unreguläre rauhe Fläche. Das leicht ausgebreitete distale Ende, besitzt auf der dorsalen Seite einen tiefen Sulcus tendineus, der durch zwei scharf umrissene Knochenkämme begrenzt ist, die superior auf den inferioren Teil des Körpers hinauslaufen. Die zweite Sehnenrinne liegt auf der lateralen Seite des distalen Endes, ist bedeutend schwächer angedeutet und bei einigen Exemplaren ist sie gänzlich unsichtbar. Der Proc. styoidus radii ist scharf und stark inferior vorgeschoben.

Die Ulna, deren Körper eine flache schmale Knochenleiste bildet, verwächst vermittels eines Knochenverwuchses mit dem Radius. Die dauernde Verschmelzung durch das Knochengewebe kann man erst bei Individuen beobachten, die älter sind als 6-7 Jahre, aber bei den übrigen lässt sich dieser Verwuchs verhältnismässig leicht auseinander reissen. Die Unterarmknochen unterliegen im oberen Abschnitt des Körpers des Radius keinem Verwuchs und bilden ein Spatium interossum von ciner Länge, die zirka 1/4 der ganzen Körperlänge gleich ist. Der z.weite Spalt, nur ein viel kleinerer, kommt bei einigen jüngeren Individuen auf dem weiteren Abschnitt des Körpers zum Vorschein.

Der Olecranon stellt sich als cine flache Knochenplatte mit einem rcchteckigen Umriss und einem leicht medial umgewickelten scharfen 
Rand dar. Dieser Rand geht in einen sanften Bogen superior über, wo er sich ausbreitend, den gering ausgebauten einzigen Tuber olecrani bildet. Es muss unterstrichen werden, dass der Ellenfortsatz des Hirsches im Verhältnis zu der Länge der Unterarmknochen verhältnismässig niedrig, und seine kaudale Ausneigung gering ist und im Zusammenhang damit stellen sein kaudaler Rand mit dem Rand des Körpers der Ulna auf dem Abschnitt ihrer Vereinigungen fast eine gerade Linie dar.

Etwaige sich zu beschreiben lassende morphologische Unterschiede zwischen den Karpaten- und Flachlandhirschen liessen sich schwer beobachten. Bei der Vergleichung hat man immer den Eindruck, dass die Knochen der K-Hirsche bedeutend schlanker sind. Dies ergibt sich vielleicht daraus, dass die Unterschiede in den Längen sich in grossen Werten ausdrücken und leichter festzustellen sind, als die für das Auge geringen Unterschiede auf den Breiten der Körper. Die Ziffernergebnisse sprechen vielmehr von den proportionellen Unterschieden in den einzelnen Grössen. Die Unterschiede in den Längen der Unterarmknochen sind beträchtlich (Die Länge der Ulna beträgt z. B. $\mathrm{P}=331 ; \mathrm{O}=356$ und $\mathrm{K}=381 \mathrm{~mm}$ ) und der Abstand zwischen den einzelnen Gruppen ist weiterhin beibehalten.

\section{d. Handwurzelknochen (Ossa carpi)}

$\mathrm{Zu}$ dem Bestand der Handwurzel gehören sechs in zwei Niveaus gelagerte Knochen. Die Ordo antebrachialis enthält drei verschieden gestaltete Knochen, aber von angenäherten Grössen; dies sind Os carpi radiale, Os carpi intermedium und Os carpi ulnare und noch der viel kleinere lateral abgeflachte zusätzliche Handwurzelknochen $O$. c. accesorium.

Die Ordo metacarpalis besteht aus zwei Knocheneinheiten, von denen die grössere mit $O s$ carpale secundum et tertium vereinigt ist und aus dem viel kleineren Os carpale quartum.

\section{e. Mittelhandknochen (Ossa metacarpi)}

Das grundsätzliche Element des Skelettes der Mittelhand sind die verwachsenen Knochen III und IV.

Der durch $M c_{3}$ und $M c_{4}$ gebildete gemeinschaftliche Körper ist proportional zu seiner Masse und Breite sehr schlank. Seine starke laterale Abflachung wirft sich in die Augen und sie bewirkt, dass die Dicke des Körpers bedeutend grösser ist als seine Breite. Einer dorso-ventralen Abflachung unterliegt er erst dicht über dem distalen Ende.

Kleinste Breite des Körpers $\times 100$

Der Index Grösste Länge d. Knochen d. Mittelhand, der im Mittel für Hirsche zirka 9,2 beträgt, illustriert wohl am besten die überaus starke 
Ausdehnung dieses Knochens im Verhältnis zu seiner Breite. In den Ziffern der absoluten Werte stellen sie sich folgendermassen dar: Grösste Länge $\mathrm{P}=251 ; \mathrm{O}=264 ; \mathrm{K}=275$ und die kleinste Breite des Körpers dementsprechend: 22, 24, 27.

Die Handflächenseite der Mittelhandknochen bildet die fast längs des ganzen Körpers verlaufende tiefe Rinne, die lateral durch zwei Kämme begrenzt ist, von denen der mediale deutlich höher ist. Die auf der Facies palmaris auftretenden For. palmare superior et inferior sind gut ausgeprägt und meistenteils gleich, wenn es sich um ihre Grösse handelt. Der bei dem Foramen dorsale superior beginnende Sulcus dorsalis ist flach und schmal, aber er ist dennoch bis zur Stelle seines Schwundes d. i. bis zum For. dorsale inf. gut sichtbar.

Die sich lecht ausbreitende Extremitas proximalis ist auf der dorsalen Seite von $M c_{3}$ in eine nicht besonders stark entwickelte Tuberositas ossis metacarpi versehen, aber die Facies palmeris $\mathrm{Mc}_{4}$ besitzt eine kleine $\mathrm{Ge}-$ lenkfläche, die zur Zusammensetzung mit $M c_{3}$ dient. Das distale Ende bilden zwei Blöckchen, die, wenn es sich um ihre Breite handelt, gleich sind. Die Cristae sagittales teilen die Gelenkflächen der Blöckchen auf ungleiche Teile, von denen die medialen etwas grösser sind.

Wenn es um Unterschiede zwischen den einzelnen lokalen Gruppen geht, so verhalten sich die Mittelhandknochen ebenso, wie die oben besprochenen langen Knochen des vorderen Gliedmasses. Die Unterschiede in den absoluten Werten sind deutlich und gleichzeitig proportional, wovon die Tabelle mit den Indizes zeugt. Diese Erscheinung kann bei verschiedenen Vergleichsarbeiten auf eine grössere Skale vom Nutzen sein, denn das Knochenmaterial aus dem zeugopodialen Abschnitt ist am leichtesten zu erhalten wie auch zu präparieren.

\section{f. Fingerknochen der Hand (Digiti manus)}

Das abere Ende (Basis phalangis) des ersten Fingergliedes ist beim Hirsch in der Querrichtung abgeflacht, aber kaudal ziemlich stark ausgebaut. Bei einem schwach entwickelten unteren Ende und stark verlängerten quer abgeflachten Körper, nimmt das Ganze dieses Knochenelementes einen Umriss eines verlängerten Dreieckes an, wenn wir es von der lateralen Seite beobachten.

Die ersten Fingerglieder der Hand bei den einzelnen lokalen Hirschgruppen vergleichend, sehen wir, dass die sich bemerken lassenden Unterschiede in den vorher besprochenen Knochen in diesem Falle in einem beträchtlichen Grade schwinden. Bei ziemlich grossen individuellen Unterschieden (von 50-62 $\mathrm{mm}$ in der Flachlandgruppe) scheint der Unterschied zwischen den Flachland- und Karpatenhirschen (im Mittel für Flachl.-H -57 und Karp.-H. - 61) nicht so wesentlich zu sein. 
Bei den Beobachtungen jedoch lenkt die grössere Massivität der Fingerglieder des Karpatenhirsches die Aufmerksamkeit auf sich. Dies findet f ine gewisse Bestätigung in den Ziffern, denn die Grenzen der Breitenmasse des Körpers überdecken sich auf eine geringe Weise $(14-18 \mathrm{~mm}$ bei Flachland- und $18-19 \mathrm{~mm}$ bei K-Hirschen).

Das Fingerglied II, wenn auch bedeutend kürzer vom ersten, behält weiterhin eine verlängerte Gestalt bei, denn bei einer Gliedlänge von zirka $44 \mathrm{~mm}$ beträgt die Körper-Breite $15 \mathrm{~mm}$. Seine starke Querabflachung verursacht, dass der Umriss des Querschnittes mehr an eine Ellipse angenähert ist, als an ein Dreieck, das mit seiner Basis nach der Handflächenseite gerichtet ist.

Auf dem Klauenknochen des Hirsches beobachtet man keine so starke Verlängerung wie dies bei den dritten $\mathrm{F}$ inge rgliedern der Fall war. Dieser Knochen unterliegt schliesslich einer besonders grossen individuellen Differenzierung. Das Augenmerk auf sich lenkt die Lage der Gelenkfläche, die bedeutend mehr kaudal gerichtet ist als superior. Noch bedeutend stärker kaudal ist diese Fläche bei dem Klauenknochen des Elches gerichtet, bei dem die Verlängerung des Fingergliedes III bedeutend stärker zum Ausdruck kommt als beim Hirsch, was man von den vorigen Gliedern der Finger nicht behaupten konnte.

6. HINTERES GLIEDMASS (EXTREMITAS POSTERIOR)

\section{a) Becken (Pelvina)}

Der linke und rechte Hüftknochen vereinigen sich durch einen dauernden Knochenverwuchs verhältnismässig spät, denn erst im Alter von 7-8 Jahren, während dessen die Ansätze der langen Knochen schon bei fünf bis sechsjährigen Exemplaren verwachsen. Die Symphysis pelvis ist beim Hirsch verhältnismässig kurz, in Folge wovon der Ischiasbogen tief eingeschnitten ist und einen Umriss eines scharfwinkeligen Dreieckes bildet, das mit seinem Gipfel nach vorn gerichtet ist.

Auf der lateralen Fläche der Symphysis pelvis ist bei alten Individuen ein sehr deutlicher Knochenkamm mit einer oder zwei Erhebungen von unregulärer Gestaltung sichtbar. Dieser Kamm teilt sich nach dem Erreichen des Arcus ischiadicus auf und geht auf seine Ränder über.

Das Becken hat in seinem allgemeinen Umriss eine schlanke Gestalt, was sich aus der starken Ausbiegung kaudal zum Tuber sacrale ergibt. nur gering ausgebeugten Fläche von derjenigen des Hüftbeinkörpers liegen, folglich mehr senkrecht gestellt sind. Der anteriore Rand Ides I'iügels (Crista iliaca) ist wenig eingesunken, aber verhältnismässig lang, was sich aus der starken Ausbiegung kaudal zum Tuber sacrale ergibt. Von der anderen Seite verursacht die oben erwähnte Ausbiegung des Tu- 
ber sacrale eine Verkürzung und Vertiefung der Incisura ischiadica maior. Der am meisten latero-anterior liegende Tuber coxae bildet nur cine unwesentliche Verdickung der Knochenlamelle des Flügels.

Die Facies glutea ist glatt, die Facies pelvina besitzt, sich schwach abgrenzende Rauheiten, die die Facies muscularis und Facies auricularis darstellen, aber eine etwas deutlichere Verhöckerung lässt sich nicht absondern. Der Corpus ossis ilium wie auch der Corpus ossis ischium bilden verhältnismässig flache aber hohe Platten, deren superiore Ränder über der Pfanne den Crista iliaca ausgestalten, der mit ihnen in einer Fläche liegt.

Der inferiore Rand des Darmbeinkörpers ist ziemlich scharf, aber kaudal, nicht bis zum Acetabulum gelangend, teilt er sich auf zwei sekundäre Leisten, die die tiefe, spaltige Grube begrenzen. Die Tabulu ischiadica ist sehr massiv im Gegensatz zum Bau des ganzen Beckens. Das Tuber ischiadicum besteht aus drei massiven Abzweiguingen, von denen die zwei ersten von gleicher Länge sind, aber die dritte, kaudal verschoben, ist deutlich länger.

Die Grössendifferenzierung des Beckens zwischen den einzelnen lokalen Gruppen ist sehr deutlich. Grosse Ausmasse dieses Knochenelementes beim $\mathrm{K}$-Hirsch verursachen möglicherweise eine Effektsteigerung dieses Eindruckes, aber besonders bei der Vergleichung mit, dem Becken des P-Hirsches. Die Vergleichung der Ziffern allein gibt schliesslich ein gewisses Bild von diesen Verhältnissen.

Die grösste Länge der Hüftbeine beträgt beim P-Hirsch $335 \mathrm{~mm}$, aber beim K-Hirsch erreicht sie $402 \mathrm{~mm}$. (Diese Grösse für den O-Hirsch liegt in der Mitte). Trotz der grossen Unterschiede in den absoluten Massen kann man keine Verschiedenheiten sowohl in den morphologischen Einzelheiten wie auch in den Beckenproportionen bei den einzelnen Gruppen feststellen, was schliesslich die fur eine ganze Reihe von Massen berechneten Indizes bestätigen.

\section{b. Schenkelknochen (Os femoris)}

Caput femoris hat die Gestalt einer auf die mediale Seite gerichteten Halbkugel. In seinem Gipfelteil befindet sich eine deutlich ersichtliches, wenn auch ziemlich kleines Fovea capitis überwiegend von einem dreieckigen Umriss. Lateral vom Hals erhebt sich der hohe das Niveau des Kopfes überragende Trochanter maior. Der Gipfel des Trochanters ist durch eine kleine Kerbe auf zwei sekundäre Teile geteilt d. i. den vorderen und den hinteren Höcker. Beide Höcker haben eine rundliche Gestalt. Das Tuberculum ant. trochanteris maior richtet sich senkrecht superior, aber es schiebt sich nicht nach vorn und rundet sich erst am Cipfel selbst ab. Seine Höhe gleicht gewöhnlich entweder dem Tubercu- 
lum post. oder sie ist vom posterioren Höcker kleiner. Allgemein genommen baut sich der Trochanter maior superior auf und cr schiebt sich sehr wenig auf die laterale Seite. Im Zusammenhang damit ist die Crista intertrochanterica, die einen scharfen Rand besitzt, fast senkrecht inferior zum Trochanter minor gerichtet, der deutlich auf der kaudalen Seite liegt und sich nicht auf die mediale Seite wölbt. Vom Trochanter minor zieht sich superior und zur medialen Seite die schwach sichtbare Crista crilli post. Die sehr grosse Fossa trochanterica hat eine ovale Gestalt. Ihren superioren Rand bildet die von hinten ziemlich sichtbare Cristu colli lateralis, und ihren lateralen Rand stellt die aben erwähnte Crista. intertrochanterica dar. Auf der medialen Seite geht diese Grube ohne cieutlicher Grenze in das Collum femoris über.

Der Körper des Schenkelbeines ist verlängert und schlank. Von der Basis des Trochanter maior und minor verlaufen inferior zwei deutlich sichtbare Knochenlinien, nämlich Labium lat. et med. In dem kaudo- lateralen Teil des Körpers ist die gut ausgebildete Fossa flexoris ersichtlich.

Das distale Ende des Schenkelbeines bildet von vorn ein stark lateral abgeflachtes Blöckchen, das aus zwei Cristae patellares med. et lat. besteht, von denen die mediale viel besser ausgestaltet ist und ausserdem langer und höher von der lateralen ist. Sie werden durch einen tiefen Sulcus patellaris abgeteilt, superior von dieser Rinne ist eine schmale verlängerte Fossa suprapatellaris sichtbar.

Auf der kaudalen Seite des distalen Endes unterscheiden wir zwei stark entwickelte Condylen, von denen der laterale viel massiver ausgebaut ist als der mediale. Der Epicondylus lateralis ist ebenfalls grösser und vom Epicondylus medialis deutlicher ausgeprägt. Von hinten auf die Gelenkflächen der Condylen schauend, kann man feststellen, dass sie zur Achse des langen Knochens schräg gestellt sind. Beide, aber besonders d $€ r$ mediale, sind superior und auf die laterale Seite gerichtet. Die Fossa intercondyloidea ist sehr flach.

Wenn man bei Vergleichungen der Armbeine aus den einzelnen lokalen Gruppen den Eindruck hatte, dass der Unterschied hauptsächlich auf der Verlängerung beruht, wodurch diese bei den Karpatenhirschen schlanker zu scin schienen, so scheint der Längenunterschied bei der Vergleichung der Schenkelbeine nicht so hervorragend zu sein. Das Schenkelbein des $\mathrm{K}$-Hirsches ist von den übrigen Gruppen grösser und massiver, aber mit dem Vermerk, dass diese Unterschiede proportionaler $z u$ sein scheinen. Die Überlegenheit der Länge entspricht anderen Massen, wodurch der ganze Knochen massiver ist. Dieser Unterschied ist im Verhältnis zum F-Hirsch sehr gross, aber auch im Verhältnis zum O-Hirsch noch gut merklich. Die Ausmassen des Schenkelbeines des O-Hirsches nehmen 
eine Mittelstellung ein, aber ausser der kleinsten Breite des Körpers, die vielmehr an den Poznan'schen angenähert ist.

c. Schienbein (T'ibia)

Extremitas proximalis tibiae wird durch zwei Condylen Condylus medialis et lateralis gebildet. Ihre obere Fläche bildet zwei flache Gelenkfelder - die Testa condyloidea. Der laterale Teller ist grösser und breiter vom medialen. Beide bilden sattelige Vertiefungen, deren mediale Seiten sich superior errichten, indem sie die Eminentia intercondyloidea ausgestalten. Diese Wölbung bewirken zwei Höcker, der laterale und der etwas grössere mediale. Sie werden von vorn durch die Fovea intercondyloidea ant. geteilt, die eine an ein Rechteck angenäherte Form hat, das von der Mitte nach der lateralen Seite gelegen ist. Von hinten sind die Höcker durch die Fovea intercondyloidea post. abgeteilt.

Die vorderen Flächen des proximalen Endes werden durch die Tuberositas tibiae gebildet. Ihre superiore und anteriore Fläche ist deutlich durch cine flache Rinne auf zwei, ziemlich scharfe superiorc Ränder besitzende, Teile geteilt. Die Tuberositas tibiae geht inferior in den Schienbeinkamm über und bildet mit ihm zusammen eine sehr hohe aber dünne Knochenleiste, die schräg inferior und zur medialen Seite verläuft. Dieser Kamm ist im Verhältnis zur gänzlichen Länge des Knochens ziemlich kurz, denn seine Länge entspricht kaum einem Drittel der superioren Länge des Körpers. Der vordere Rand des Schienbeinkammes biegt sich deutlich auf die laterale Seite aus, indem er an seiner Basis eine ziemlich tiefe Rinne bildet. Ungefähr in der Hälfte der Länge ist auf diesem Rand eine Verdickung sichtbar, die sich ebenfalls auf die laterale Seite ausbiegt. Der Körper des Schienbeines ist lang und schlank. Die Mehrzahl der langen Knochen des Hirsches charakterisiert sich schliesslich durch Schlankheit, aber im Falle mit dem Schienbein ist dies besonders sichtbar. Dies bestätigt ebenfalls der Index $\frac{\text { Kleinste Breite d. Körpers } \times 100}{\text { Grösste Länge d. Schienbeins }}$, der für Flachlandhirsche im Mittel 7,9 und für Karpatenhirsche 8,4 beträgt.

Der Malleolus tibialis in Gestalt eines langen und ziemlich scharf beendeten Fortsatzes ist in medialer und kaudaler Richtung ausgebogen.

Auf der lateralen Seite des distalen Ansatzes ist eine sehr kleine Gelenk fläche von rundlicher Gestalt sichtbar, die zur Zusammenstellung mit Os malleolare dient. Os malleolare selbst hat die Gestalt eines Rechteckes und auf seiner superioren und inferioren Fläche sind Gelenkflächen von unregulärer Gestalt sichtbar.

Das Schienbein des K-Hirsches unterscheidet sich morphologisch genommen ausser dem mehr massiven Aussehen von den Flachländischen 
nicht. Wenn es sich um Ausmasse handelt, treffen wir auf eine ähnliche Situation wie beim Schenkelbein d.h. eine deutliche Überlegenheit (proportional zu allen Massen) des Karpatenhirsches, aber mit dem Vorbemerk, dass zu dem in der Mitte stehenden O-Hirsch in Hinsicht auf seine Grösse dieser Unterschied weniger drastisch ist.

\section{d. Fusswurzelknochen (Ossa tarsi)}

In ihren Bestand treten 5 Knocheneinheiten: Os tarsi tibiale s. talus, Os tarsi fibulare s. calcaneus, Os cubonaviculare s. centrotarsale, Os tarsale compositum s. tarsale magnum II + III, Os tarsale I.

Tuber calcanei ist in cier Querrichtung stark abgeflacht und ausserordentlich ausgedehnt. Die Spitze des Apex ist schwach ausgebaut. Die Lamelle des Corpus os. calcani wie auch das Sustentaculum sind nicht besonders massiv, was bei dem verlängerten Tuber calcanei dem ganzen Fersenbein eine schlanke Gestalt verleiht. Die grösste Länge des Fersenbeines beträgt für die einzelnen lokalen Gruppen: $\mathrm{P}=112 \mathrm{~mm} ; \mathrm{O}=121$ und $\mathrm{K}=128 \mathrm{~mm}$, während die Dicke des Fersenbeinhöckers dementsprechend 31,33 und $36 \mathrm{~mm}$ ausmacht. Im Zusammenhang damit hält sich der Index dieser beiden Grössen in den Grenzen 27-28.

Auf dem Sprungbein lässt sich eine derartige Schlankheit wie auf dem Fersenbein nicht bemerken. Seine Gestaltung als Ganzes ist sehr gedrungen. Dies illustrieren schliesslich die Ziffern (die Mittel für den O-Hirsch), die von dem Verhältnis der grössten Höhe zu Breite sprechen, nämlich $53 \mathrm{~mm}$ und $36 \mathrm{~mm}$. Der Index dieser beiden Grössen beträgt zirka 68 .

Die übrigen Fusswurzelknochenelemente nehmen ahnlich wie das sprungbein gedrungene Formen an, was diese im Gegensatz zum Fersenbein bei ihrer Beschreibung an die domestizierten Wiederkäuer annähert. Die Fusswurzelknochen des Hirsches mit denjenigen des Elches vergleichend, stellten wir eine grosse Ähnlichkeit in der Ausgestaltung der einzelnen Elemente fest. Lediglich das Fersenbein dank seiner Massivität ähnelt mehr demjenigen des Rindes.

\section{e. Mittelfussknochen (Ossa metatarsi)}

Das Skelett des Mittelfusses besteht aus den verwaichsenen Knochen int III und mt IV. Die Gestalt dieses zusammengesetzten Elementes ist ausgelängert und lateral abgeflacht. Die Knochenenden sind sehr schmal und dieses ist am distalen Ende besonders augensichtlich, das zugleich stark ausgelängert und dorso-ventral abgeflacht ist.

Das Verhältnis der Breite zur Dicke des distalen Endes wie auch die Länge des ganzen Elementes im Verhältnis zur Breite des Körpers sind Merkmale, die eine Unterscheidung der Knochen des Mittelfusses und der Mittelhand auf eine entschiedene Weise ermöglichen. 
Das vereinigte superiore Ende der Mittelfussknorhen von der Gelenkfläche beschauend, sehen wir, als wenn es lateral abgeflacht wäre d.i., dass die Dicke des superioren Endes seine Breite überragt, was man mit einem aus der Flachlandpopulation des Hirsches genommenen Beispiel illustrieren kann. Die durchschnittliche Dicke des oberen Ansatzes beträgt $38 \mathrm{~mm}$, während die Breite $35 \mathrm{~mm}$ ausmacht. Die Gelenkfläche am superioren Ende der Mittelfussknochen hat einen Umriss mit rückwärtiger Lage d. h. dass sie vielmehr in die Breite ausgebaut ist und eine mit ihrer längeren Achse zum Ansatz quer gelegene Ellipse bildet. Als Beispiel hierfür die Mittel für dieselben Hirsche wie vorher angebend, ersehen wir, dass die Breite des superioren Endes $=43 \mathrm{~mm}$ ist, während scine Dicke kaum $31 \mathrm{~mm}$ ausmacht. Ein zweites von den erwähnten Merkmalen ist die Länge des Körpers, die verursacht, dass die Mittelfussknochen beim durchschnittlichen Hirsch zirka $30-35 \mathrm{~mm}$ länger sind, bei einem geringen Unterschied der Breite des Körpers, denn diese schwankt in den Grenzen eines Millimeters.

Auf der dorsalen Seite des Körpers ist ein deutlich ausgeprägter mit scharfen Kanten umrahmter Sulcus dorsalis sichtbar, der sich auf seiner ganzen Länge langzieht. Im inferioren Teil des Sulcus dorsalis befindet sich eine ziemlich weite dorso-inferiore Öffnung. Auf der Handinnenfläche ist ein breiter und tiefer durch hohe laterale Ränder begrenzter Sulcus palmaris sichtbar. Diese Rinne zieht sich auf 4/5 der ganzen Länge des Körpers entlang. Der superiore und inferiore Teil des Körpers ist durch das For. palmare sup. et inf. durchstochen.

Unterschiede im Bau der Mittelfussknochen der besprochenen Hirsche aus den drei lokalen Gruppen betreffen wie gewöhnlich hauptsächlich die Grösse, die proportional vom Poznań'schen bis zunı Karpatischen anwächst. Es zeichnet sich hier nur die grösste Breite des inferioren Endes der vereinigten Knochen aus, denn sie beträgt nämlich für Flachlandhirsche 42 und für den Karpatischen $48 \mathrm{~mm}$. Die Grenzen dieses Masses überdecken sich nicht bei Individuen aus den Gruppen: Olsztyn - Karpaten.

\section{d. Die Zehen des Fusses (Digite pedis)}

Die einzelnen Glieder der Zehen des Fusses entsprechen ihrer Gestaltung nach den Fingergliedern der Hand. Die bei einer sehr eingehenden Analyse vielleicht ergreifbaren möglichen Unterschiede, aber nur bei einem grösseren zur Verfügung stehenden Material (vor dem Mazerieren gekennzeichneten) sind so gering, dass man beim Zusammenwerfen aller Zehenglieder eines Individuums sie nachher mit grösster Mühe fehlerlos segregieren kann. Diese Unterschiede können also keine grössere Be- 
deutung bei Vergleichsuntersuchungen der verschiedenen lokalen Gruppen des Hirsches haben.

Es fällt auch schwer irgendwelche Unterschiede in den Längen - oder Breitenmassen der einzelnen Glieder zu finden. Die Unterschiede zwischen den Längen eines bestimmten Zehengliedes bei einem gewissen Individuum schwanken in den Grenzen vom 1-2 $\mathrm{mm}$, aber diese Erscheinung kommt unpaarig vor, folglich müssen diese Unterschiede ebenfalls zwischen den linken und rechten Gliedmassen auftreten, oder auch ganz zufällig sein.

In der Tabelle der Masse der Zehenglieder wurden diejenigen Werte (gemeinsam für die Finger der Hand und des Fusses) angegeben, die das Ergebnis im Mittel von acht Exemplaren des gegebenen Gliedes sind.

\section{BESPRECHUNG DER ERGEBNISSE}

\section{Schädel}

Die in dieser Arbeit angegebenen morphologischen Merkmale, die den Schädel des Karpatenhirsches von demjenigen der Flachlandhirsche zu unterscheiden scheinen, sind nur im Falle eines gleichzeitigen Beobachtens der zu vergleichenden Objekte zu bemerken. Begriffe wie: Grössere Faltung der Stirnbeine, weitere superorbitale Rinnen, grössere Wölbungen der Nasenbeine oder einer weiteren Tränengrube sind nur sehr bedingte Begriffe, die keinen Anhaltspunkt haben, folglich würde es schwer sein, der Versuchung zu unterliegen, um beim Untersuchen eines einzigen Schädels von unbekannter Herkunft ihn zu dieser oder jener lokalen Gruppe zu qualifizieren. Wenn man dabei die grosse individuelle Variabilität in Betracht zieht, die die Hirschschädel kennzeichnet und ausserdem die Subjektivität der Beschreibungsmethode, so scheint die Feststellung gerechtfertigt $\mathrm{zu}$ sein, dass es für taxonomische Zwecke an genügenden Differenzierungen in der morphologischen Beschreibung des Schädels mangelt. Zur Durchführung der Vergleichungen zwischen den Proben aus den drei untersuchten Populationen wurde also die Methode der kraniometrischen Masse angenommen, deren Ergebnisse in Tabelle 1 zusammengestellt sind.

Diese Tabelle analysierend, ersehen wir, dass in der Mehrzahl der Tälle die Mittelwerte für die einzelnen Masse solch eine Anordnung darstellen, in der Poznańsche Hirsch vom Olsztynschen kleiner ist und letzterer wiederum kleiner vom Karpatischen. Die einzelnen Masse paar weise in Gruppen überprüfend, sehen wir, dass die höher erwähnte Anordnung ohne Ausnahme bei der Vergleichung der Werte betreffs des Poznańschen Materiales mit dem Karpatischen beiluehalten ist. Eine ge- 
wisse Abweichung bemerken wir dort, wo die Olsztynsche Gruppe in Frage kommt. Die Mittel der Masse Nr. 9 und $15(N-N$ si und $P m-P d)$ sind nämlich etwas höher bei der Poznańschen Gruppe als in der Olsztynschen und das Mittel für das Mass Nr. $17(\mathrm{Ni}-\mathrm{Ni})$ ist bei der Olsztynschen und der Karpatischen identisch.

Zum Wirklichkeitsbeweis der Unterschiede in den Schädelmassen wurden aus den einzelnen Gruppen die am besten illustrierenden Masse der Schädelgrössen wie folgt ausgewählt: Grösste Länge $(P-O p)$, zygomatische Breite $(z y-z y)$, laterale Länge des Gesichtsschädels $(Z l-P)$, laterale Länge des Gehirnschädels $(Z l-O p)$ und die Breite der Gehirnkapsel $(e u-e u)$. Für diese Masse wurde eine Variantenanalyse in einer Richtung durchgeführt (Test von Fischer). Aus Anlass der verschiedenen Anzahlmässigkeit in den Gruppen, wurde der Wirklichkeitsunterschied 7.wischen ihnen apart für jedes Gruppenpaar mit Hilfe des Testes " $t$ " von Student bei $\mathrm{P}=0,05$ durchgeführt. $\mathrm{Zu}$ den Berechnungen wurden ebenJalls die zwei oben erwähnten Masse Nr. 9 und 15 miteinbezogen.

Der Unterschied in den Anordnungen: $\mathrm{K}-\mathrm{P}$ und $\mathrm{K}-\mathrm{O}$ erwies sich als statistisch hoch signifikant. Ebenfalls real erwiesen sich die Unterschiede 7wischen den beiden Flachlandgruppen in Betreff aller Masse ausser der Breite der Gehirnkapsel (eu-eu).

Der Wertunterschied der Masse 9 und 15, wo der P-Hirsch den $\mathrm{O}$-Hirsch auf eine geringe Weise übertraf, erwies sich, wie man dies voraussehen konnte, als unreal. Die Tatsache des Bestehens von statistischen Realitäten in der Schädelgrösse zwischen beiden Flachlandgruppen lässt keine Vereinigung unter ihnen zu, um sie dann dem Karpatenhirsch gegenüber zu stellen, sondern erfordert Vergleichungen für jede Gruppe hesonders.

Die Erlangung von Informationen über den Unterschied in der Schädelgrösse ist für uns noch ungenügend. Nicht weniger wichtig ist der Beweis, ob diese Differenzierung, wenn es sich um die Grösse handelt, von derselben Reihe zwischen $\mathrm{K}-\mathrm{O}$ wie $\mathrm{O}-\mathrm{P}$ ist, ob die einzelnen Masse sich bei der Vergleichung der Gruppen auf eine ähnliche Weise verhalten und in welchem Grade sich ihre Extremwerte überdecken. Das Analysieren der Tabelle 1 unter solch einem Gesichtspunkt ist recht schwierig. Man musste folglich daran gehen, Frequenzkurven zu entwerfen (Abb. 1 his 29) und dies für alle Masse, deren Zahlenmässigkeit genügend vorhanden war. Die erwähnten Diagramme analysierend, ersieht man, dass man in Abhängigkeit der gegenseitigen Verschiebungen zwischen den Gipfelpunkten der Kurven die einzelnen Masse in gewisse besonderc Zusammenspiele vereinigen kann.

Am zahlreichsten nämlich 14 Masse umfassend $(P-O p, \quad Z l-P$, $\mathrm{Zl}-\mathrm{Op}, \mathrm{P}-\mathrm{Br}, \mathrm{St}-\mathrm{P}, \mathrm{Mol}-\mathrm{P}, \mathrm{Pm}-\mathrm{Mo-Mo}, \mathrm{Nm}-\mathrm{Nm}, \mathrm{M}-\mathrm{M}$, 
$Z y-Z y, D a-D a, S p h-B r$, if - goc, Länge des Margo adentalis des Unterkiefers) ist das Zusammenspiel in der die Gipfel der Kurven sich auf solch eine Weise anordpen, dass die Verschiebung zwischen der Kund O-Gruppe deutlich grösser ist als zwichen der $P$ und $O$. Dies betrifft sowohl die Längen-Breitenmasse wie auch die Höhenmasse. Der verrin-

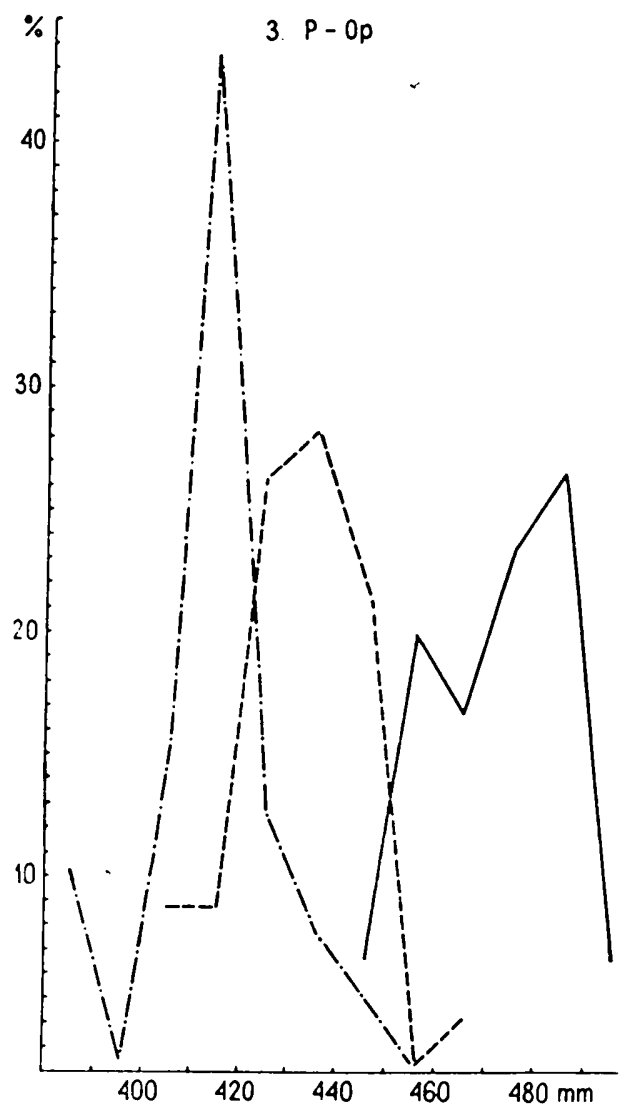

Abb. 1.

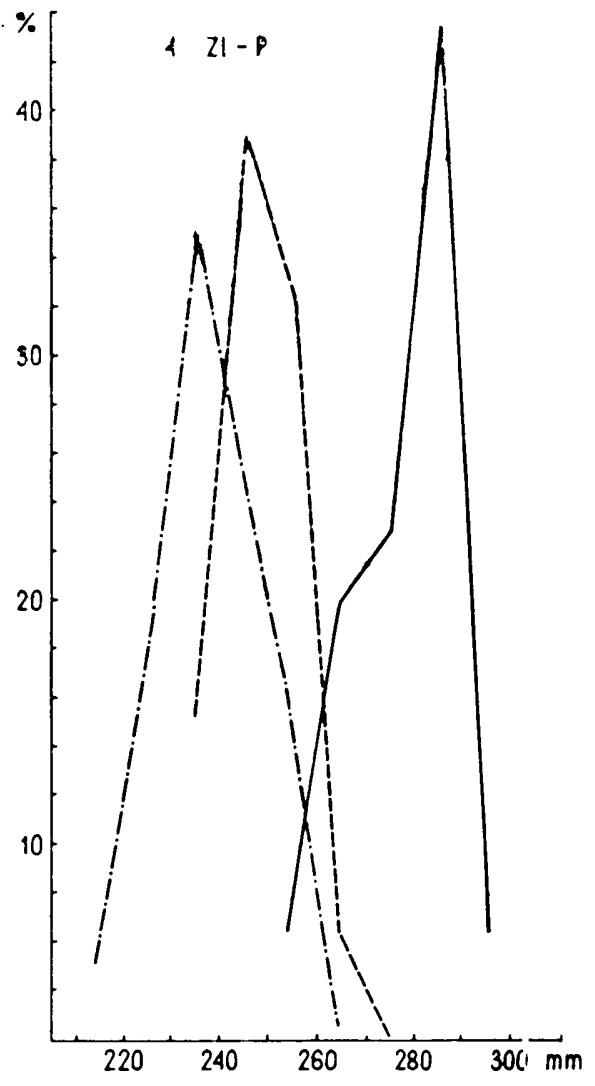

Abb. 2.

Abb. 1-29. Anordnung der Frequenzkurven einer Reihe von Schädelmassen nach lokalen Gruppen.

Bemerkung: In den $\mathrm{Abb}$. von 1 bis 30 wurden für die einzelnen lokalen Gruppen folgende Zeichen angenommen:

Poznańscher Hirsch Karpatenhirsch

gerte Abstand zwischen den Flachlandgruppen berechtigt die Vereinigung in eine Ganzheit nicht, denn zu diesem Zusammenspiel der Masse gehören auch diejenigen, für die statistische Realität erwiesen worden ist. 
$\mathrm{Zu}$ diesem Zusammenspiel muss man auch die Diagramme der Masse 23 und 28 anrechnen. Sie unterscheiden sich zwar durch die Zweigipfelkeit der Kurve, die die Olsztynsche Population betrifft, aber sie illustriert einen ähnlichen Charakter in der Differenzierung.

Viel kleiner der Zahlenmässigkeit nach ist das Zusammenspiel von folgenden sechs Massen: $\mathrm{Op}-\mathrm{Br}, \mathrm{Pm}-\mathrm{P}, \mathrm{Mo}-\mathrm{Mo}, \mathrm{Ect}-\mathrm{Ect}, \mathrm{Ot}-$ $O t, N s i$ - Margo adent., deren Gipfelpunkte der Kurven voneinander gleichmässig entfernt sind, d. h. dass Masswerte für den O-Hirsch ungefähr in der Mitte liegen. Diese beiden Zusammenspiele, die 22 Masse um-

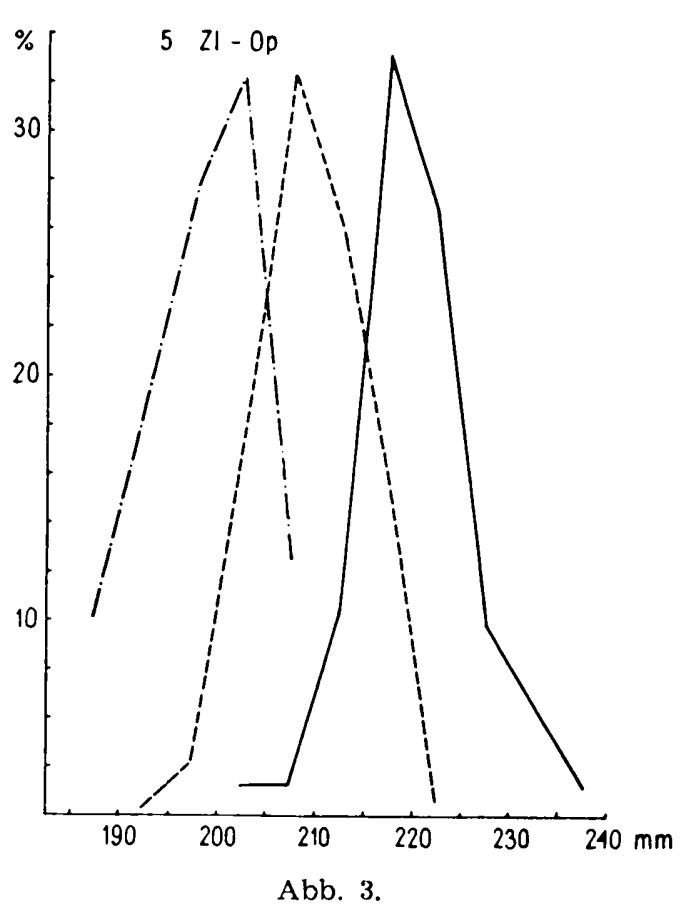

Abb. $4 . \quad-\rightarrow$

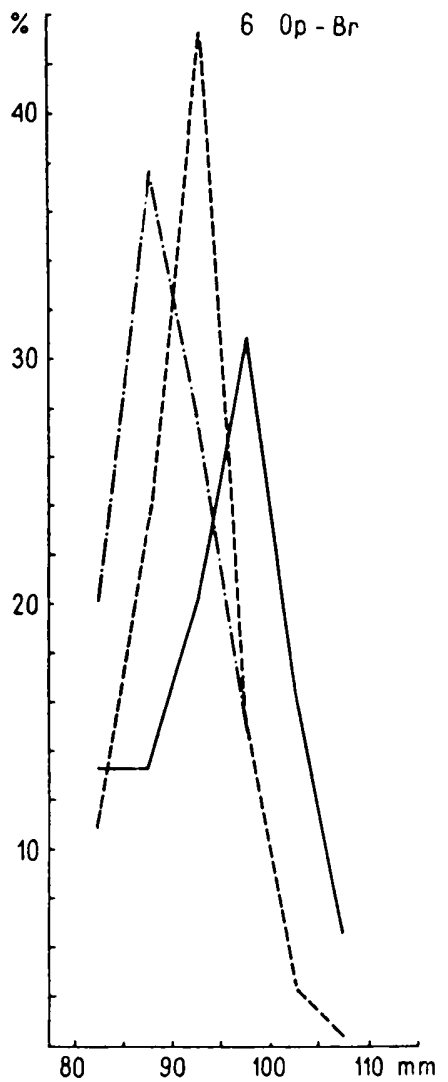

lassen, kann man in Hinsicht auf ihren Charakter gemeinsam untersuchen. Anders verhält sich das 3. Zusammenspiel der Masse $\mathrm{Br}-\mathrm{N}$, $N-N s i, P m-P d$, eu - eu, Länge der Zahnreihe des Unterkiefers, $g o v$ - cr. In diesem Falle befinden sich die Gipfelpunkte der Kurven für beide Flachlandgruppen auf derselben Wertabtragung, während die Kurve für den Karpatenhirsch deutlich gegen die rechte Seite verschoben ist. In diesem Zusammenspiel befinden sich die Werte: $N-N s i, P m-P d$, $e u$ - eu, die bei statistischen Berechnungen unreale Unterschiede zwi- 
schen den Flachlandgruppen erwiesen haben, aber reale, wenn es sich um die Karpatische handelt.

Das einzige Mass, dass sich zu keinem Zusammenspiel qualifizieren läst, ist Mass Nr. 17 und das ist die kleinste Breite der Nasenbeine. Die Gipfelpunkte aller drei Kurven befinden sich in diesem Falle auf derselben Wertabtragung, wenn man nur von einer jedoch geringen Differenzierung dieses Merkmals spricht. (Solch ein für die einzelnen Gruppen

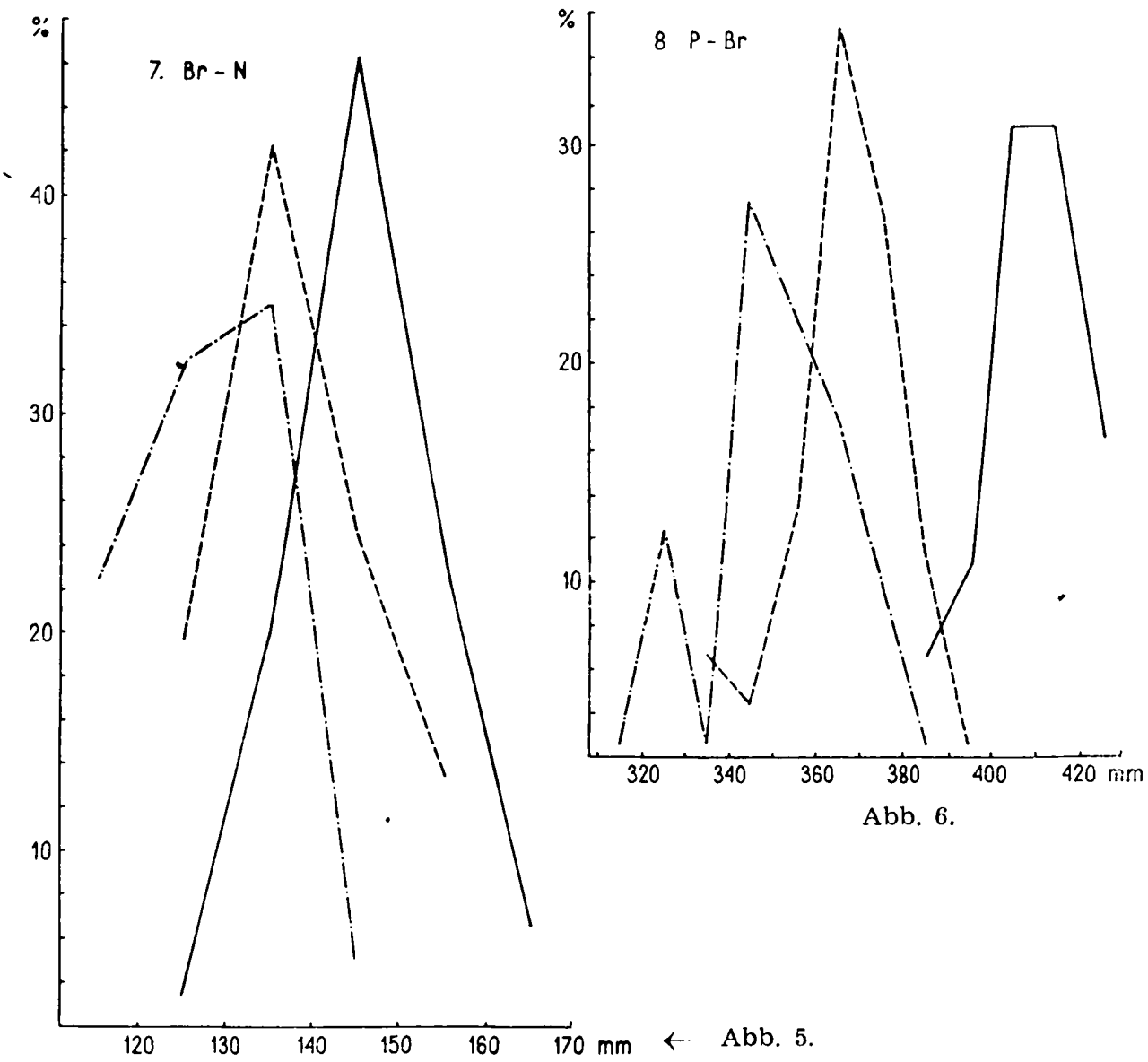

gemeinsames Merkmal könnte als Wertabtragung bei der Untersuchung der Schädelproportion interessant sein, wenn der Wert dieses Masses nicht zweifelhalft wäre, denn im Rahmen nur der Poznańschen Gruppe schwankt er von 24 bis $41 \mathrm{~mm}$ ).

Die besprochenen Diagramme sowohl in Zusammenspielen wie auch einzeln in Hinsicht auf die Differenzierung der untersuchten lokalen Hirschgruppen erörternd, können wir 2 Wahrnehmungen notieren. 
Die erste von ihnen ist die Tatsache, dass die bewiesenen Unterschiede hinsichtlich der Grösse einer gewissen lokalen Gruppe als Ganzes nicht als Hilfsfaktor im Qualifizieren für ein einzelnes, durchschnittliches Individuum dieser oder jener Gruppe sein können. Wir sehen nämlich, dass
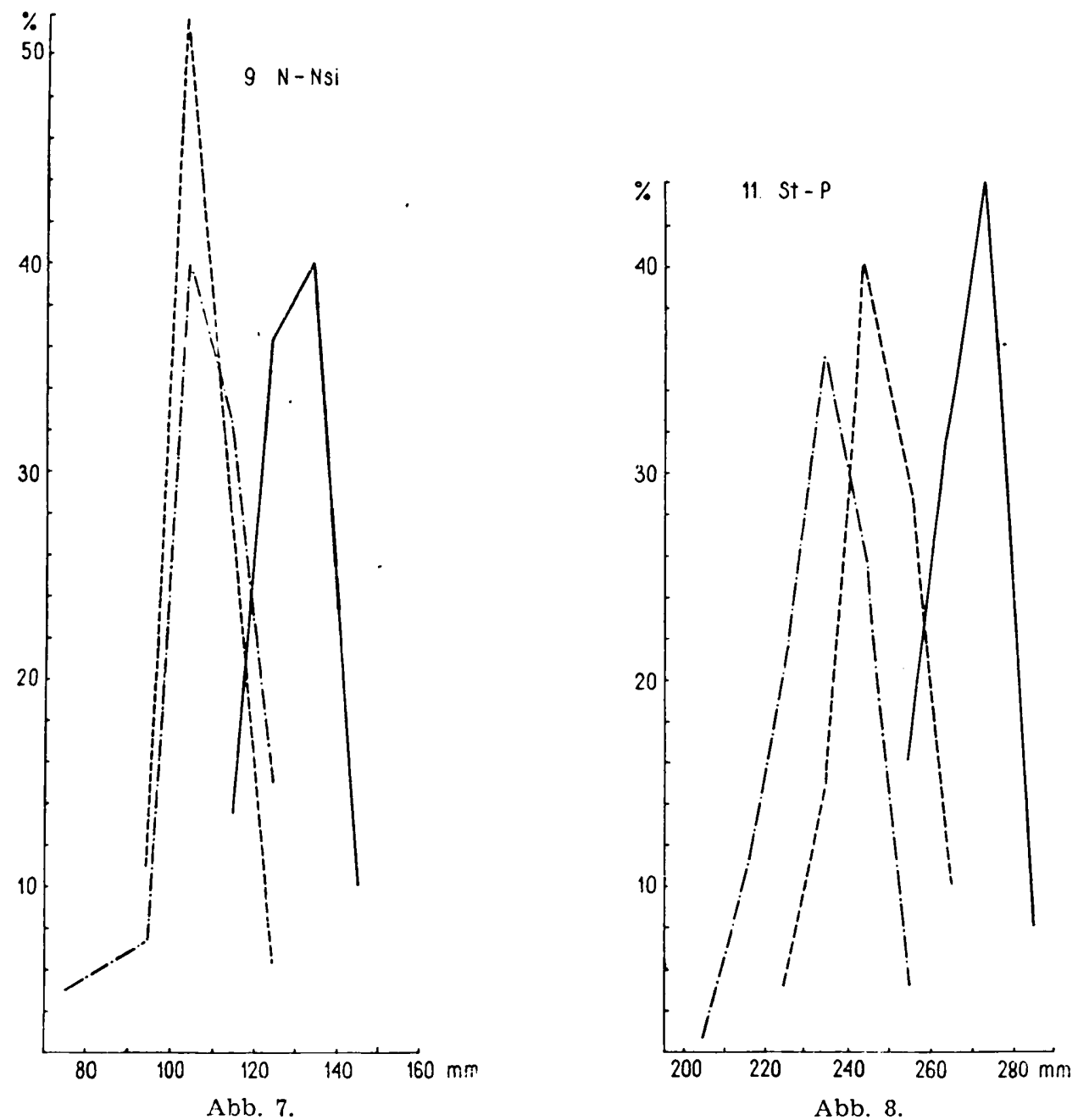

die Grössengrenzen fast aller Masse sich tief überdecken. Eine Ausnahme hierfür bilden die Masse Nr. $12(\mathrm{Mol}-\mathrm{P})$ und 14 ( $\mathrm{Pm}-\mathrm{Mo}-\mathrm{Mo})$, wo die Poznańsche sich mit der Karpatischen Gruppe nicht miteinander verzühnt. Dies bringt aber nicht viel ein angesichts der Tatsache des Bestehens der Olsztynschen Gruppe, die in allen Fällen ohne Ausnahme mit ihren Grössengrenzen die beiden Nachbargruppen weit überdeckt und daher die Qualifikationsprobe eines gewissen Hirsches zu Flachländischen 


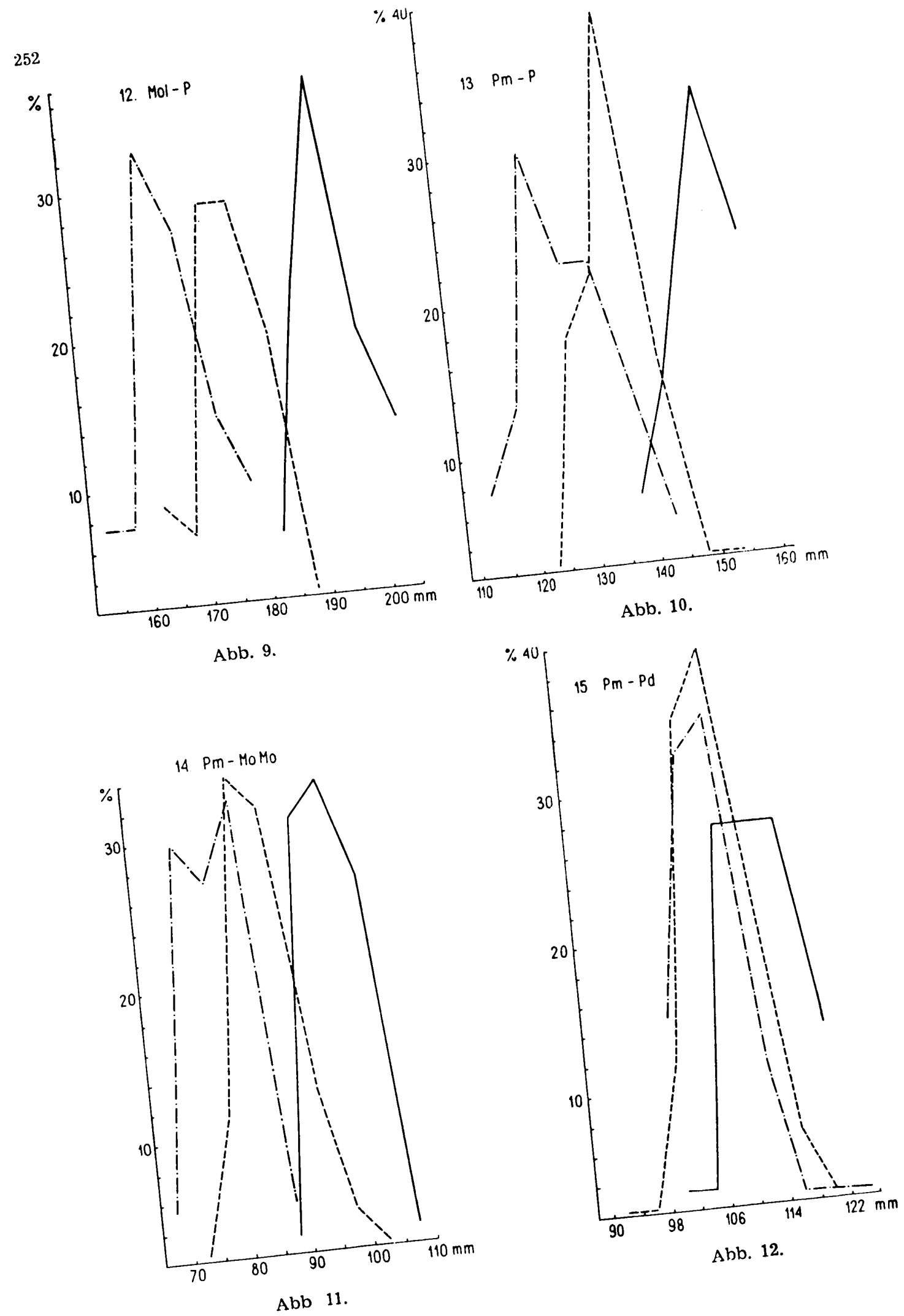



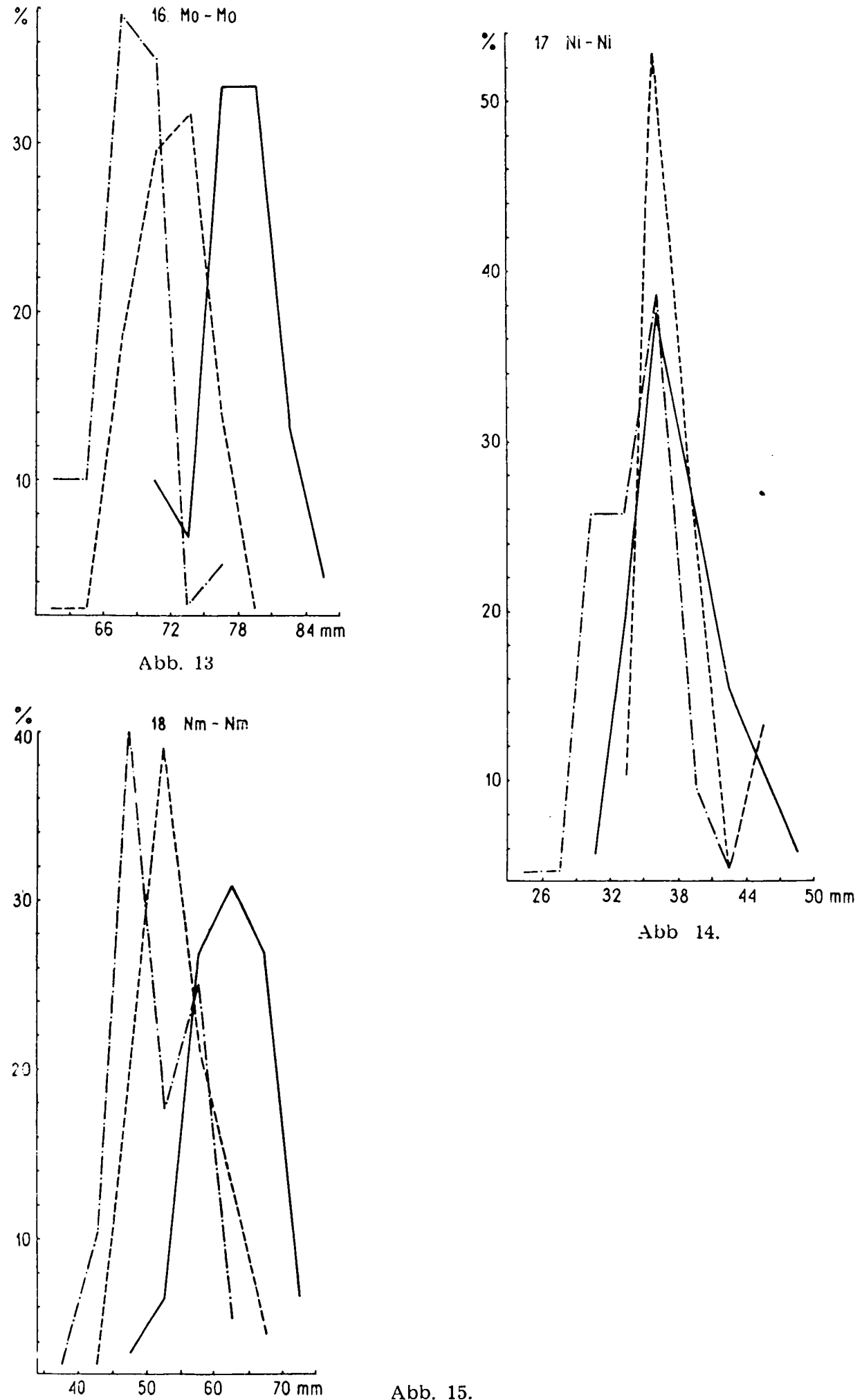

Abb. 15 . 

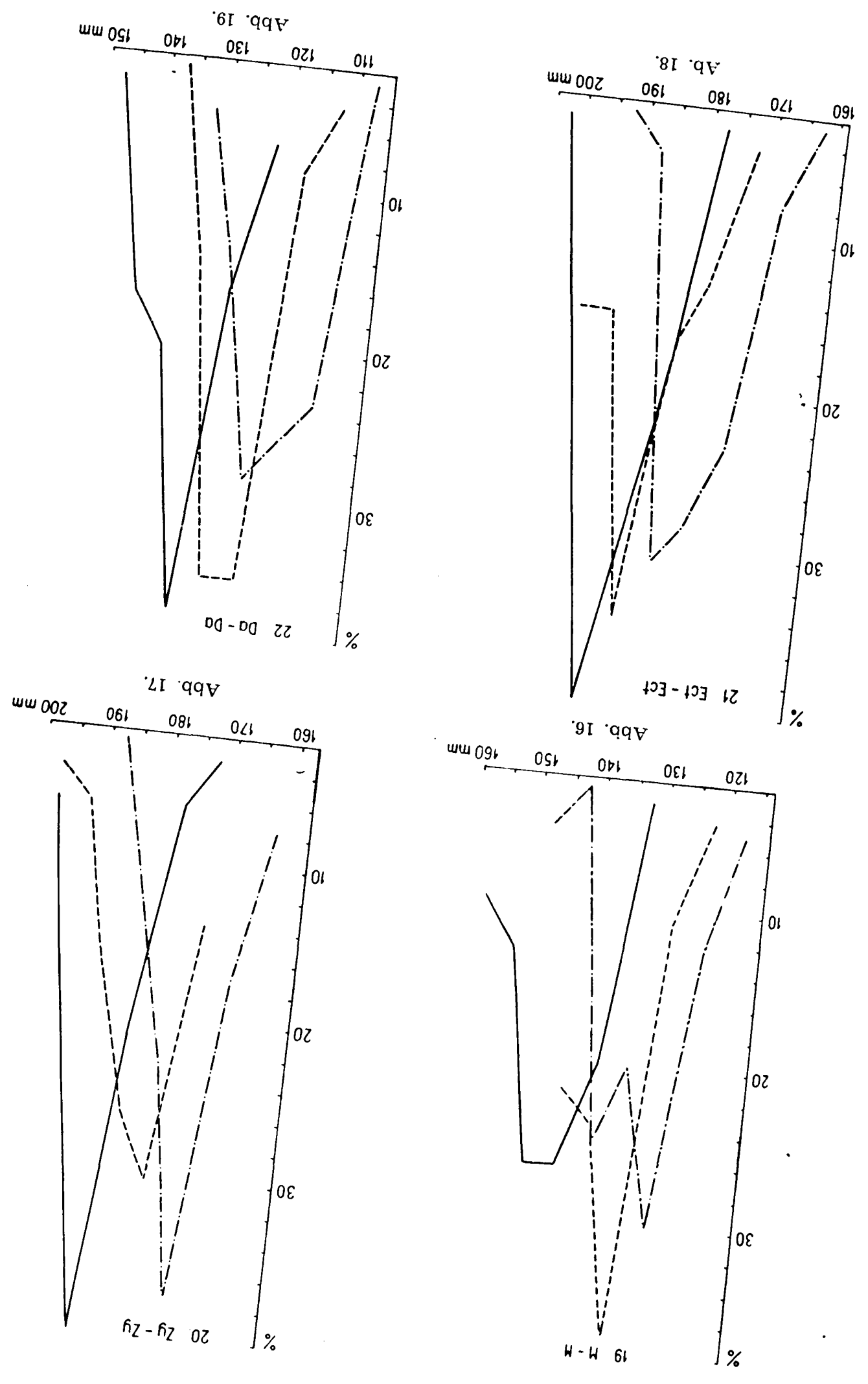

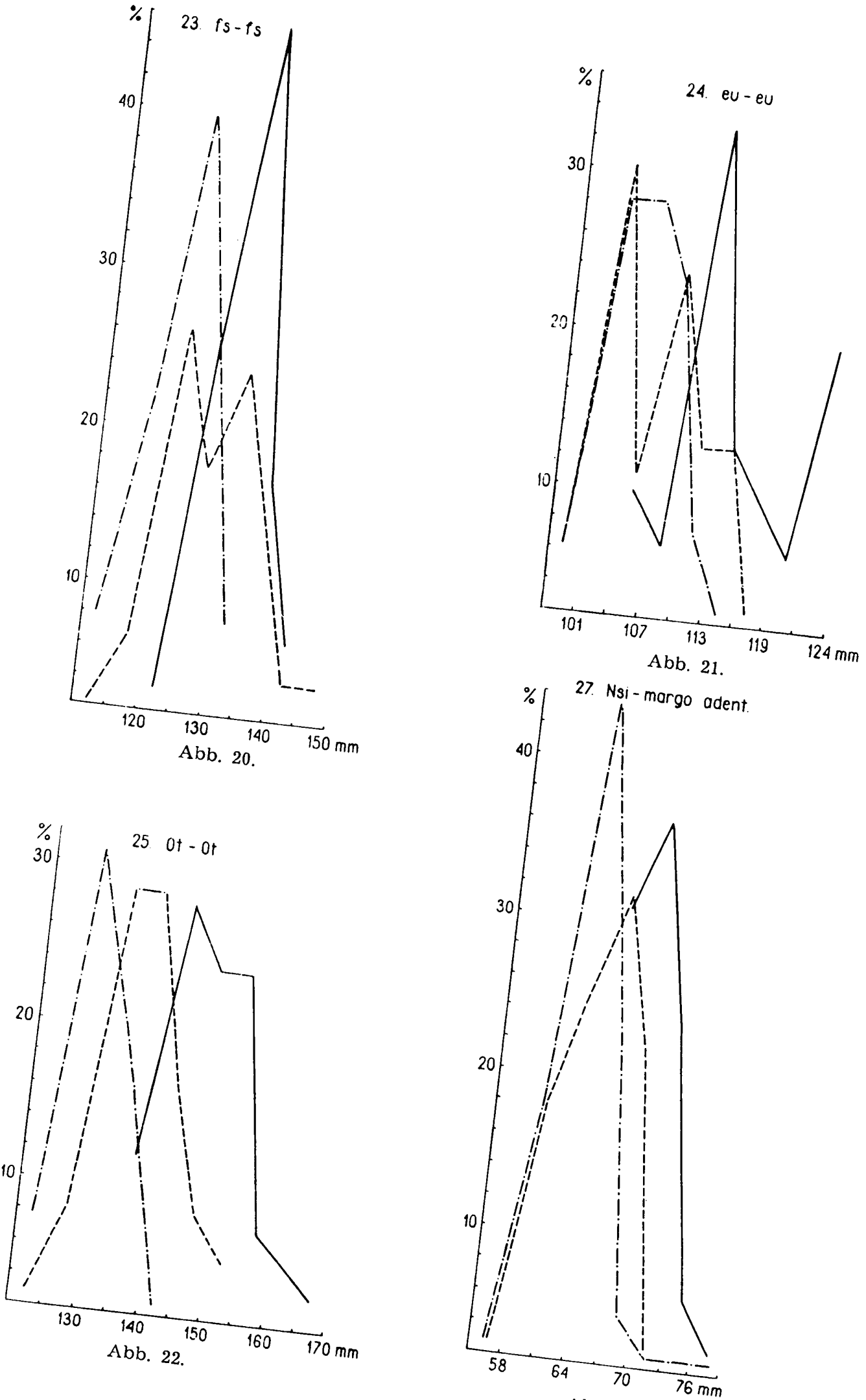

Abb. 23. 
oder Berghirschen im Wege von Vergleichungen der absoluten Grössen der einzelnen Masse unmöglich macht.

Die zweite Wahrnehmung besteht auf Tatsache der ungleichmässigen Kurvenanordnung in den einzelnen Massen einander gegenüber, was das Bestehen von Unterschieden in den Schädelproportionen suggeriert.

Zum Durchkontrollieren dieser Wahrnehmung wurden Diagramme nach Methode Jenty S-S zaferow a (1959) angefertigt. Es wurden die prozentsatzmässigen Abweichungen eines jeden Merkmales verglichen: Im ersten Falle von dem arithmetischen Mittel von den drei untersuch ten Gruppen, das als 100 angenommen wurde (Abb. 30) und im zweiten von der Olsztynschen Gruppe, die als 100 betrachtet wurde (Abb. 31).
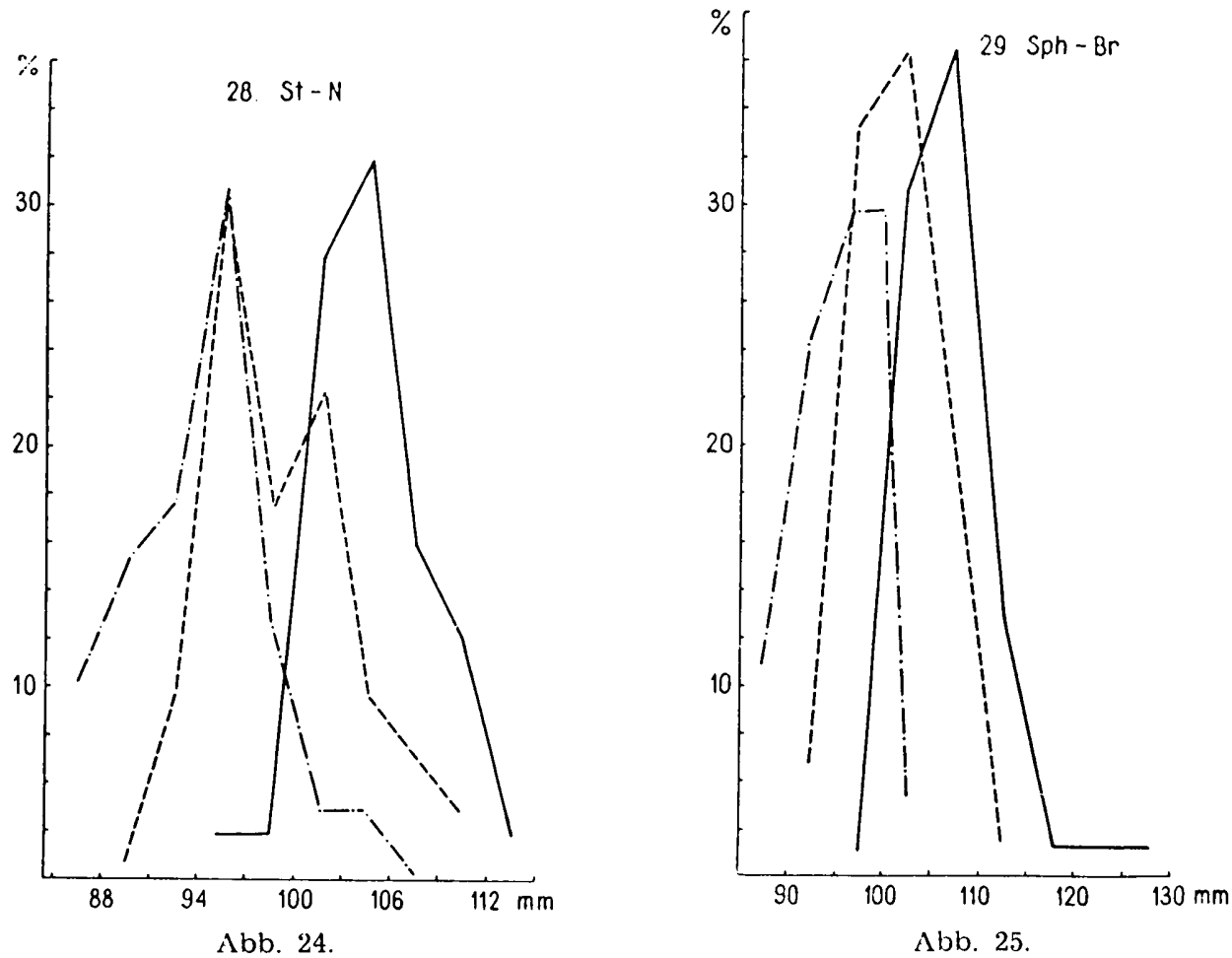

Wenn sich die Hirschschädel der drei besprochenen Gruppen nur durch ihre Grösse unterscheiden würden, bei Beibehaltung derselben Massproportionen, so würden die erwähnten Diagramme eine weniger oder mehr einander gegenüber verschobene Anordnung von parallelen Geraden darstellen. In Wirklichkeit aber haben wir hier mit gebrochenen Linien zu tun. Eine gewisse Differenzierung in den Schädelproportionen besteht zwischen allen drei lokalen Gruppen. 


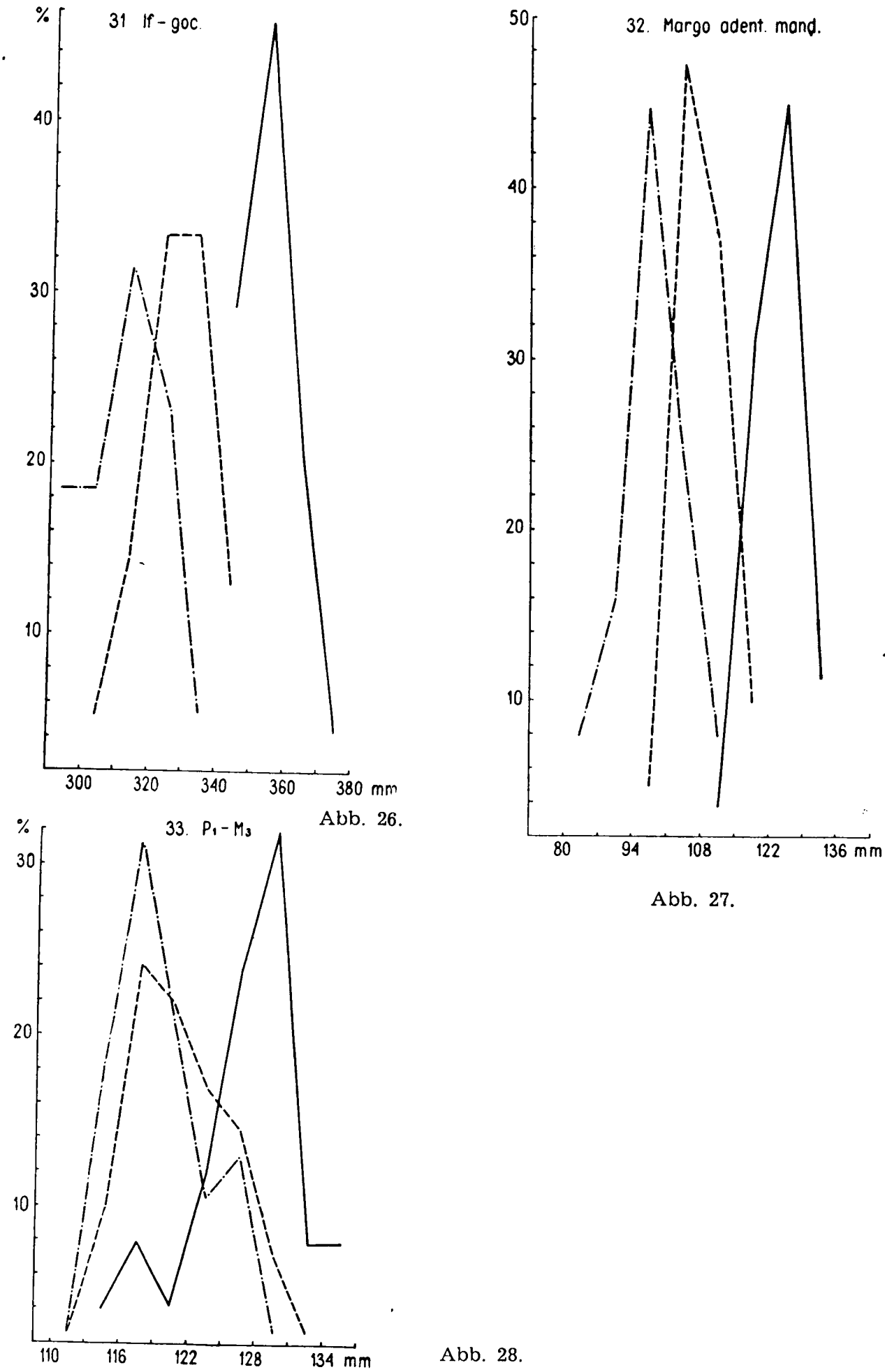


Das Ziehen von weiter gehenden Folgerungen in Anlehnung an diese. Diagramme wäre insofern riskant, dass jedes dieser Merkmale das Mittel in seiner Gruppe darstellt, folglich im hohen Grade die individuelle Variabilität anulliert. Nichtdestoweniger sind diese Diagramme wertvoll, denn sie charakterisieren auf eine allgemeine Weise die Schädelproportionen einer gegebenen Gruppe und dienen als Ausgangspunkt zum Typisieren von Schädelindizes. Die Diagramme und am häufigsten angewandte Indizes anderer Autoren in Betracht ziehend, wurden für jedes

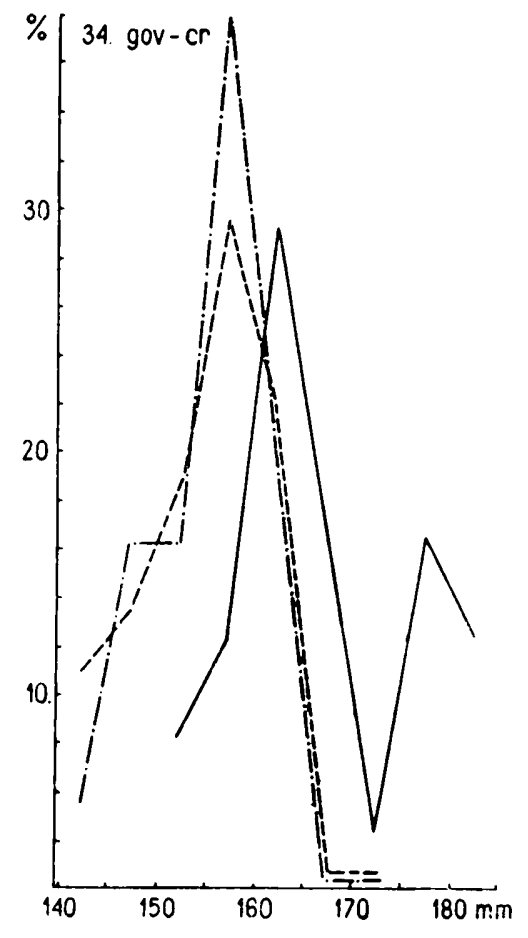

Abb. 29.

der Individuen 16 Schädelindizes berechnet, deren Mittelwerte wie die Diagramme in der Tabelle 2 zusammengestellt wurden. Ohne Anwendung graphischer Methoden diese Tabelle analysierend, ersehen wir, dass gewissc geringe Unterschiede in den Mittelwerten für die einzelnen Populationen bestehen, aber besonders dort, wo das Längenmass der Nasenbeine oder die Zehnreihe das Unterkiefers in Frage kommen, was schliesslich mit den oben erwähnten Profilen von J e n t y s-S z a f e r ow a (1956) übereinstimmt. Von diesen Unterschieden kann man jedoch nur bei der Vergleichung der Gruppen als Ganzes sprechen, denn die Streuung der Werte für die einzelnen Individuen ist so gross, dass von der Auswahl eines dic Angehörigkeitsbestimmung ermöglichenden In- 


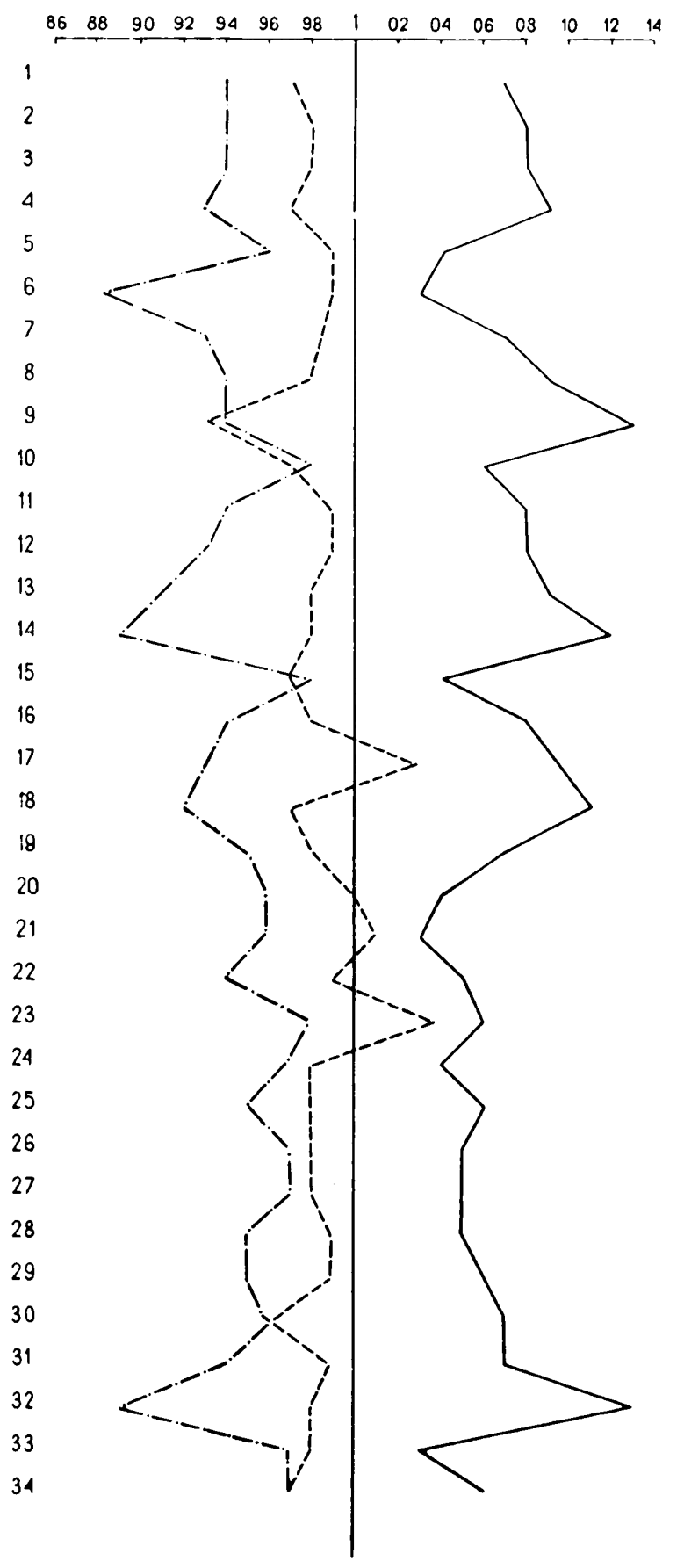

Abb. 30. Mittelwertvergleichungen der einzelnen Schädelmasse nach Methode Jentys-Szaferowa (1959) bei Annahme des Populationsmittels als 100. 


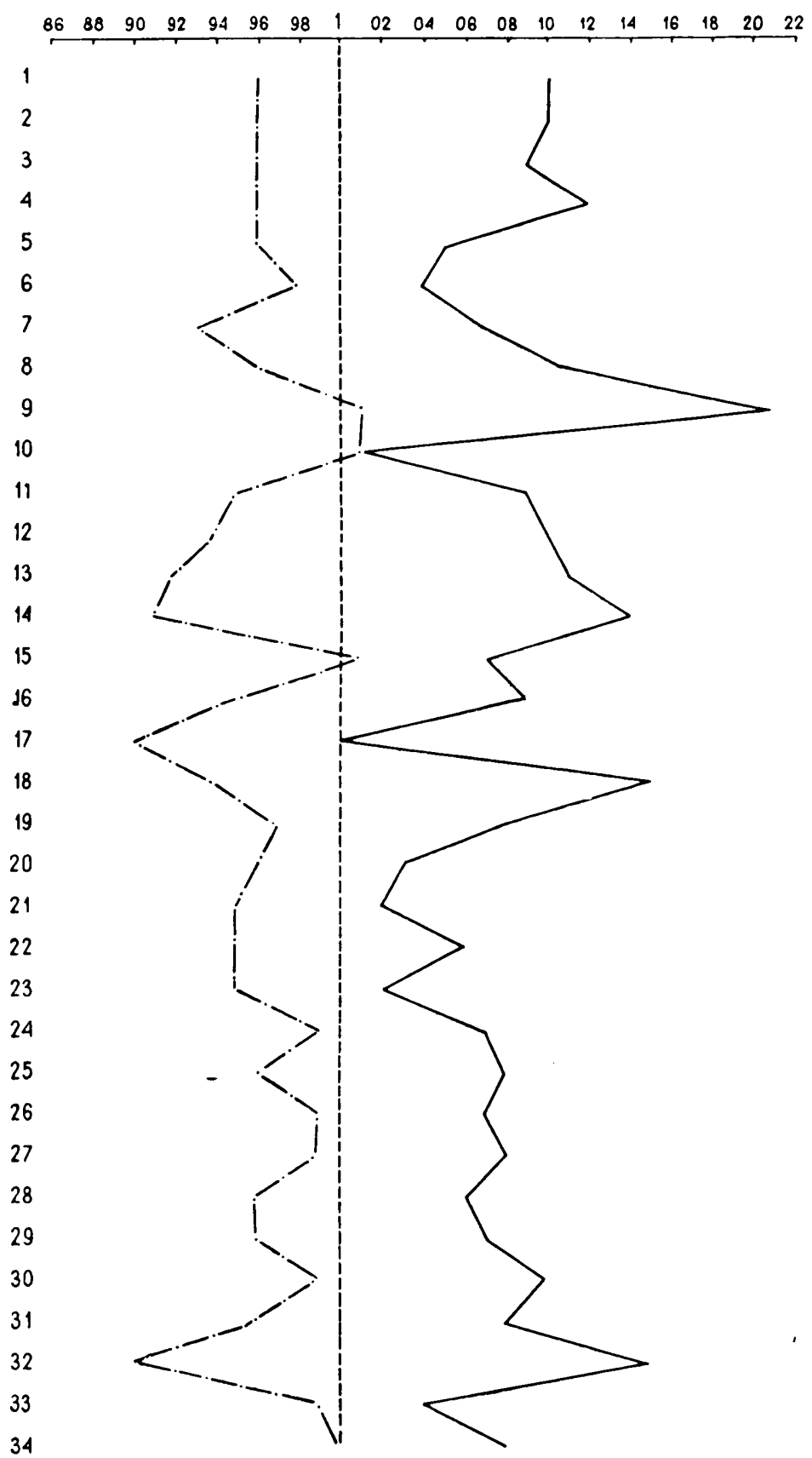

Abb. 31. Profile von Jentys-Szaferow a (1959) bei Annahme des Olsztynschen Hirsches als 100. 
dexes für ein einzelnes Individuum aus irgend einer Gruppe nicht die Fiede sein kann.

Diese Beobachtungen in Hinsicht der Hirschschädel aus den drei Gruppen summierend, scheint die Konklusion gerechtfertigt zu sein, dass sie sich hauptsächlich in der Grösse unterscheiden. Dieser Unterschied ist zwischen den Flachlandgruppen genau so real wie auch zwischen der Olsztynschen und Karpatischen. Obwohl diese Unterschiede zwischen den einzelnen regionalen Gruppen real sind, wenn wir sie als Ganzes behandeln, so sind sie jedoch nicht so gross, als dass sie zur Bestimmung eines einzelnen Individuums dienen könnten.

Die bestehenden geringen Unterschiede in den Schädelproportionen kann man, keine Qualitätsunterschiede nachsuchend, mit bestehenden Grössenunterschieden auf folgende Weise auszulegen versuchen. Aus den Untersuchungen einer Reihe von Autoren (S z u n y o g h y, 1963; M y s tk ow s k a, 1966) wissen wir, dass der Anwuchsprozess der einzelnen Elemente des Hirschschädels, in der Zeit, nicht auf eine gleichmässige Weise verläuft. Anderseits scheint die Feststellung ( $\mathrm{C} \mathrm{z} \mathrm{a} \mathrm{ja,} \mathrm{1959)} \mathrm{gerecht-}$ fertigt zu sein, dass infolge von spezifischen Milieu-Bedingungen die Karpatenhirsche im Vergleich mit den Flachländischen spät reifende Tiere sind, was schliesslich mit dem Erreichen von grösseren Körperausmassen ihrerseits als Begleiterscheinung vor sich geht (Szunyog$\mathrm{h} y, 1959)$. Angesichts dieser Tatsachen würde hier die Anwendung der Hypothese I n ge b rig t s e n (1927) angebracht sein, der Unterschiede in den Proportionen einiger lokaler Hirschformen West-Europas besprechend, feststellt, dass bei schmächtigeren Formen eine mehr ,jugendliche" Proportion in den Schädelmassen, trotz der Reife der untersuchten Individuen besteht. Der Autor erklärt diese als eine Degeneration einer gewissen Population.

In den klimatischen Bedingungen, in denen die in dieser Arbeit erwähnten drei Populationen leben, scheinen die Unterschiede zur Bildung von früher oder später anreifenden Formen ausreichend zu sein, um gewisse phenotypische Veränderungen in den Schädelproportionen von reifen Individuen nach sich zu ziehen.

Von Unterschieden in den Proportionen wie schliesslich auch in der Grösse kann man in Hinsicht auf die ganze Probe aus einer Population sprechen. Es besteht kein Index, der die Bestimmung zur lokalen Angehörigkeit eines Individuums ermöglicht, folglich kann man nicht von Unterschieden in den Schädelproportionen sprechen, die eine taxonomische Bedeutung haben könnten. Angesichts der oben erwähnten Untersuchungen scheint die Absonderung des Karpatenhirsches in eine besondere Unterart (L ubicz-Niezabitowski, 1933) wenig gerechtferigt zu sein, denn die Grösse ist in diesem Falle ktin genügendes Merk- 
mal (A h l e n, 1965). Zum Schluss der Erwägungen in Betreff des Schädels scheint die Vergleichung der erhaltenen kraniometrischen Angaben hinsichtlich des Karpatenhirsches mit Angaben anderer Autoren interessant zu sein. Vergleichungen der Angaben über die Flachlandgruppen können unterlassen werden, denn dies wurde schon durch Mystkows k a (1966) durchgeführt.

\section{Skelett des Rumpfes und der Gliedmassen}

Eine eingehendere Behandlung der morphologischen Beschreibung des Skelettes und der Gliedmassen wurde durch zwei Ursachen hervorgerufen. Erstens: Man könnte annehmen, dass die spezirîschen Geländebedingungen, in denen der Karpatenhirsch seit einer Reihe von Generationen lebt, hier mehr ausgeprägte Veränderungen hervorrufen könnten als im Schädel. Zweitens: Der Mangel an einer derartigen Beschreibung im Schrifttum benötigte, wenn auch in einem bescheidenen Grade, die Ausfüllung dieser Lücke, wie auch das Erlangen eines Anhaltspunktes zur Durchführung von Vergleichungen dieser drei untersuchten Populationen.

Die zeitraubenden, mühseligen Vergleichungen hinsichtlich der Beschreibungsunterschiede, des diese Gruppe repräsentierenden Knochenmateriales, erbrachten Ergebnisse, die wenn sie auch im Text dieser Arbeit notiert worden sind, keine längere Besprechung an dieser Stelle zu verdienen scheinen. Die davongetragenen Eindrücke einer grösseren Schlankheit der einzelnen Elemente der Brustgliedmassen oder auch der grösseren Massivität der entsprechenden Abschnitte der Beckengliedmasse:n des Karpatenhirsches beginnen Zweifel zu wecken, wenn wir mit einem einzelnen Exemplar zu tun haben, aber besonders tritt dies dann ein, wenn es ein Individuum aus der O-Population sein wird, die eine Mittelstellung im Verhältnis zu den beiden übrigen einnimmt. Dasselbe betrifft die Dornfortsätze beim K-Hirsch, die im Verhältnis zum ganzen Wirbel gross sind. Schliesslich haben die hier erwähnten Merkmale einen Grössencharakter, also müssen sie ihre Bestätigung in den osteometrischen Vergleichungen finden. Die in Tabele 3 zusammengestellten Massangaben vergleichend, ersehen wir, dass die enorme Mehrzahl an Mittelwerten der einzelnen Masse sich auf eine ähnliche Weise anordnet nämlich: Immer der kleinste ist der P-Hirsch, der bedeutend grössere der $\mathrm{K}$-Hirsch, aber fast ideal in der Mitte steht der O-Hirsch. Eine Ausnahme bjldet hier das Kreuzbein, das beim O-Hirsch grösser ist als beim Karpatischen. Die Unterschiede in der Grösse der Dornforsätze der Brustwirbel sind tatsächlich gross zu gunsten des K-Hirsches, aber auch nicht viel kleiner ist der Unterschied zwischen dem O- und P-Hirsch. Es ist zwar wahr, dass das Mittel für den O-Hirsch in den zwei ersten Brustwirbeln 
sich deutlich zu dem Poznańschen neigt, wenn es sich um die Höhe des Dornfortsatzes handelt, aber man muss darauf acht geben, dass in diesem Falle die individuellen Schwankungen sehr gross sind. Die Grenzwerte für die einzelnen Masse beobachtend, kann man bemerken, dass umgekehrt, wie es beim Schädel war, die maximalen Grössen für den P-Hirsch sich nur in seltenen Fällen mit den minimalen für $\mathrm{K}$-Hirsche vereinigen oder auch verzahnen. Die in der Mitte stehende Olsztynsche Gruppe verzahnt sich tief mit den beiden Nachbarn auf gleichmässige Weise. Von cieser Regel weichen zwei Masse ab nämlich: Die Höh€ des Dornfortsatzes des Lendenwirbels III, wo der Grenzwert für die O-Gruppe sich in einem minimalen Grade mit den übrigen Gruppen verzahnt, ähnlich verhält sich auch das Mass - kleinste Breite des Körpers der Mittelfussknochen. In beiden diesen Fällen behält der O-Hirsch seine Mittelstellung bei. Das einzige Mass, dessen Grenzwerte für die O- und K-Gruppe sich nicht verzahnen, ist die grösste Breite des distalen Endes des Mittelfussknochens. Höchstwahrscheinlich würden derartige Ausnahmen nicht zutreffen, wenn das Material etwas zahlreicher wäre.

Zur statistischer Analyse wurden diejenigen Masse ausgesucht, die auf eine direkte Weise die Grösse des Tierkörpers zu charakterisieren scheinen wie: Länge des Brustabschnittes, Lge. des Lendenabschnittes, Lge. des Kreuzbeines, äussere Lge. des Schulterblattes, Lge. des Armbeines vom Kopfe aus, Lge. des Radius, grösste Lge. der Mittelhandknochen, grösste Lge. des Hüftbeines, physiologische Lge. des Schenkelknochens, grösste Lge. des Schienbeines, grösste Lge. der Mittelfussknochen. Die Variationsanalyse stellte man die Realität der sich vollziehenden Unterschiede fest. Die Wahrscheinlichkeit einer Zufälligkeit der Anordnung $\mathrm{K}$ - grösser - $\mathrm{O}-$ grösser $-\mathrm{P}$ ist verschwindend gering. Bei der paarweisen Vergleichung der Gruppen $\mathrm{K}-\mathrm{O} ; \mathrm{K}-\mathrm{P} ; \mathrm{O}-\mathrm{P}$ besteht die Realität der Unterschiede überall mit Ausnahme von zwei Fällen. Der erste - ist die Länge der Mittelfussknochen, wo O sich weder mit K oder $\mathrm{P}$ real unterscheidet; der zweite - die Länge des Kreuzbeines, wo sich der Unterschied $\mathrm{K}$ - O als unreal erwies.

Man bewies also den Unterschied von zahlenmässigem Charakter zwischen den untersuchten Populationen, aber weder auf dem Weg der Beschreibung noch der Messungsmethode wurden Merkmale erwiesen, die zur Qualifizierung eines einzelnen Individuums zu dieser oder jenen Gruppe ausreichend sein könnten. In der Suche nach eventuellen Qualitätsunterschieden im untersuchten Material wurden zu Vergleichungen Prozentwerte angenommen, die von sich vollziehenden Proportionen zwischen den einzelnen Massen sprechen.

Zum Erfassen von eventuellen Variabilitäten in den Proportionen, 


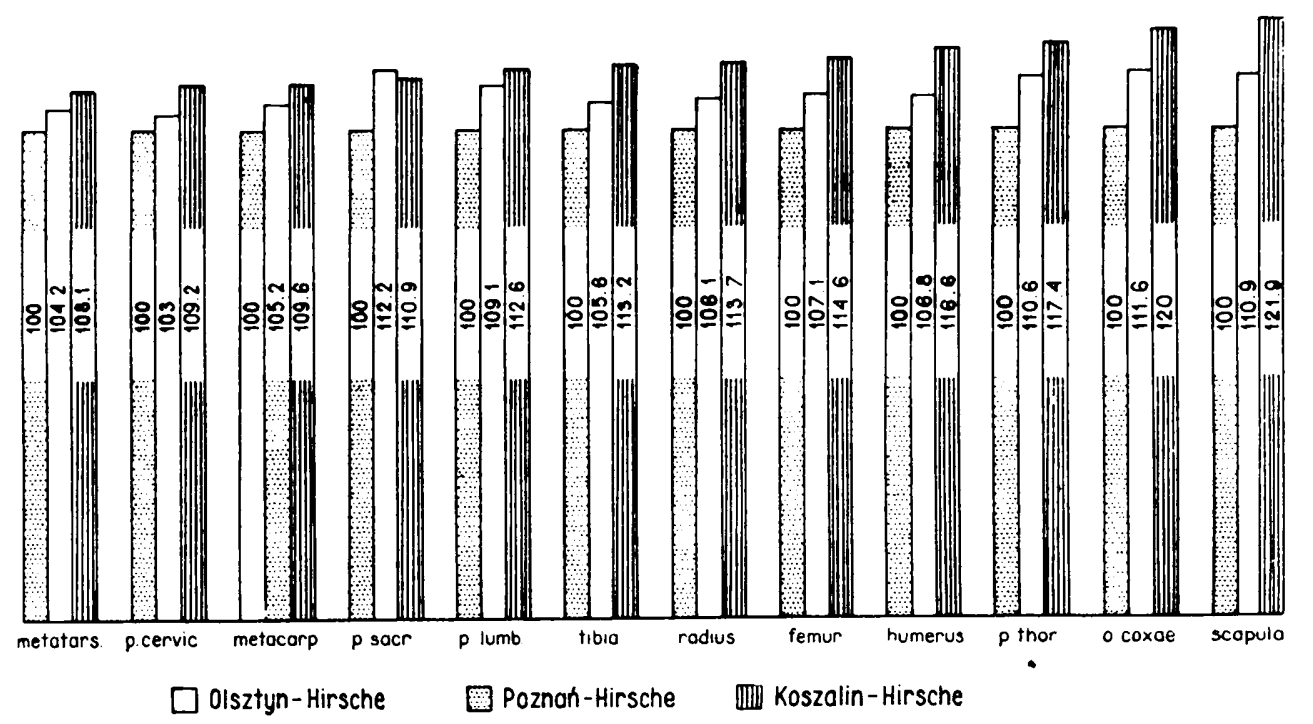

Abb. 32. Profile von Jentys-Szaferowa (1959) für einige Skelettmasse (Als 100 wurde die Olsztynsche Gruppe angenommen).

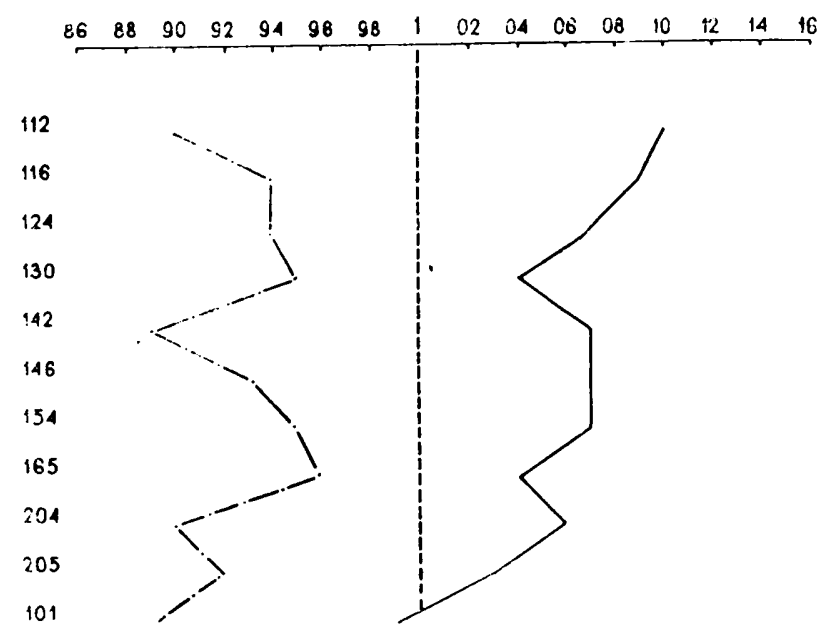

Abb. 33. Das Diagramm stellt Proportionsveränderungen einiger Skelettabschnitte dar, in Hinsicht des als 100 angenommenen Poznanschen Hirsches.

wurden die grundsätzlichen absoluten Grössen in Form von prozentsatzmässigen Unterschieden auf den Diagrammen (Abb. 32, 33) von J e nt y s-S z a f e r o w a dargestellt.

Diese Abbildungen bestätigen die zuvor erhaltenen Wahrinehmungen in betreff der Grössenunterschiede zwischen den Populationen und der 
Stellung der O-Hirsche im Verhältnis zu den übrigen Gruppen, aber gleichzeitig weisen sie auf eine gewisse ungrosse Differenzierung in den Proportionen hin, wobei diese bei Vergleichungen der Mittelwerte für cinige Masse auftreten.

Bei der Anfertigung der Indizes (Tabelle 4) wurden die erwähnten Abbildungen und ausserdem einige Werte aus Tabelle 3 , wie auch die wahrgenommenen scheinbaren Unterschiede bei der morphologischen Beschreibung berücksichtigt. Unabhängig davon wurde eine ganze Reihe von Indizes berechnet, die sich bei der Vergleichung der untersuchten Gruppen als wenig geeignet erwiesen, aber dennoch zu eventuellen Vergleichsarbeiten mit dem Fundmaterial dienen könnten. Aus den Arbeiten von Krysiak (1955, 1956 und 1959) ist bekannt, dass Knochenüberreste von Hirschen sehr oft bei den auf dem Gebiet von Polen durchgeführten archeologischen Arbeiten vorgefunden werden.

Die Analyse der Indizestabelle scheint ziemlich deutlich darauf hinzuweisen, dass die Differenzierung in den Proportionen, die bei der Vergleichung der Mittel von einigen Massen dargestellt werden, einen ganz. zufälligen Charakter trägt. Die individuelle Streuung in den Indizeswerten ist so hoch und ihre Grenzwerte verzahnen sich zwischen allen drei Gruppen so beträchtlich, dass von einer Typisierung von Indizes, die auf eine deutliche Weise die Angehörigkeit eines Individuums zu einer bestimmten Gruppe charakterisieren, nicht die Rede sein kann.

Die Erwägungen über das Rumpf- und Gliedmassenskelett summierend, riskiert man wohl keinen Fehler bei der Behauptung, dass noch auf eine deutlichere Weise als beim Schädel die Unterschiede zwischen den lokalen Gruppen in dem übrigen Teil des Skelettes sich auf den Grössenunterschied der drei untersuchten Populationen zurückführen lassen.

\section{SCHRIFTTUM}

1. Ahlen I., 1965: Studies on the red deer, Cervus elaphus L. in Scandinavia. Viltrevy — Swed. Wildl., 3, 2: 89-176. Uppsala.

2. B a li š M., 1959: Predbežna zprava o studiu kraniologickeho materialu jelena horneho (Cervus elaphus L.) z Tatranskeho Narodneho Parku. Sborn. Prac o Tatranskom Narodnom Parku, 3: 164-171. Bratislava.

3. B e n in d e J., 1940: Die Fremdblutkreuzung beim Rotwild. Z. Jagdkde. Sonderheft: $80-112$. Berlin.

4. B i o m e R. E., 1957: Kraniologičeskaja charakteristika krymskogo olenja (srav. nitelno s kavkazkim). Zool. Ž., 36, 10: 1557-1564. Moskva.

5. Botezat E., 1904: Gestaltung und Klassifikation der Geweihe des Edelhir sches. Gegenbaurs Morph. Jb. 32: 104-157. Leipzig.

6. Botezat E., 1922: Die Varietäten des Edelhirsches im Gebiete der Östlichen Waldkarpaten. Bull. Soc. Stiintifice, 5: 11-80. Bucaresti. 
7. Cenkier S., 1957: Uwagi o pochodzeniu naszych jeleni nizinnych. Eowiec pol., 15-16, 1072-3: 3-6. Warszawa.

8. C z a j a M., 1959: Biologiczne podstawy selekcji jelenia. „Łowiectwo” — skrypt. Wyd. Min. Leśn. i P. D.: 368-390. Warszawa.

9. Duerst I. W., 1926: Vergleichende Untersuchungsmethoden am Skelett bei Säugern (Abderhalden; Hdb. d. biol. Arbeitsmethoden). 7: 125-531. Berlin Vien.

10. Empel W. \& Roskos z T., 1963: Das Skelett der Gliedmassen des Wisents (Bison bonasus Linna e s, 1758). Acta theriol., 7, 13: 250-300. Białowieża.

11. Fle r o v K. K., 1952: Fauna SSSR, mlekopitajuščie. 1, 2: 1-255. Zool. Inst. Ak. N. SSSR. Moskva.

12. Ge ptner V. G. \& Calkin V. I., 1947: Oleni SSSR. Izd. Moskovskogo Obšč. Isp. Prirody: 1-175. Moskva.

13. Gromovi. M., Gureev A., Novikov G., Sokolovi., Strelkov P. \& C a pskij K., 1963: Mlekopitajuščie fauny SSSR. Izd. Ak. N. SSSR 2: 6392000. Moskva, Leningrad.

14. Ingebrigtse $\mathrm{n}$ O., 1927: Das norwegische und scotische Rotwild, Cervus elaphus L. Nyt. Mag. Nat.: 175-220. A. W. Broggers Boktrykkeris Forlag. Oslo.

15. Jentys-S z a f e r ow a J., 1959: Graficzna metoda porównywania kształtów roślinnych. Nauka Polska, 3 (27): 79-110.

16. K ow a lski K., 1964 [ed.]: Klucze do oznaczania kręgowców Polski. 5, Ssaki - Mammalia. Państw. Wyd. Nauk: 1-280. Kraków.

17. Krysiak K., 1955: Wykopaliskowe szczątki zwierzęce z Grodziska koło Łęczycy. Studia wczesnośredniowieczne, 3: 360-370. Wrocław.

18. Krysiak K., 1956: Wyniki badań nad materiałem zwierzęcym z wykopalisk w Gdańsku. Prace wykop. Tow. Nauk. seria B, 78: 1-94. Wroclaw.

19. Kry siak K., 1959: Material zwierzęcy z wykopalisk w Strzelcach $w$ powiecie mogilańskim. Font. archeol. poznan. 10: 96-99. Poznań.

20. L i c h a č ev A. I., 1947: Osevoj skelet tulovišča i hvosta sovremiennych olenej Sibiri. Novosyb. Selskochoz. Inst. (tezisy doklada), 16-18, 2; 1-9. Nowosybirsk.

21. Lubicz-Niezabitowski E., 1933: Klucz do oznaczania zwierząt ssących Polski. Kolo Przyr. Uczniów U. J.: 1-124. Kraków.

22. My s tk ow ska E. T., 1966: Morphological variability of the skull and body weight of the red deer. Acta theriol., 11, 5: 129-194.

23. Philipowicz I., 1961: Das Rotwild der Ostkarpaten. Z. Jagdwiss., 7, 1: 1-18. Hamburg und Berlin.

24. Poplewski R., 1948: Anatomia ssaków. Czytelnik. 2: 1-690. Stockholm.

25. R a e sf eld F., 1957: Das Rotwild. P. Parey: 1-386. Berlin.

26. Roskosz T., 1962: Morphologie der Wirbelsäule des Wisents, Bison bonasuis L. Acta theriol., 6, 5: 113-164. Białowieża.

27. Szunyoghy J., 1959: Data to our knowledge concerning the body weights of stags in the Carpathian basin. Ann. Hist. Nat. Mus. Nat. Hungarici. 51: 483-488. Budapest.

28. Szunyoghy J., 1963: A magyarorszagi szarvas. Muzeumok rotauzemeben: 1-193. Budapest.

Received August 3, 1965.

Forstforschungsinstitut,

Warszawa, Wery Kostrzewy 3. 


\section{BADANIA OSTEOLOGICZNE NAD JELENIEM NIZINNYM W POLSCE}

\section{Streszczenie}

Autor przeprowadził badania na materiale kostnym obejmującym 22 kompletne szkielety oraz 116 czaszek dorosłych samców jeleni (Cervus elaphus Linnae us, 1758). Materiał ten pochodził $\mathrm{z}$ trzech grup lokalnych jeleni a mianowicie: jeleni poznańskich (zwanych również nadnoteckimi - P). olsztyńskich (mazurskich - O) oraz jeleni karpackich zamieszkujących Bieszczady (K). Celem pracy było porównanie osteologiczne tych trzech grup.

W opisie morfologicznym czaszki uwzględniono jedynie cechy wydające się różnić jelenie górskie od nizinnych bowiem szczegółowy opis tych ostatnich dokonany został przez M y tk owską (1966).

Opis kośćca tułowia i kończyn potraktowano obszerniej, zwracając uwagẹ na cechy charakterystyczne dla jelenia jako gatunku, jak również szczegóły, które wydawały się do pewnego stopnia różne u poszczególnych grup.

Dla osteometrycznego scharakteryzowania materiału przyjęto 34 pomiary czaszki (Tabela 1) oraz 201 pomiarów szkieletu tułowia i kończyn (Tabela 3). Dla szeregu pomiarów obliczono 174 wskaźniki, które zestawiono w tabelach 2 i 4 . Ilustracją różnic lokalnych $\mathrm{w}$ pomiarach czaszek są sporządzone dla większości $\mathrm{z}$ tych pomiarów krzywe frekwencji (Ryc. 1-29), oraz oparte na wartościach średnich profile pcrównawcze J enty S-Szaferowej (1959) (Ryc. 30 ： 31). Różnice w wielkościach średnich ważniejszych odcinków tułowia i kończyn obrazuje sporządzony, wspomnianą wyżej metodą wykres (Ryc. 32) jak również diagram (Ryc. 33). Dla statystycznego udowodnienia różnic $\mathrm{w}$ wielkości zwierząt z poszczególnych grup, dla szeregu pomiarów wykonana została jednokierunkowa analiza wariancji (test Fishera). Wyniki przeprowadzonej przez autora analizy materiału kostnego sprowadzają się do następujących konkluzji.

Odmienności morfologiczne tak w czaszce jak i pozostałej części szkieletu są zbyt słabo zaakcentowane a przy tym podlegają zbyt dużej zmienności indywidualnej by mogły być wystarczające dla dokonania w oparciu o nie jakiegokolwiek podziału badanych jeleni.

Wielkości absolutne poszczególnych pomiarów wykazują istnienie statystycznie istotnych różnic pomiędzy trzema badanymi populacjami przy czym jeleń karpacki osiąga największe rozmiary, poznański najmniejsze a olsztyński zajmuje stanowisko pośrednie. Różnice choć istotne przy porównywaniu poszczególnych prób z populacji nie są na tyle duże by można było w oparciu o nie, biorąc pod uwagę dużą zmienność indywidualną, zakwalifikować pojedynczego osobnika w sposób bezbłędny do tej lub innej grupy.

Różnice $w$ proporcjach nieznaczne jeśli chodzi o szkielet tułowia i kończyn, zaakcentowane są wyraźniej w czaszce. Zauważalne są one przy porównywaniu wartości średnich dla grup, ulegają jednak tak dużym wahaniom indywidualnym że nie mogą stanowić podstawy do wprowadzenia podzialu badanych jeleni na drobniejsze grupy systematyczne.

Opierając się na wspomnianych spostrzeżeniach autor stoi na stanowisku, że jeleni zamieszkujących polskie Karpaty nie można, na podstawie badań osteologicznych̀, wydzielać w osobną grupę systematyczną i przeciwstawiać ich jeleniom nizinnym jako całości. 
